\author{
Universidade de São Paulo \\ Instituto de Física
}

\title{
Estados eletrônicos do ânion de 8-oxo-guanina
}

\author{
Leonardo Bitencourt Vetritti
}

Dissertação de mestrado apresentada ao Instituto de Física da Universidade de São Paulo, como requisito parcial para a obtenção do título de Mestre em Ciências.

Banca Examinadora:

Prof. Dr. Marcio Teixeira do Nascimento Varella (IF-USP)

Prof. Dr. Marcio Henrique Franco Bettega (UFPR)

Prof. Dr. Paulo Manuel Assis Loureiro Limão-Vieira (FCT-NOVA)

São Paulo 
FICHA CATALOGRÁFICA

Preparada pelo Serviço de Biblioteca e Informação do Instituto de Física da Universidade de São Paulo

Vetritti, Leonardo Bitencourt
2021. $\quad$ Estados eletrônicos do ânion de 8-Oxo-Guanina. São Paulo,
Dissertação (Mestrado) - Universidade de São Paulo. Instituto de
Física. Depto. de Física Geral.
Orientador: Prof. Dr. Márcio Teixeira do Nascimento Varella
Área de Concentração: Física Molecular e Modelagem
Unitermos: 1. Espalhamento; 2. Física molecular; 3. Física
computacional.
USP/IF/SBI-004/2021




\title{
University of São Paulo \\ Physics Institute
}

\section{Electronic states of the 8-oxo-guanine anion}

\section{Leonardo Bitencourt Vetritti}

\author{
Supervisor: Prof. Dr. Marcio Teixeira do Nascimento Varella
}

Dissertation submitted to the Physics Institute of the University of São Paulo in partial fulfillment of the requirements for the degree of Master of Science.

Examining Committee:

Prof. Dr. Marcio Teixeira do Nascimento Varella (IF-USP)

Prof. Dr. Marcio Henrique Franco Bettega (UFPR)

Prof. Dr. Paulo Manuel Assis Loureiro Limão-Vieira (FCT-NOVA) 


\section{Agradecimentos}

Ao Prof. Dr. Marcio Teixeira do Nascimento Varella por ter me aceitado como aluno de mestrado, pelo aprendizado proporcionado durante esse período, pela orientação e pelo acompanhamento da escrita desta dissertação.

Ao grupo de Fisica Atômica e Molecular pelas discussões, aprendizados e apoio. Em partícular ao Julio Ruivo por ter me guiado no começo do projeto.

A FAPESP, pelo financiamento do cluster Gauss.

Ao Instituto de Física da USP por ter me dado a oportunidade de participar do programa de Mestrado.

Aos amigos que fiz durante todos esses anos na USP, que me proporcionaram muitas discussões, aprendizados e apoio nos momentos de dificuldade.

A minha família pela formação, apoio moral e financeiro, especialmente nos momentos complicados que sucederam quando decidi mudar de área e fazer graduação em Física.

Ao meu pai, falecido em 2012, que certamente me apoiaria durante toda essa etapa da minha vida.

A CAPES, pelo apoio financeiro que tornou possível a dedicação em tempo integral ao mestrado.

O presente trabalho foi realizado com apoio da Coordenação de Aperfeiçoamento de Pessoal de Nível Superior - Brasil (CAPES) - Código de Financiamento 001. 


\section{Resumo}

Neste trabalho, os estados do ânion de 8-oxo-guanina e Guanina foram caracterizados por meio das ressonâncias na seção de choque integral de espalhamento, e foi realizada uma discussão comparativa com resultados calculados e publicados para a Guanina, com o objetivo de encontrar aspectos que possam indicar processos dissociativos induzidos por captura eletrônica dissociativa (DEA), visando a entender se a presença da 8-oxo-guanina na cadeia de DNA pode gerar mais radicais reativos ao sofrer reações induzidas por elétrons e consequentemente, produzir efeito protetor às células sadias quando expostas à radiação ionizante. O método multicanal de Schwinger foi utilizado nos cálculos de espalhamento, na aproximação de núcleos fixos, com a descrição da função de onda de espalhamento nas aproximações estático-troca e estático-troca mais polarização. Foram encontradas quatro ressonâncias com caráter $\pi^{*}$ para 8-oxo-guanina e Guanina sendo que as ressonâncias, $\pi_{1}^{*}$ e $\pi_{4}^{*}$, apresentaram estabilização e indicaram aumento do tempo de vida em relação aos respectivos estados aniônicos da Guanina, podendo favorecer processos dissociativos na 8-oxo-guanina. Também foi caracterizado o estado ligado por dipolo para as duas moléculas, através do método CCSD(T), e concluiu-se que a forma oxidativa estabiliza o estado ligado por dipolo em $\sim 80 \mathrm{meV}$. Aspectos relacionados com a captura eletrônica dissociativa foram discutidos, para eliminação de $\mathrm{H}$ e $\mathrm{NH}_{2}$, na Guanina em comparação com resultados experimentais publicados de intensidade de DEA e com auxilio de cálculos de estrutura eletrônica semi-empiricos (G4MP2) e multiconfiguracionais (CASSCF) para obtenção de limiares de dissociação e acoplamentos não adiabáticos. Conclui-se que as eliminações de $\mathrm{H}$ e $\mathrm{NH}_{2}$ podem ser iniciadas por meio das ressonâncias $\pi_{1}^{*}$ e $\pi_{2}^{*}$ com a participação de acoplamentos entre estados $\pi^{*}$ DBS permitindo que ressonâncias vibracionais de Feshbach participem do processo dissociativo através de acoplamentos DBS $/ \sigma^{*}$. Para a eliminação de $\mathrm{NH}_{2}$ também conclui-se que uma reação recombinativa deve ocorrer visto que a eliminação simples do grupo $\mathrm{NH}_{2}$ não é energeticamente possível. Por fim, foi realizado um estudo semelhante na 8-oxo-guanina, em comparação com os resultados obtidos para G, em razão de não existirem resultados de intensidade de DEA publicados para a 8-oxo-guanina, visando compreender se esses processos dissociativos também podem ocorrer. Os limiares de dissociação de $\mathrm{H}$ e $\mathrm{NH}_{2}$ e os acoplamentos não adiabáticos possuem menores energias na 8-oxo-guanina. A dissociação desses fragmentos, em energias abaixo de $1.6 \mathrm{eV}$, devem ser iniciadas através de ressonâncias vibracionais de Feshbach, caso ocorram. Contudo, não é possível concluir se a 8-oxo-guanina pode apresentar a formação de um maior número de radicais ao interagir com elétrons sem os resultados experimentais de medidas de intensidade de DEA.

Palavras-chaves: radiossensibilizadores. espalhamento elástico. 8-oxo-guanina. Guanina. método multicanal de Schwinger. estados aniônicos. captura eletrônica dissociativa. 


\section{Abstract}

In this work, the anion states of 8-oxo-guanine and Guanine were described through the resonances in the elastic scattering integral cross section. A comparative analysis between the published and obtained data for Guanine with the 8-oxo-guanine data was done afterwards to find evidences that suggest dissociation processes which undergo dissociative electron attachment (DEA), aiming to better understand whether 8-oxo-guanine gives rise more reactive free radicals on DNA than Guanine by electron-induced reactions and hence protect the healthy cells from ionising radiation. Scattering calculations were performed by the Schwinger Multichannel Method, in the fixed nuclei approximation, using the static-exchange and static-exchange plus polarisation approximations to describe the scattering wavefunction. Four $\pi^{*}$ shape resonances were identified in the integral cross section for both molecules. The resonances $\pi_{1}^{*}$ and $\pi_{4}^{*}$ in 8-oxo-guanine are more stable and exhibited higher lifetime than Guanine which suggests dissociation processes may be preferred in 8-oxo-guanine. The dipole bound states were described for both molecules using the $\operatorname{CCSD}(\mathrm{T})$ method which resulted that the oxidazed form stabilizes the dipole bound state in $\sim 80 \mathrm{meV}$. Some evidences related to DEA were investigated for $\mathrm{H}$ and $\mathrm{NH}_{2}$ elimination in Guanine, comparing the experimental ion yield data to the semiempirical (G4MP2) and multiconfigurational (CASSCF) electronic structure calculations applied to obtain dissociation thresholds and non-adiabatic couplings, respectively. The $\mathrm{H}$ and $\mathrm{NH}_{2}$ elimination may be triggered by the resonances $\pi_{1}^{*}$ and $\pi_{2}^{*}$ with involvement of $\pi^{*}$ /DBS couplings which allows vibrational Feshbach resonances to mediate the dissociation processes through $\mathrm{DBS} / \sigma^{*}$ couplings. In the case of $\mathrm{NH}_{2}$ elimination is also concluded that a recombination reaction is preferred than the simple elimination of the $\mathrm{NH}_{2}$ group since the dissociation takes place in lower energies than the dissociation threshold for the simple elimination. Finally, the same study was done for 8-oxo-guanine comparing to the previous results obtained for Guanine due to the lack of experimental ion yield measurements for 8-oxo-guanine to comprehend whether the dissociation processes may take place in oxidized form. The thresholds for elimination of $\mathrm{H}$ and $\mathrm{NH}_{2}$, and the non-adiabatic couplings exhibit lower energies in 8-oxo-guanine. The dissociation of these fragments, in energies below $~ 1.6$ $\mathrm{eV}$, may be driven by the formation of vibrational Feshbach resonances which undergo dissociation through DBS $/ \sigma^{*}$ couplings. Nonetheless, the analysis of the efficiency for 8-oxo-guanine fragmentation by interaction with low energy electrons depends on the measurements of the DEA ion yield and for this reason, is not possible to conclude that 8-oxo-guanine may provide protection to the healthy cells from ionising radiation.

Key-words: radiosensitizers. elastic scattering. 8-oxo-guanine. Guanine. Schwinger Multichannel Method. Anionic States. dissociative electron attachment. 


\section{Lista de ilustrações}

Figura 1 - Caracterização do tipo de ressonância. A esquerda a representação da energia do estado fundamental e do estado excitado, que são os estadospai, e a direita a representação da energia das ressonâncias de forma e de Feshbach. . . . . . . . . . . . . . . . . . . . . . 13

Figura 2 - Curvas típicas de energia potencial do estado fundamental da molécula neutra (em preto), do ânion $\pi^{*}$ (vermelho) e $\sigma^{*}$ (azul). A seta vertical vermelha sinaliza a captura eletrônica no orbital do tipo $\pi^{*}$ e a seta vertical azul sinaliza a captura eletrônica no orbital do tipo $\sigma^{*} \ldots$. . . 14

Figura 3 - Estrutura planarizada da molécula de Guanina otimizada com o método B3LYP/aug-cc-pVTZ. O átomo de Oxigênio está representado em vermelho, Nitrogênio em azul, Carbono em cinza e Hidrogênio em branco. Os comprimentos de ligação (em $\AA$ ) e a convenção de numeração dos átomos nos anéis também são indicados. . . . . . . . . . . . . . .

Figura 4 - Estrutura planarizada (esquerda) e não planarizada (direita) da molécula de 8-oxoG otimizada com o método B3LYP/aug-cc-pVTZ. O átomo de Oxigênio está representado em vermelho, Nitrogênio em azul, Carbono em cinza e Hidrogênio em branco. Os comprimentos de ligação (em $\AA$ ) e a convenção de numeração dos átomos nos anéis também são indicados. 43

Figura 5 - Componente $A^{\prime \prime}$ da seção de choque integral para o espalhamento elástico de elétrons por Guanina. As curvas preta e vermelha correspondem a cálculos realizados nas aproximações SE e SEP, respectivamente. . .

Figura 6 - Orbitais virtuais com caráter $\pi^{*}$ da Guanina obtidos no nível HF/6$31 \mathrm{~g}(\mathrm{~d})$ utilizando a geometria planar $\left(\mathrm{C}_{s}\right)$. Todos os orbitais foram obtidos com isovalor de $0.03 . \ldots \ldots \ldots \ldots \ldots$

Figura 7 - Vetor momento de dipolo (esquerda) e orbital SOMO do DBS para a molécula de Guanina (direita). Orbital obtido com isovalor de 0.008. .

Figura 8 - Componente $A^{\prime}$ (curva tracejada) e $A^{\prime \prime}$ da seção de choque integral para o espalhamento elástico de elétrons por 8-oxoG. As curvas preta e vermelha correspondem a cálculos realizados nas aproximações SE e SEP, respectivamente. . . . . . . . . . . . . . .

Figura 9 - Seção de choque integral para o espalhamento elástico de elétrons por 8-oxoG utilizando a geometria pertencente ao grupo $\mathrm{C}_{1}$. As curvas preta e vermelha correspondem a cálculos realizados nas aproximações SE e SEP, respectivamente. . . . . . . . . . . . . . . 
Figura 10 - Orbitais virtuais com caráter $\pi^{*}$ da 8-oxoG obtidos no nível HF/6$31 \mathrm{~g}(\mathrm{~d})$, na geometria planar $\left(\mathrm{C}_{s}\right)$ da 8-oxoG (cima) e na geometria da 8-oxoG pertencente ao grupo $\mathrm{C}_{1}$ (baixo). Todos os orbitais foram obtidos com isovalor de 0.03 .

Figura 11 - Vetor momento de dipolo (esquerda) e orbital SOMO do DBS (direita) para a molécula de 8-oxoG na geometria planarizada $\mathrm{C}_{s}$ (cima) e na geometria pertencente ao grupo $\mathrm{C}_{1}$ (baixo). Orbitais obtidos com isovalor de 0.008 .

Figura 12 - Geometria da interseção cônica DBS/ $\pi_{1}^{*}$ estimada com base no acoplamento $\mathrm{S}_{0} / \pi_{1}^{*}$ (esquerda) e $\pi_{1}^{*} / \pi_{2}^{*}$ (direita) obtida por $\operatorname{CASSCF}(9,8) /$ ccpVDZ para G. . . . . . . . . . . . . . . . . . . . . . .

Figura 13 - Geometria da interseção cônica DBS/ $\pi_{1}^{*}$ estimada com base no acoplamento $\mathrm{S}_{0} / \pi_{1}^{*}$ obtida por CASSCF $(9,8) /$ cc-pVDZ para 8-oxoG. . . . . .

Figura 14 - Orbitais virtuais com caráter $\sigma^{*}$ da Guanina obtidos no nível HF/6$31 \mathrm{~g}(\mathrm{~d})$, na geometria planarizada $\left(\mathrm{C}_{s}\right) \ldots \ldots \ldots \ldots$

Figura 15 - Evolução dos orbitais A'-LUMO e A'-LUMO+2 da Figura 14 com o estiramento da coordenada $\mathrm{C}-\mathrm{NH}_{2}$. Orbitais gerados com valor de contorno de isosuperfície de $0.03 \ldots \ldots \ldots \ldots \ldots$

Figura 16 - Orbitais virtuais com caráter $\sigma^{*}$ da 8-oxoG obtidos no nível HF /6-31g(d), na geometria planarizada $\left(\mathrm{C}_{s}\right) \ldots \ldots \ldots \ldots \ldots$

Figura B1 - Espaço ativo utilizado nos cálculos de energia mínima de excitação da Guanina. . . . . . . . . . . . . . . . . . . . .

Figura B2 - Orbitais utilizados no espaço ativo dos cálculos de estimativa das ressonâncias e de acoplamentos não adiabáticos para o ânion de G. Os orbitais $\pi$ e $\pi^{*}$ estão presente em todos os cálculos enquanto apenas os orbitais $\sigma$ e $\sigma^{*}$ na coordenada estudada estão presentes nos cálculos, formando um espaço ativo com 10 orbitais para os cálculos de acoplamentos $\pi^{*} / \sigma^{*} \ldots \ldots \ldots \ldots \ldots \ldots \ldots$

Figura B3 - Espaço ativo utilizado nos cálculos de energia mínima de excitação da

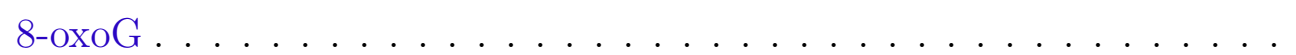

Figura B4 - Orbitais utilizados no espaço ativo dos cálculos de estimativa das ressonâncias e de acoplamentos não adiabáticos para o ânion de 8-oxoG. Os orbitais $\pi$ e $\pi^{*}$ estão presente em todos os cálculos enquanto apenas os orbitais $\sigma$ e $\sigma^{*}$ na coordenada estudada estão presentes nos cálculos, formando um espaço ativo com 10 orbitais para os cálculos de acoplamentos $\pi^{*} / \sigma^{*}$. 


\section{Lista de tabelas}

Tabela 1 - Posições e larguras (informadas entre parênteses) das ressonâncias obtidas para a molécula de Guanina, em unidades de eV. Os resultados deste trabalho são apresentados nas aproximações SE e SEP. . . . . . .

Tabela 2 - Posições e larguras (informadas entre parênteses) das ressonâncias obtidas para a molécula de 8-oxoG, em unidades de eV. Os resultados da seção de choque integral de espalhamento elástico são apresentados nas aproximações SE $\left(\mathrm{SE}-C_{s}\right)$ e $\operatorname{SEP}\left(\mathrm{SEP}-C_{s}\right) . \ldots \ldots$

Tabela 3 - Resumo dos resultados experimentais das medidas de intensidade de DEA para espalhamento de elétrons por G. São indicados os fragmentos, a relação massa/carga $(\mathrm{m} / \mathrm{z})$ que os caracteriza, a energia em que ocorrem as máximas intensidades de detecção, e as intensidades (cps).

Tabela 4 - Limiares de dissociação de Hidrogênio e $\mathrm{NH}_{2}$ com correção entrópica (coluna 3) e com correção de ponto zero (coluna 4) para a molécula de Guanina . . . . . . . . . . . . . . . . . . . . . .

Tabela 5 - Energias estimadas para acoplamentos não adiabáticos na $\mathrm{G}$, em eV, no nível SA-CASSCF $(11,10)$ /cc-pVDZ, em relação ao estado fundamental.

Tabela 6 - Limiares de dissociação de Hidrogênio e $\mathrm{NH}_{2}$ com correção entrópica (coluna 3) e com correção de ponto zero (coluna 4) para a molécula de

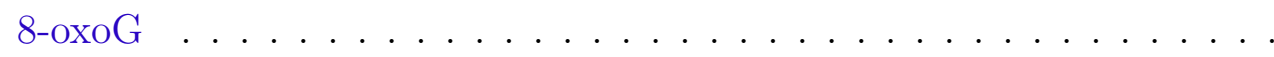

Tabela 7 - Energias estimadas para acoplamentos não adiabáticos na 8-oxoG, em eV, no nível SA-CASSCF $(11,10) /$ cc-pVDZ, em relação ao estado fundamental. . . . . . . . . . . . . . . . . .

Tabela A1 - Coordenadas otimizadas da 8-oxoG para a geometria pertencente ao grupo $\mathrm{C}_{s}$ em unidades de Angström $(\AA)$ obtidas com B3LYP/aug-cc-

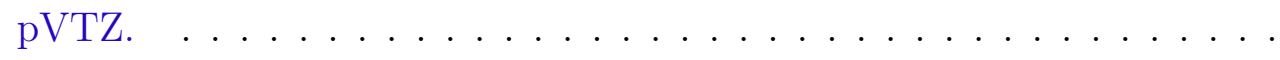

Tabela A2 - Coordenadas otimizadas da 8-oxoG para a geometria pertencente ao grupo $\mathrm{C}_{1}$ em unidades de $\AA$ ngström $(\AA)$ obtidas com B3LYP/aug-cc-

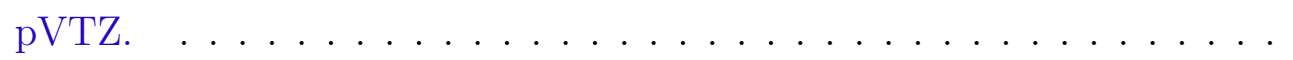

Tabela A3 - Coordenadas otimizadas da Guanina para a geometria pertencente ao grupo $\mathrm{C}_{s}$ em unidades de Ångström $(\AA)$ obtidas com B3LYP/aug-cc-pVTZ. 75

Tabela A4 - Expoentes das funções de base tipo gaussianas não contraídas no sistema cartesiano para os átomos de Carbono, Nitrogênio e Oxigênio (unidades atômicas $\ldots \ldots \ldots \ldots \ldots \ldots \ldots \ldots \ldots \ldots \ldots \ldots \ldots \ldots \ldots \ldots$

Tabela A5 - Expoentes das funções de base tipo gaussianas contraídas e seus respectivos coeficientes de contração no sistema cartesiano para o átomo de Hidrogênio (unidades atômicas) . . . . . . . . . . . . . . . 


\section{Sumário}

Introdução $\ldots \ldots \ldots \ldots \ldots \ldots \ldots \ldots \ldots \ldots \ldots$

Métodos Teóricos . . . . . . . . . . . . . . . . . . . . 17

Teoria de Espalhamento . . . . . . . . . . . . . . . . . . . . . 17

Princípio Variacional de Schwinger _. . . . . . . . . . . . . . 19

Método Multicanal de Schwinger _. . . . . . . . . . . . . . . . 21

Seção de Choque Diferencial e Integral . . . . . . . . . . . . . . . . . 24

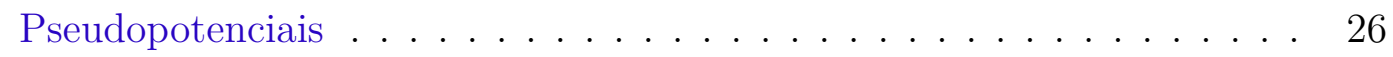

Espaço de configurações . . . . . . . . . . . . . . . . . . . . 27

Métodos de Estrutura eletrônica . . . . . . . . . . . . . . . . 28

Método Hartree-Fock . . . . . . . . . . . . . . . . . . . . . . . . 29

Teoria de Perturbação Möller-Plesset . . . . . . . . . . . . . . . . . 32

Coupled Cluster . . . . . . . . . . . . . . . . . . . . . 33

Métodos Multiconfiguracionais . . . . . . . . . . . . . . . . 34

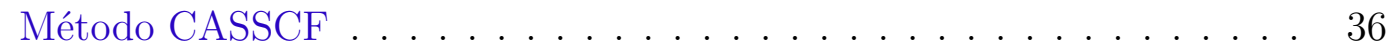

Método CASPT2 . . . . . . . . . . . . . . . . . . . 37

Teoria do funcional da densidade . . . . . . . . . . . . . . . . 39

Resultados . . . . . . . . . . . . . . 41

Procedimentos Numéricos . . . . . . . . . . . . . . . . . . . . . . . 41

Estados Aniônicos . . . . . . . . . . . . . . . . . . 45

Guanina . . . . . . . . . . . . . . . . . . . 45

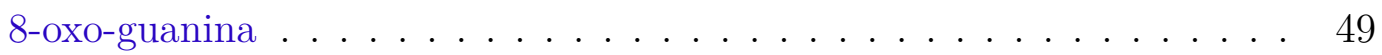

Captura eletrônica dissociativa . . . . . . . . . . . . . . . 54

Considerações Finais $\ldots \ldots \ldots \ldots \ldots \ldots \ldots \ldots \ldots \ldots$

Referências . . . . . . . . . . . . . . . 67

Apêndices

APÊNDICE A-Coordenadas atômicas das moléculas de G e 8oxoG e coeficientes de funções de base dos cálculos de espalhamento . . . . . . . . . 74

APÊNDICE B - Os orbitais do espaço ativo nos cálculos multiconfiguracionais . . . . . . . . . . 77 


\section{Introdução}

O espalhamento entre os elétrons de baixa energia por moléculas é de fundamental importância para estudos de ânions transientes, formados por captura eletrônica, na física molecular. Sua importância está tradicionalmente relacionada ao estudo de plasmas frios e de fenômenos astrofísicos, em baixas temperaturas, ligados ao entendimento da física e química de atmosferas planetárias e do meio interestelar (1). Nos plasmas frios, que são constituídos por gases ionizados ou parcialmente ionizados, fora do equilibrio termodinânimico, há interações entre elétrons livres de baixa energia e moléculas ionizadas ou neutras. Essas interações promovem a geração de íons e radicais que tipicamente agem sobre a superfície de um material alvo alterando suas propriedades físicas e químicas de superfície. Esses plasmas são comumente empregados em técnicas de processamento de materiais (plasmas de processamento) em diversas áreas de tecnologia para corrosão e descontaminação de materiais, deposição de filmes finos, entre outras aplicações $(2,3)$. Elétrons de baixa energia também são bastante importantes na fabricação de microestruturas e nanoestruturas com a técnica FEBID (Focused electron beam induced deposition). A FEBID baseia-se em dissociações causadas por interações entre elétrons e moléculas através da emissão de um feixe localizado de elétrons de alta energia em uma superfície com moléculas previamente adsorvidas por um processo de deposição molecular com um fluxo gasoso. Essa interação entre elétrons de alta energia com as moléculas da superfície gera uma série de colisões elásticas, inelásticas e processos de ionização produzindo elétrons secundários de baixa energia próximos à superfície do material, os quais podem induzir a fragmentação das moléculas adsorvidas (4).

A interação entre o elétron livre incidente e a molécula alvo permite a formação de ressonâncias no processo de espalhamento, que são estados eletrônicos instáveis do ânion (Transient Negative Ions, TNIs), com tempo de vida limitado por autoionização, que podem ser descritos por meio de um estado localizado, formado através da captura eletrônica do elétron incidente em um dos orbitais virtuais desocupados da molécula alvo, acoplado a um contínuo de estados de espalhamento. A formação de ressonâncias também pode iniciar processos dissociativos através do mecanismo de captura eletrônica dissociativa (Dissociative Electron Attachment, DEA), que será descrito adiante. Os métodos usuais de estrutura eletrônica fazem uso das condições de contorno de estados ligados, que não permitem descrever o decaimento para os estados contínuos do elétron capturado. A rigor, a formação de ressonâncias pode ser estudadas de duas maneiras: por métodos modificados de estrutura eletrônica (que incluem a autoionização) $(5,6)$ ou por métodos de espalhamento, que foi o método empregado neste trabalho.

A principal grandeza física calculada por este trabalho foi a amplitude de espalha- 
mento de elétrons por moléculas, a qual permite a observação de ressonâncias através da seção de choque integral, cuja formação se manifesta na forma de picos idealmente lorentzianos, associados a energias complexas $E=E_{i}-i \frac{\Gamma}{2}$, onde $E_{i}$ é a energia da ressonância e $\Gamma$ a sua largura de autoionização, sendo $\Gamma$ relacionado de forma inversa com o tempo de vida do TNI pelo princípio de incerteza de Heisenberg.

As ressonâncias eletrônicas podem ser caracterizadas de três maneiras, como ressonâncias de forma, ressonâncias de forma de caroço excitado e ressonâncias de Feshbach. Na ressonância de forma, o estado-pai é o estado fundamental da molécula alvo sendo que o ânion metaestável, formado através da captura do elétron incidente em um dos orbitais virtuais da molécula, possui energia mais alta do que a energia do estado-pai, havendo em primeira aproximação, apenas o envolvimento do elétron incidente na formação da ressonância. As ressonâncias de caroço excitado são processos que envolvem duas ou mais partículas, a captura do elétron incidente e a excitação de um elétron do alvo. Podem ser classificadas como ressonâncias de forma de caroço excitado se o ânion transiente formado possuir maior energia que o estado-pai da ressonância, que neste caso é um estado excitado da molécula neutra, ou como ressonância de Feshbach se a energia do ânion metaestável formado for menor que a energia do estado-pai. Excitações vibracionais também podem formar ressonâncias vibracionais de Feshbach sendo estas formadas quando existe um estado aniônico estável, com energia mais baixa que o estado-pai (estado fundamental da molécula neutra), cujos estados vibracionais excitados produzem ânions metaestáveis, que são instáveis frente à ejeção eletrônica acompanhada pelo decaimento vibracional. A Figura 1 sumariza os tipos de ressonâncias em função das suas energias relativas ao estado-pai.

O interesse por espalhamento de elétrons por biomoléculas surgiu das evidências de que elétrons com baixa energia, de $1 \mathrm{eV}$ a $20 \mathrm{eV}$, podem causar ruptura simples ou dupla na fita de DNA por DEA (7). O mecanismo de DEA consiste na captura de um elétron por uma molécula alvo que acarreta na formação de um radical reativo e um ânion estável.

$$
[\mathrm{AB}]+\mathrm{e}^{-} \rightarrow[\mathrm{AB}]^{-} \rightarrow[\mathrm{A}]^{\bullet}+[\mathrm{B}]^{-} \text {ou }[\mathrm{A}]^{-}+[\mathrm{B}]^{\bullet}
$$

A dissociação por DEA em biomoléculas ocorre, tipicamente, de forma direta, iniciada pela captura eletrônica num orbital dissociativo $\sigma^{*}$, ou de forma indireta através da captura de um elétron em um orbital $\pi^{*}$ que, durante a relaxação da geometria molecular (movimento vibracional), pode transferir população eletrônica para um orbital $\sigma^{*}$ dissociativo através de acoplamentos não adiabáticos (Figura 2).

O dano causado ao DNA por captura eletrônica dissociativa, no entanto, é relevante em tratamentos radiológicos, radioterápicos, e hadronterápicos. A radiação ionizante, utilizada durante o tratamento, produz uma quantidade muito grande de elétrons livres 


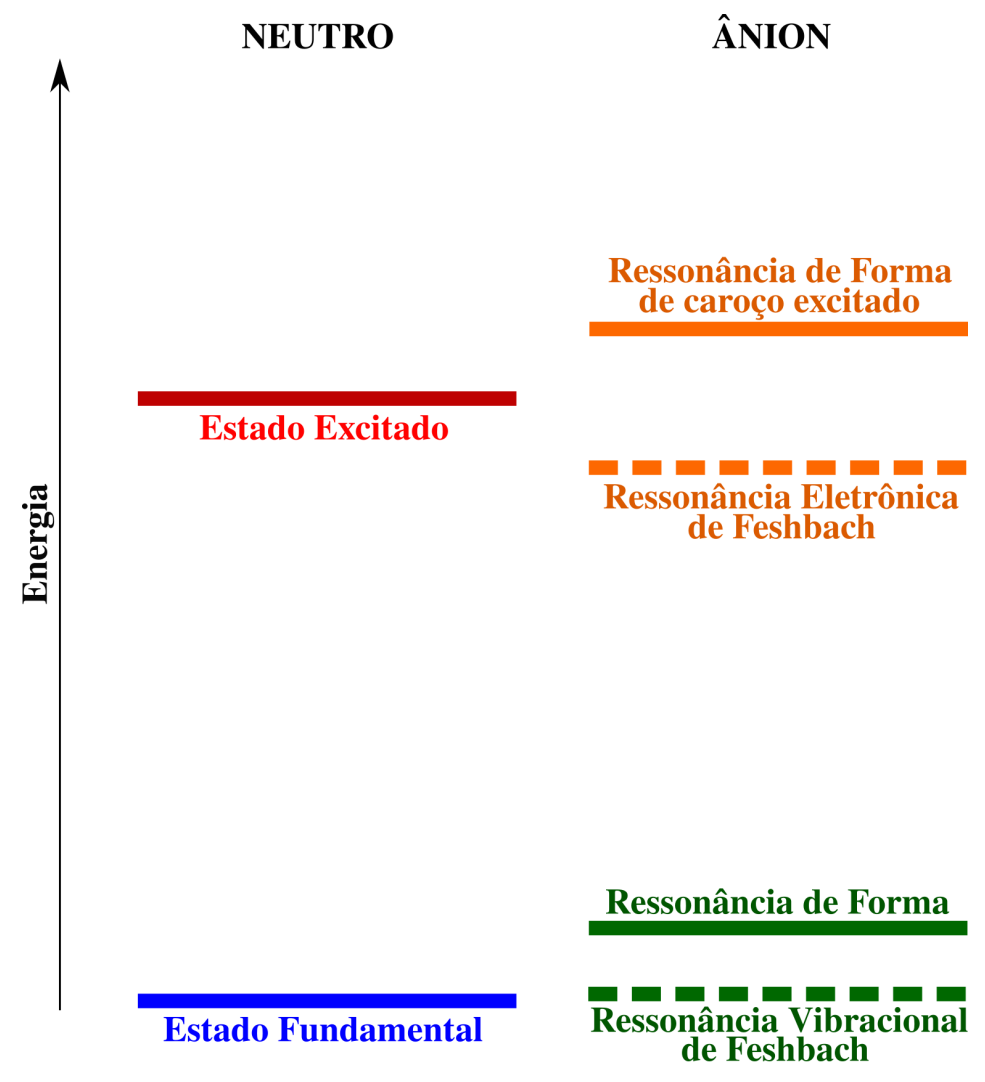

Figura 1 - Caracterização do tipo de ressonância. A esquerda a representação da energia do estado fundamental e do estado excitado, que são os estados-pai, e a direita a representação da energia das ressonâncias de forma e de Feshbach.

com alta energia em meio celular. Esses elétrons, através de colisões inelásticas com as moléculas do meio geram uma série de ionizações que podem reagir com outras moléculas gerando dissociações e a emissão de elétrons com menor energia. Essas ionizações são responsáveis pela formação de radicais $\mathrm{OH}$ a partir da dissociação de moléculas de água que, consequentemente, podem causar dano molecular ionizando diretamente as moléculas do DNA. Os elétrons livres secundários com energias menores que $20 \mathrm{eV}$, oriundos do resultado das reações primárias e de uma série de colisões inelásticas, são as espécies secundárias de maior abundância com cerca de $5 \times 10^{4}$ por $\mathrm{MeV}$ no meio celular, possibilitando que esses elétrons possam ser capturados por sítios específicos de biomoléculas que compõem o meio celular, levando à formação de estados aniônicos transientes e podendo causar dissociações por DEA $(7,8)$. A eficiência no tratamento de câncer por técnicas baseadas em radiação ionizante é maior do que métodos baseados em indução de lesões endógenas ao DNA devido a distribuição espacial dessas lesões. O dano ao DNA causado pela radiação ionizante tende a ser mais localizado com rupturas simples, duplas e multiplas (clustered damage) na fita de DNA, enquanto a distribuição das lesões ao DNA de forma endógena tende a ser homogênea (9).

A exposição de moléculas saudáveis à radiação ionizante, no entanto, é uma con- 


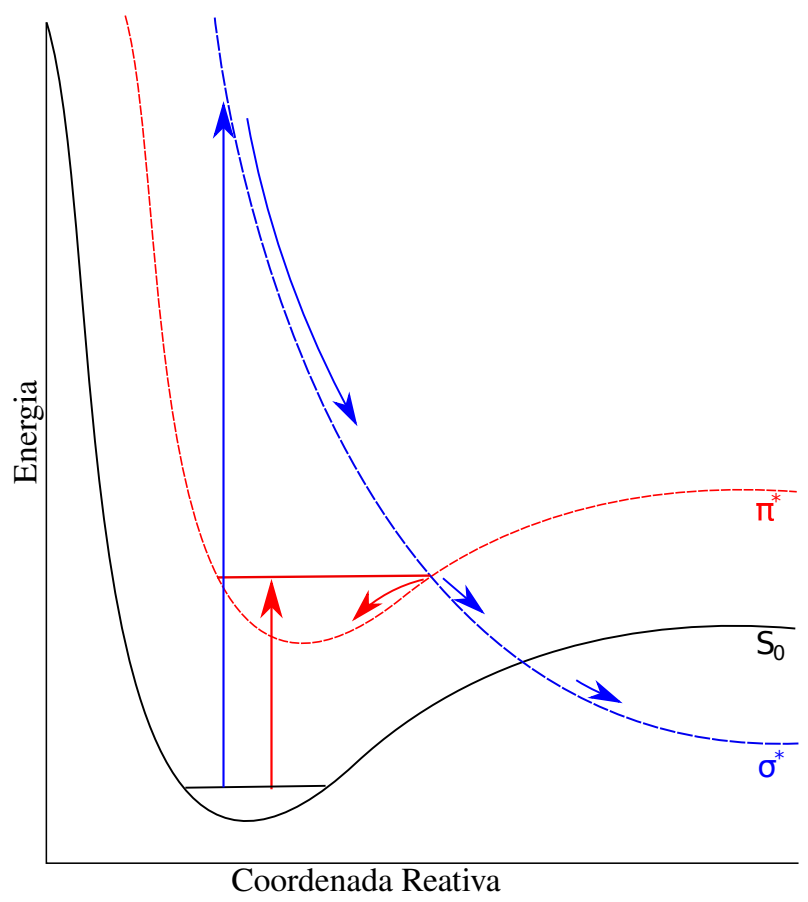

Figura 2 - Curvas típicas de energia potencial do estado fundamental da molécula neutra (em preto), do ânion $\pi^{*}$ (vermelho) e $\sigma^{*}$ (azul). A seta vertical vermelha sinaliza a captura eletrônica no orbital do tipo $\pi^{*}$ e a seta vertical azul sinaliza a captura eletrônica no orbital do tipo $\sigma^{*}$

sequência indesejada que pode ser atenuada através do uso de compostos que apresentam sinergia com a radiação ionizante e aumentam o dano as células cancerígenas possibilitando a diminuição das doses de radiação durante o tratamento. Os compostos com potencial radiossensibilizador são aqueles que intensificam o efeito da radiação ionizante e são normalmente introduzidos por quimioterapia em tratamentos de câncer para aumentar a eficácia da radioterapia. Os radiossensibilizadores têm a função de tornar as células cancerígenas mais vulneráveis aos efeitos da radioterapia. Isto é feito através da formação de complexos reativos com o DNA ou enzimas reparadoras sendo estes consumidos preferencialmente pelas células cancerígenas devido ao seu metabolismo acelerado $(10,11)$. As Uracilas modificadas (12) por um átomo halógeno (5-halouracilas), formam uma classe de biomoléculas que apresentam potencial radiossensibilizador. Essas moléculas são incorporadas ao DNA através da substituição da Timina (T) e podem interagir com elétrons e outras espécies reativas produzindo radicais nas próprias cadeias de DNA, que em etapas subsequentes podem causar dano ao DNA (13). As seções de choque de DEA para eliminação de $\mathrm{Br}^{-}$na 5-Br-Uracila (14) sugerem produção eficiente de radicais pela interação com elétrons de baixa energia. Visto que o mecanismo de radiosensibilização de biomoléculas pode estar relacionado com a formação de radicais gerados por DEA com elétrons secundários de baixa energia, estudos vêm sendo realizados com moléculas com potencial radiossensibilizador para melhor entendimento dos mecanismos de sua atividade biológica $(12,15,16,17,18,19)$. 
No presente trabalho, a molécula de interesse é uma lesão oxidativa e mutagênica da base nitrogenada Guanina $(\mathrm{G})$, denominada 8-oxo-guanina (8-oxoG). A presença desta lesão mutagênica na molécula de DNA induz pareamentos incorretos de G-T e acarreta na formação de pareamentos 8-oxoG - Citosina (C) na conformação estrela (anti) e 8-oxoG - Adenina (A) na conformação eclipsada (syn) (20). Apesar de seus efeitos deletérios como lesão mutagênica, existem estudos que demonstram que a 8-oxoG pode reparar dímeros de ciclobutano de pirimidina (cyclobutane pyrimidine dimer, CPDs), uma lesão carcinogênica causada por radiação UV e que provoca grandes distorções estruturais no DNA, quando fotoexcitada $(21,22)$. A 8-oxoG também apresenta tempo de vida do estado excitado próximo ao encontrado nas bases canônicas do DNA em solução aquosa, menores que 1 ps (23), o que indica que a 8-oxoG apresenta fotoestabilidade semelhante às bases canônicas, e corrobora a hipótese da 8-oxoG como percursora de biomoléculas. A 8-oxoG pode apresentar efeitos semelhantes as Uracilas modificadas (12). Como afirmado, a interação entre elétrons e as 5-halouracilas produz espécies reativas danosas na cadeia do DNA tumoral, levantando uma questão interessante sobre a 8-oxoG: na presença de elétrons produzidos por radiação ionizante, como se comportaria essa lesão? Apresentaria processos de DEA com maior eficiência em relação à G pristina, produzindo mais radicais no DNA das células tumorais que tenderiam a aumentar a eficiência do tratamento? $\mathrm{Ou}$ apresentaria menores seções de choque de DEA, tendendo a proteger o tumor do tratamento radioterápico? As seções de choque de DEA da G apresentam eliminações de fragmentos diversos ao das demais bases nitrogenadas, com menor eficiência de eliminação de $\mathrm{H}$ e uma maior variedade de fragmentos eliminados em energias abaixo do limiar de excitação eletrônica associados com a degradação da estrutura cíclica da molécula (24). Uma vez que a 8-oxoG é produzida através da $\mathrm{G}$ por processos oxidativos na cadeia de DNA (25), a inclusão do grupo Carbonila, que deve introduzir ressonâncias e canais de fragmentação adicionais, pode resultar em alterações nas taxas de dissociação por DEA.

O objetivo central deste trabalho foi caracterizar as ressonâncias da 8-oxoG e G por meio da seção de choque integral de espalhamento de elétrons pelas moléculas neutra, para então compará-las e discutir aspectos relacionados a processos dissociativos induzidos por DEA. A discussão foi realizada com base nas ressonâncias obtidas, nas estimativas dos acoplamentos não adiabáticos com métodos de estrutura eletrônica multiconfiguracionais, além de outros cálculos de estrutura eletrônica auxiliares que permitiram a obtenção de limiares de excitação eletrônica e de dissociação, e a caracterização de estados ligados por dipolo. Para a G, a discussão incluiu a comparação com os resultados experimentais de intensidade de DEA (24). O estudo da dinâmica das dissociações por métodos de dinâmica molecular quântica está fora do escopo deste trabalho.

Este texto foi dividido em quatro capítulos sendo este a Introdução seguido por um segundo capítulo de Métodos Teóricos que trata de descrever a teoria do espalhamento e os métodos de estrutura eletrônica utilizados durante o projeto. O terceiro capítulo, 
Resultados, apresenta a análise e os resultados dos cálculos realizados e o quarto capítulo, de Considerações Finais, é um resumo dos resultados mais importantes. 


\section{Métodos Teóricos}

Neste capítulo são descritos os métodos teóricos utilizados para obtenção dos resultados apresentados na seção seguinte. Parte-se da descrição teórica do método de espalhamento abordando o princípio variacional de Schwinger, o método multicanal de Schwinger e detalhes de sua implementação numérica. Posteriormente são descritos os métodos de estrutura eletrônica mono e multi configuracionais, e a teoria do funcional densidade, utilizados como ferramenta auxiliar para otimização de geometrias e caracterização de propriedades da G e 8-oxoG. As equações apresentadas durante este capítulo serão descritas no sistema de unidades atômicas, onde $\hbar=e=\mathrm{m}_{e}=1$.

\subsection{Teoria de Espalhamento}

O processo de espalhamento consiste na incidência de um feixe de partículas com energia bem definida sobre um alvo, que posteriormente é detectado em uma região fora do alcance do potencial de interação entre partículas e alvo. O alvo normalmente é um gás de moléculas com densidade baixa para que as distâncias entre as moléculas sejam muito maiores que o comprimento de onda de Broglie das partículas incidentes, permitindo que efeitos de coerência sejam desprezados (26). Neste trabalho foi considerado o espalhamento de uma partícula, no caso um elétron livre de baixa energia $(<12 \mathrm{eV})$, por uma molécula alvo neutra. O espalhamento entre elétrons e moléculas pode apresentar diferentes desdobramentos como excitações rotacionais, vibracionais ou eletrônicas, ionização e dissociação sendo que cada um destes eventos define um canal de espalhamento. Um canal é considerado aberto caso a energia total do sistema for conservada,

$$
E=\frac{k_{i}^{2}}{2}+E_{i}=\frac{k_{f}^{2}}{2}+E_{f}
$$

Na equação 2.1, o termo proporcional ao módulo do vetor de onda, $k_{i}\left(k_{f}\right)$, representa a energia inicial (final) do elétron incidente e $E_{i}\left(E_{f}\right)$ representa a energia inicial (final) da molécula alvo. A colisão é denominada elástica caso a interação do elétron livre com a molécula alvo não provoque mudanças na estrutura interna do alvo, ou inelástica caso haja transições rotacionais, vibracionais e/ou eletrônicas do alvo devido a transferência de energia do elétron incidente.

A descrição teórica do espalhamento é comumente realizada através da aproximação de núcleos fixos, desacoplando as soluções nucleares e eletrônicas, e solucionando-as separadamente. Neste caso, os canais relacionados com o movimento dos núcleos atômicos (excitações rotacionais, vibracionais e dissociação) são desconsiderados durante os cálculos 
de espalhamento. O Hamiltoniano de espalhamento do sistema de $N+1$ elétrons pode ser escrito conforme a equação:

$$
H_{N+1}=H_{0}+V=\left(H_{N}+T_{N+1}\right)+V
$$

onde $H_{0}$ é o Hamiltoniano não interagente que é composto pelos termos em parênteses, $H_{N}$ é o Hamiltoniano de $N$ elétrons da molécula alvo, $T_{N+1}$ é um operador de energia cinética do elétron incidente, indicado por $(N+1)$, e $V$ é o potencial de interação entre o elétron $(N+1)$ com os $N$ elétrons e $M$ núcleos da molécula alvo.

$$
\begin{gathered}
T_{N+1}=-\frac{1}{2} \nabla_{N+1}^{2}, \\
V=\sum_{i=1}^{N} \frac{1}{\left|\vec{r}_{N+1}-\vec{r}_{i}\right|}-\sum_{A=1}^{M} \frac{Z_{A}}{\left|\vec{r}_{N+1}-\vec{r}_{A}\right|} .
\end{gathered}
$$

As autofunções estacionárias do Hamiltoniano de espalhamento devem satisfazer a equação de Schrödinger (Equação 2.5) e a condição de contorno assintótica de espalhamento, assumindo uma função de onda conforme a Equação 2.6, cujo primeiro termo representa a solução do Hamiltoniano não interagente $H_{0}$ enquanto o segundo termo representa uma onda esférica divergente que é dependente do vetor de onda $\vec{k}_{j}$ final de cada canal aberto e modulada pela amplitude de espalhamento $f\left(\vec{k}_{j}, \vec{k}_{i}\right)$, que possui toda a informação sobre transições entre os canais abertos de espalhamento e seu módulo ao quadrado é diretamente proporcional à seção de choque diferencial.

$$
H_{N+1} \Psi_{\vec{k}_{i}}^{(+)}\left(\vec{r}_{1}, \ldots, \vec{r}_{N+1}\right)=E \Psi_{\vec{k}_{i}}^{(+)}\left(\vec{r}_{1}, \ldots, \vec{r}_{N+1}\right)
$$

onde

$$
\Psi_{\vec{k}_{i}}^{(+)}\left(\vec{r}_{1}, \ldots, \vec{r}_{N+1}\right)=S_{\vec{k}_{i}}\left(\vec{r}_{1}, \ldots, \vec{r}_{N+1}\right)+\sum_{j}^{\text {abertos }} f\left(\vec{k}_{j}, \vec{k}_{i}\right) \Phi_{j}\left(\vec{r}_{1}, \ldots, \vec{r}_{N}\right) \frac{\exp \left(i \vec{k}_{j} \cdot \vec{r}_{N+1}\right)}{r_{N+1}}
$$

A solução não interagente $S_{\vec{k}_{i}}$ é autofunção de $H_{0}$ com autovalores $E_{i}+k_{i}^{2} / 2$ sendo composta pelo produto de uma função de onda contínua do elétron incidente, representada por uma onda plana, e por uma função de onda discreta dos estados eletrônicos da molécula alvo:

$$
S_{\vec{k}_{i}}\left(\vec{r}_{1}, \ldots, \vec{r}_{N+1}\right)=\Phi_{i}\left(\vec{r}_{1}, \ldots, \vec{r}_{N}\right) \exp \left(i \vec{k}_{i} \cdot \vec{r}_{N+1}\right)
$$

Através da equação de Lippman-Schwinger, é possível incorporar a condição de contorno assintótica de espalhamento diretamente a equação de Schrödinger com a aplicação 
do formalismo das funções de Green. A equação 2.8 é composta por um termo semelhante ao apresentado na equação 2.7, que é a solução não interagente, e por um termo dependente do potencial de interação elétron-molécula e da função de Green, que representa uma onda esférica divergente (+) ou convergente (-) no limite assintótico. Ambas as soluções da onda esférica são matematicamente possíveis, entretanto, apenas a solução de onda esférica divergente contém significado físico.

$$
\left|\Psi_{\vec{k}_{i, f}}^{( \pm)}\right\rangle=\left|S_{\vec{k}_{i, f}}\right\rangle+G^{( \pm)} V\left|\Psi_{\vec{k}_{i, f}}^{( \pm)}\right\rangle
$$

onde

$$
G^{( \pm)}=\lim _{\epsilon \rightarrow 0} \frac{\mathbb{1}}{E-H_{0} \pm i \epsilon} .
$$

O operador identidade $\mathbb{1}$ contido na expressão do operador de Green na equação 2.9 representa o produto interno entre o espaço de Hilbert contínuo de dimensão 1 do elétron incidente e o espaço de Hilbert de dimensão $N$ discreto da molécula alvo, que forma um espaço de dimensão $N+1$, onde o Hamiltoniano não interagente $H_{0}$ está contido. Com isto e com a conservação de energia da equação 2.1, o operador de Green na base do Hamiltoniano $H_{0}$ pode ser escrito conforme a equação 2.10, no qual o simbolo $£$ representa a soma sobre todos os $i$ estados discretos da molécula alvo e uma integral sobre os estados $\vec{k}$ do contínuo para o elétron incidente.

$$
G^{( \pm)}=\lim _{\epsilon \rightarrow 0} \oiint_{i} \int d^{3} k \frac{\left|\Phi_{i} \vec{k}\right\rangle\left\langle\Phi_{i} \vec{k}\right|}{\frac{k_{i}^{2}}{2}-\frac{k^{2}}{2} \pm i \epsilon}
$$

\subsubsection{Princípio Variacional de Schwinger}

O princípio variacional de Schwinger foi desenvolvido com o objetivo de aplicar os métodos variacionais na teoria quântica de espalhamento (27). Na teoria de espalhamento, o procedimento proposto por Schwinger utiliza a forma bilinear da amplitude de espalhamento, que será descrita a seguir. As equações 2.11 e 2.12 para amplitude de espalhamento foram obtidas através das soluções das equações de Lippman-Schwinger com onda esférica divergente e convergente, respectivamente

$$
\begin{gathered}
f_{\vec{k}_{f}, \vec{k}_{i}}=-\frac{1}{2 \pi}\left\langle S_{\vec{k}_{f}}|V| \Psi_{\vec{k}_{i}}^{(+)}\right\rangle, \\
f_{\vec{k}_{f}, \vec{k}_{i}}=-\frac{1}{2 \pi}\left\langle\Psi_{\vec{k}_{f}}^{(-)}|V| S_{\vec{k}_{i}}\right\rangle .
\end{gathered}
$$

Multiplicando a equação de Lippman-Schwinger (Equação 2.8) por $V$ e reagrupando os termos, obtém-se o operador $A^{( \pm)}$e uma terceira forma integral para a amplitude de 
espalhamento ao substituir o termo $V\left|S_{\vec{k}_{i}}\right\rangle$ na equação 2.12 pelo termo $A^{( \pm)}\left|\Psi_{\vec{k}_{i}}^{( \pm)}\right\rangle$da equação 2.13 .

$$
\begin{gathered}
A^{( \pm)}\left|\Psi_{\vec{k}_{i}}^{( \pm)}\right\rangle=\left(V-V G^{( \pm)} V\right)\left|\Psi_{\vec{k}_{i}}^{( \pm)}\right\rangle=V\left|S_{\vec{k}_{i}}\right\rangle, \\
f_{\vec{k}_{f}, \vec{k}_{i}}=-\frac{1}{2 \pi}\left\langle\Psi_{\vec{k}_{f}}^{(-)}\left|A^{+}\right| \Psi_{\vec{k}_{i}}^{(+)}\right\rangle .
\end{gathered}
$$

A forma bilinear da amplitude de espalhamento é construida através da combinação dos resultados obtidos nas equações $2.11,2.12$ e 2.14 .

$$
\left[f_{\vec{k}_{f}, \vec{k}_{i}}\right]=-\frac{1}{2 \pi}\left[\left\langle S_{\vec{k}_{f}}|V| \Psi_{\vec{k}_{i}}^{(+)}\right\rangle+\left\langle\Psi_{\vec{k}_{f}}^{(-)}|V| S_{\vec{k}_{i}}\right\rangle-\left\langle\Psi_{\vec{k}_{f}}^{(-)}\left|A^{(+)}\right| \Psi_{\vec{k}_{i}}^{(+)}\right\rangle\right]
$$

Para que o princípio variacional de Schwinger possa ser aplicado ao funcional da equação 2.15, é preciso que este funcional apresente estabilidade em relação a variações arbitrárias, $\left|\Psi_{\vec{k}_{i}}^{(+)}\right\rangle \rightarrow\left|\Psi_{\vec{k}_{i}}^{(+)}\right\rangle+\left|\delta \Psi_{\vec{k}_{i}}^{(+)}\right\rangle$e $\left|\Psi_{\vec{k}_{f}}^{(-)}\right\rangle \rightarrow\left|\Psi_{\vec{k}_{f}}^{(-)}\right\rangle+\left|\delta \Psi_{\vec{k}_{f}}^{(-)}\right\rangle$. Essa estabilidade variacional ocorre se as condições das equações 2.16 e 2.17 forem respeitadas e, através das equações 2.17 e 2.13, conclui-se também que $A^{(+) \dagger}=A^{(-)}$.

$$
\begin{gathered}
A^{(+)}\left|\Psi_{\vec{k}_{i}}^{(+)}\right\rangle=V\left|S_{\vec{k}_{i}}\right\rangle, \\
A^{(+) \dagger}\left|\Psi_{\vec{k}_{f}}^{(-)}\right\rangle=V\left|S_{\vec{k}_{f}}\right\rangle .
\end{gathered}
$$

Expandindo os estados $\left|\Psi_{\vec{k}}^{( \pm)}\right\rangle$em uma base de funções tentativas $\left(\left|\chi_{\mu}\right\rangle\right)$, com as condições mencionadas anteriormente, é possível obter expressões analíticas para os coeficientes variacionais $\alpha_{\mu}^{( \pm)}(\vec{k})$.

$$
\left|\Psi_{\vec{k}}^{( \pm)}\right\rangle=\sum_{\mu} \alpha_{\mu}^{( \pm)}(\vec{k})\left|\chi_{\mu}\right\rangle
$$

A expansão dos estados em uma base de funções tentativas aplicada à equação 2.15 juntamente com a aplicação do método variacional permite que a amplitude de espalhamento possa ser expressa conforme a equação 2.19 .

$$
f_{\vec{k}_{f}, \vec{k}_{i}}=-\frac{1}{2 \pi} \sum_{\mu \nu}\left\langle S_{\vec{k}_{f}}|V| \chi_{\mu}\right\rangle\left(d^{-1}\right)_{\mu \nu}\left\langle\chi_{\nu}|V| S_{\vec{k}_{i}}\right\rangle
$$

com

$$
d_{\mu \nu}=\left\langle\chi_{\mu}\left|A^{(+)}\right| \chi_{\nu}\right\rangle
$$


O comportamento das funções tentativas no limite assintótico $(r \rightarrow \infty)$, na equação 2.19, não é relevante visto que estas funções são multiplicadas pelo potencial $V$, e no limite assintótico $V \rightarrow 0$, o que permite a expansão da função de onda de espalhamento em funções de base quadraticamente integráveis sem perda significativa de informação. Contudo, essa formulação, apesar de permitir o uso de funções tentativas de quadrado integrável, é computacionalmente inviável. Os elementos de matriz $d_{\mu \nu}$ possuem um termo dependente do operador de Green, cuja representação envolve os estados de ionização do contínuo do alvo (Equação 2.10), no qual representam canais de ionização. Esses canais de ionização apresentam uma contribuição importante para assegurar a antissimetria (28) do segundo termo da equação de Lippman-Schwinger (Equação 2.8), entretanto, a representação numérica de um contínuo de estados localizados é de difícil implementação.

\subsubsection{Método Multicanal de Schwinger}

O método multicanal de Schwinger (Schwinger Multichannel Method, SMC) é uma derivação alternativa do princípio variacional de Schwinger com a adição de um projetor sobre os canais energeticamente abertos da molécula alvo (Equação 2.21). Essa abordagem permite que os estados de ionização do alvo sejam desconsiderados na função de Green, viabilizando a implementação numérica do método para obtenção da amplitude de espalhamento através de uma base de funções tentativas quadraticamente integraveis de dimensão $(N+1)$.

$$
P=\sum_{l=0}^{\text {open }}\left|\Phi_{l}\right\rangle\left\langle\Phi_{l}\right| .
$$

A projeção sobre os estados eletrônicos energeticamente abertos leva a equação de LippmanSchwinger e o operador de Green às formas mostradas nas equações 2.22 e 2.23.

$$
P\left|\Psi_{\vec{k}_{i}}^{( \pm)}\right\rangle=\left|S_{\vec{k}_{i}}\right\rangle+G_{P}^{( \pm)} V\left|\Psi_{\vec{k}_{i}}^{( \pm)}\right\rangle
$$

onde

$$
G_{P}^{( \pm)}=\lim _{\epsilon \rightarrow 0} \sum_{l}^{\text {abertos }} \int d^{3} k \frac{\left|\Phi_{l} \vec{k}\right\rangle\left\langle\Phi_{l} \vec{k}\right|}{\frac{k_{l}^{2}}{2}-\frac{k^{2}}{2} \pm i \epsilon} .
$$

Seguindo o mesmo procedimento aplicado na seção 2.1.1, o operador $A^{( \pm)}$pode ser escrito conforme a equação 2.24 .

$$
A^{ \pm}\left|\Psi_{\vec{k}_{i}}^{( \pm)}\right\rangle=\left(P V-V G_{P}^{( \pm)} V\right)\left|\Psi_{\vec{k}_{i}}^{( \pm)}\right\rangle
$$


Entretanto, a condição de estabilidade variacional, $A^{(+) \dagger}=A^{(-)}$, não é mais satisfeita devido aos elementos $V$ e $P$ da equação 2.24 não comutarem. O projetor $P$ remove os estados referentes aos canais fechados de espalhamento. Para recuperar a informação física perdida na projeção, mantendo assim a estabilidade variacional, é necessário reescrever a função de onda de espalhamento, conforme equação 2.25, com um termo extra, (1-aP), que recupera a informação perdida pertencente ao espaço complementar do operador de projeção $P$.

$$
\left|\Psi_{\vec{k}_{i}}^{( \pm)}\right\rangle=a P\left|\Psi_{\vec{k}_{i}}^{( \pm)}\right\rangle+(1-a P)\left|\Psi_{\vec{k}_{i}}^{( \pm)}\right\rangle
$$

Na equação 2.25, o parâmetro a é uma variável arbitraria. Aplicando a função de onda de espalhamento modificada na equação de Schrödinger, levando em conta que $\left[H_{0}, P\right]$ $=0$ e $G_{0}^{( \pm)} H_{0}=1$, e utilizando a equação de Lippman-Schwinger projetada (Equação 2.22 ), após manipulações algébricas, obtém-se uma forma alternativa para $A^{( \pm)}$no qual a condição $A^{(+) \dagger}=A^{(-)}$é respeitada para todos os elementos de matriz que envolvem funções quadraticamente integráveis para qualquer valor do parâmetro $a$. O operador $\hat{H}$ na equação 2.27 é definido por $\hat{H}=E-H$.

$$
A^{( \pm)}\left|\Psi_{\vec{k}_{i}}^{( \pm)}\right\rangle=V\left|S_{\vec{k}_{i}}\right\rangle
$$

onde

$$
A^{( \pm)}=\frac{1}{2}(P V+V P)-V G_{P}^{( \pm)} V+\frac{1}{a}\left[\hat{H}-\frac{a}{2}(\hat{H} P+P \hat{H})\right] .
$$

No entanto, a equação 2.27 não mantém a condição de estabilidade variacional para os elementos de matriz que envolvam funções do contínuo. Neste caso, a estabilidade só será mantida se o parâmetro $a$ for igual a $N+1$ (29). Com isso, pode-se expandir a função de onda em funções tentativas quadraticamente integráveis $\left(\left|\chi_{\mu}\right\rangle\right)$, assim como realizado na subseção anterior, e obter o funcional de amplitude de espalhamento (Equação 2.15) através dos métodos variacionais.

$$
f_{\vec{k}_{f}, \vec{k}_{i}}=-\frac{1}{2 \pi} \sum_{\mu \nu}\left\langle S_{\vec{k}_{f}}|V| \chi_{\mu}\right\rangle\left(d^{-1}\right)_{\mu \nu}\left\langle\chi_{\nu}|V| S_{\vec{k}_{i}}\right\rangle
$$

com

$$
d_{\mu \nu}=\left\langle\chi_{\mu}\left|A^{(+)}\right| \chi_{\nu}\right\rangle
$$


e

$$
A^{( \pm)}=\frac{1}{2}(P V+V P)-V G_{P}^{( \pm)} V+\frac{1}{N+1}\left[\hat{H}-\frac{N+1}{2}(\hat{H} P+P \hat{H})\right] .
$$

A maior parte dos elementos de matriz contidos na equação 2.28 são similares aos presentes nas soluções de problemas de estados ligados, com integrais de operadores de um elétron (energia cinética ou interação elétron-núcleo) ou dois elétrons (interação elétronelétron), que apresentam, respectivamente, duas e quatro funções gaussianas cartesianas. No entanto, os elementos de matriz $\left\langle S_{\vec{k}_{f}}|V| \chi_{\mu}\right\rangle$ e $\left\langle\chi_{\mu}\left|V G_{P}^{( \pm)} V\right| \chi_{\nu}\right\rangle$, que possuem contribuição da onda plana, apresentam uma forma integral distinta (30). Para o termo $\left\langle S_{\vec{k}_{f}}|V| \chi_{\mu}\right\rangle$, a integral de um elétron apresenta uma função gaussiana cartesiana $(\alpha)$, um operador $\mathcal{O}$ de um elétron e uma onda plana, enquanto a integral de dois elétrons apresenta três funções gaussianas cartesianas $(\alpha, \beta, \gamma)$, um operador de dois elétrons e uma onda plana.

$$
\begin{gathered}
(\alpha \mid \vec{k})=\int d \vec{r}_{1} \alpha\left(\vec{r}_{1}\right) \mathcal{O}_{1} \exp \left(i \vec{k} \cdot \vec{r}_{1}\right), \\
(\alpha \beta \mid \gamma \vec{k})=\int d \vec{r}_{1} \int d \vec{r}_{2} \alpha\left(\vec{r}_{1}\right) \beta\left(\vec{r}_{1}\right) \frac{1}{\left|\vec{r}_{1}-\vec{r}_{2}\right|} \gamma\left(\vec{r}_{2}\right) \exp \left(i \vec{k} \cdot \vec{r}_{2}\right) .
\end{gathered}
$$

Para o elemento de matriz que envolve o operador de Green, $\left\langle\chi_{\mu}\left|V G_{P}^{( \pm)} V\right| \chi_{\nu}\right\rangle$, inicialmente separa-se a parte real (valor principal de Cauchy) e imaginária (resíduo) da função de Green projetada (Equação 2.23).

$$
G_{P}^{(+)}=G_{P}^{P r}+G_{P}^{R}
$$

sendo a componente real,

$$
G_{P}^{P r}=\sum_{l}^{\text {abertos }} \mathcal{P} \int_{0}^{\infty} d k \frac{k^{2}}{\frac{k_{l}^{2}}{2}-\frac{k^{2}}{2}} \int d \hat{k}\left|\Phi_{l} \vec{k}\right\rangle\left\langle\Phi_{l} \vec{k}\right|,
$$

e a componente imaginária,

$$
G_{P}^{R}=i \pi \sum_{l}^{\text {abertos }} k_{l} \int d \hat{k}\left|\Phi_{l} \vec{k}\right\rangle\left\langle\Phi_{l} \vec{k}\right|
$$

Consequentemente, o elemento de matriz também pode ser separado conforme a componente real e imaginária da função de Green.

$$
\left\langle\chi_{\mu}\left|V G_{P}^{(+)} V\right| \chi_{\nu}\right\rangle=\left\langle\chi_{\mu}\left|V G_{P}^{P r} V\right| \chi_{\nu}\right\rangle+\left\langle\chi_{\mu}\left|V G_{P}^{R} V\right| \chi_{\nu}\right\rangle
$$


Com os termos off-shell e on-shell representados nas equações 2.37 e 2.38, respectivamente

$$
\begin{gathered}
\left\langle\chi_{\mu}\left|V G_{P}^{P r} V\right| \chi_{\nu}\right\rangle=\sum_{l}^{\text {abertos }} \mathcal{P} \int_{0}^{\infty} d k \frac{k^{2}}{\frac{k_{l}^{2}}{2}-\frac{k^{2}}{2}} g_{\mu \nu}^{l}(k), \\
\left\langle\chi_{\mu}\left|V G_{P}^{R} V\right| \chi_{\nu}\right\rangle=i \pi \sum_{l}^{\text {abertos }} k_{l} g_{\mu \nu}^{l}\left(k_{l}\right),
\end{gathered}
$$

onde

$$
g_{\mu \nu}^{l}(k)=\int d \hat{k}\left\langle\chi_{\mu}|V| \Phi_{l} \vec{k}\right\rangle\left\langle\Phi_{l} \vec{k}|V| \chi_{\nu}\right\rangle
$$

As integrais radiais da equação 2.37 em $d k$ e angulares (Equação 2.39) em $d \hat{k}$ são calculadas de forma numérica através da quadratura de Gauss-Legendre (31, 30).

\subsubsection{Seção de Choque Diferencial e Integral}

A amplitude de espalhamento no método SMC é calculada no referencial de corpo fixo na molécula. Este referencial permite o uso de propriedades de simetria, o que acarreta em um ganho de performance nos cálculos computacionais. Entretanto, para obtenção da seção de choque diferencial que seja comparável com resultados experimentais, é necessário efetuar a mudança de referencial do corpo fixo (Body-Frame, BF) para o referencial fixo do laboratório (Laboratory-Frame, LF). O referencial do laboratório é definido de forma que a direção do feixe de partículas incidentes seja $\vec{k}_{i}^{\prime}=k_{i} \hat{z}^{\prime}$ (direções no BF e LF são denotadas por $\hat{r}$ e $\hat{r}^{\prime}$, respectivamente). O vetor de onda final do espalhamento $\vec{k}_{f}$, no $\mathrm{BF}$, é expandido na base das componentes de momento angular $\sum_{m=-l}^{+l}|l m\rangle\langle l m|$, dando origem à equação 2.40, cuja forma final é composta pela decomposição da amplitude de espalhamento nas componentes de momento angular $\left(f_{l, m}\right)$ e por uma combinação linear de harmônicos esféricos. O termo $f_{l, m}$ também pode ser entendido como a amplitude de espalhamento de um elétron entrando na região de interação como uma onda plana $\left|\vec{k}_{i}\right\rangle$ e saindo como uma onda parcial $|l m\rangle(30)$.

$$
f\left(\vec{k}_{f}, \vec{k}_{i}\right) \equiv\left\langle\vec{k}_{f}|f| \vec{k}_{i}\right\rangle=\sum_{l=0}^{l_{\max }} \sum_{m=-l}^{+l}\left\langle\hat{k}_{f} \mid \operatorname{lm}\right\rangle\left\langle\operatorname{lm}|f| \vec{k}_{i}\right\rangle=\sum_{l=0}^{l_{\max }} \sum_{m=-l}^{+l} f_{l, m}\left(k_{f}, \vec{k}_{i}\right) Y_{l}^{m}\left(\hat{k}_{f}\right)
$$

onde

$$
f_{l, m}\left(k_{f}, \vec{k}_{i}\right)=\int d \hat{k}_{f} Y_{l}^{m *}\left(\hat{k}_{f}\right) f\left(\vec{k}_{f}, \vec{k}_{i}\right) .
$$

O referencial da molécula fixa $(x, y, z)$ é rotacionado para o referêncial fixo do laboratório $\left(x^{\prime}, y^{\prime}, z^{\prime}\right)$ através das matrizes de rotação de Wigner $(32), D_{m^{\prime}, m}^{l}(\varphi, \theta, \gamma)$, onde $\varphi, \theta, \gamma$ são 
os ângulos de Euler. Substituindo o harmônico esférico da equação 2.41 pelo descrito na equação 2.42, obtém-se a representação da amplitude de espalhamento no referencial fixo do laboratório (Equação 2.43).

$$
\begin{gathered}
Y_{l}^{m}\left(\hat{k}_{f}\right)=\sum_{m^{\prime}} D_{m^{\prime}, m}^{l}(\varphi, \theta, \gamma) Y_{l}^{m^{\prime}}\left(\hat{k}_{f}^{\prime}\right), \\
f^{L F}\left(\vec{k}_{f}^{\prime}, \vec{k}_{i}\right)=\sum_{l, m, m^{\prime}} f_{l, m}\left(k_{f}, \vec{k}_{i}\right) D_{m, m^{\prime}}^{l *}(\varphi, \theta, \gamma) Y_{l}^{m^{\prime}}\left(\hat{k}_{f}^{\prime}\right) .
\end{gathered}
$$

Com a amplitude de espalhamento no referencial fixo do laboratório, pode-se obter a seção de choque diferencial, dependente do ângulo de espalhamento e das energias iniciais e finais da partícula incidente, através da integração sobre os ângulos azimutais (Equação 2.44). A seção de choque diferencial indica a distribuição angular do projetil e é definida como a razão do número de partículas espalhadas por unidade de tempo e ângulo sólido pelo fluxo de partículas incidente (26).

$$
\frac{d \sigma^{L F}}{d \Omega}\left(\theta_{f}^{\prime}\right)=\frac{k_{f}}{k_{i}} \frac{1}{4 \pi} \int d \hat{k}_{i} \int_{0}^{2 \pi} d \phi_{f}^{\prime}\left|f^{L F}\left(\vec{k}_{f}^{\prime}, \vec{k}_{i}\right)\right|^{2}
$$

Em experimentos de colisões de elétrons com moléculas, realizados em fase gasosa, as orientações das moléculas estão distribuídas de forma aleatória. A seção de choque diferencial incorpora esse comportamento através da média sobre as direções de incidência $\hat{k}_{i}$. Como $\hat{k}_{i}$ não foi transformado para o LF, trata-se de uma média sobre direções de incidência no $\mathrm{BF}$, que equivale a uma média orientacional no LF. A quadratura de Gauss-Legendre é utilizada nos cálculos das equações 2.41 e 2.44 .

A seção de choque integral é obtida através da integração da seção de choque diferencial em relação ao angulo de espalhamento $\theta_{f}$,

$$
\sigma\left(k_{i}, k_{f}\right)=2 \pi \int d \theta^{\prime} \sin \left(\theta^{\prime}\right) \frac{d \sigma^{L F}}{d \Omega}\left(\theta_{f}^{\prime}\right)
$$

A seção de choque integral permite a observação da probabilidade de interação entre a partícula incidente e a molécula alvo. Neste trabalho, foi considerado apenas o espalhamento elástico $\left(\left|\vec{k}_{i}\right|=\left|\vec{k}_{f}\right|\right)$ no qual não são consideradas excitações eletrônicas no limite assintótico, devido a limitação do projetor $P$ ao estado fundamental da molécula, $P=$ $\left|\phi_{0}\right\rangle\left\langle\phi_{0}\right|$. Portanto, as ressonâncias encontradas acima do limiar de excitação eletrônica são aproximações visto que suas posições podem sofrer alterações devido a acoplamentos com estados excitados. 


\subsubsection{Pseudopotenciais}

As integrais de dois elétrons são responsáveis por grande parte dos custos computacionais tanto em cálculos de estados ligados como para os cálculos de espalhamento. O aumento do número de elétrons implica crescimento muito rápido do número de integrais de dois elétrons, numa escalabilidade de $N^{4}$, sendo $N$ o número de funções atômicas, tornando praticamente inviável os cálculos que envolvem moléculas muito grandes ou moléculas médias com átomos muito pesados. Os elétrons de valência interagem muito mais fortemente com a partícula incidente do que os elétrons mais internos, de caroço, que estão mais presos aos núcleos atômicos e pouco participam do processo de espalhamento. Os pseudopotenciais permitem que esses elétrons de caroço sejam tratados juntamente com os núcleos através de um potencial efetivo que interage com os elétrons de valência e com o projétil, permintindo que os orbitais moleculares sejam representados apenas pelos elétrons de valência e, consequentemente, diminuindo o número de funções de bases necessárias durante os cálculos.

Os pseudopotenciais de Bachelet, Hamann e Schlüter (BHS) (33), implementados no SMC, são obtidos através de cálculos eletrônicos atômicos realizados com aproximações da densidade local. Esses pseudopotenciais possuem a propriedade de conservação da norma e produzem funções mais suaves próximas à origem, o que facilita a expansão da função de onda em uma base de funções tentativas (34). Esses pseudopotenciais foram implementados por Bettega et. al. (34) nos cálculos de espalhamento e de estrutura eletrônica do método SMC. As equações analíticas para os pseudopotenciais BHS são:

$$
\hat{V}_{P P}=\hat{V}_{\text {core }}+\hat{V}_{\text {ion }}
$$

onde

$$
\begin{gathered}
\hat{V}_{\text {core }}=-\frac{Z_{\text {val }}}{r} \sum_{i=1}^{2} c_{i} \operatorname{erf}\left(\sqrt{\rho_{i}} r\right), \\
\hat{V}_{\text {ion }}=\sum_{n=0}^{1} \sum_{j=1}^{3} \sum_{l=0}^{2} A_{n j l} r^{2 n} \exp \left(-\sigma_{j l} r^{2}\right) \sum_{m=-l}^{+l}|l m\rangle\langle l m| .
\end{gathered}
$$

O parâmetro $Z_{v a l}$ é o módulo da carga dos elétrons de valência e $c_{i}, \rho_{i}, A_{n j l}$ e $\sigma_{j l}$, são parâmetros tabelados conforme referência (33). A implementação dos pseudopotenciais nos cálculos de estrutura eletrônica é realizada com substituição do termo

$$
V_{\mu \nu}^{N u c l}=\int d \vec{r} \phi_{\mu}\left[-\frac{Z}{r}\right] \phi_{\nu}
$$


por um termo de contém o pseupotencial $V_{P P}$,

$$
V_{\mu \nu}^{P P}=\int d \vec{r} \phi_{\mu} \hat{V}_{P P} \phi_{\nu}
$$

O mesmo ocorre na implementação nos cálculos de espalhamento, com a integral

$$
V_{\vec{k} \nu}^{P P}=\int d \vec{r} \exp (-i \vec{k} \vec{r})\left[-\frac{Z_{C}}{r}\right] \phi_{\nu}
$$

sendo substituída pela integral

$$
V_{\vec{k} \nu}^{P P}=\int d \vec{r} \exp (-i \vec{k} \vec{r}) \hat{V}_{P P} \phi_{\nu}
$$

O uso dos pseudopotenciais requer bases apropriadas que sejam preparadas para descrever corretamente os elétrons de valência sob a ação do potencial efetivo. Essas bases foram geradas por Bettega et. al. (35) e foram utilizadas nos cálculos de espalhamento deste trabalho.

\subsubsection{Espaço de configurações}

Após a obtenção da forma bilinear da amplitude de espalhamento (Equação 2.15), conforme visto nas sessões anteriores, a função de onda de espalhamento é expandida numa base de funções tentativas (Equação 2.18) para então obter a forma final, através do princípio variacional, da amplitude de espalhamento (Equação 2.28). Essas funções tentativas, quadraticamente integráveis, são denominadas configurações. Configuração (configuration state function, CSF) é uma combinação linear de determinantes de Slater de $(N+1)$ elétrons com spin bem definido (spin-adapted linear combination). O conjunto dessas configurações de $N+1$ partículas, $\left\{\left|\chi_{m}\right\rangle\right\}$, é denominado como espaço de configurações e está diretamente relacionado com a qualidade da descrição do processo de espalhamento. Neste trabalho, as aproximações da função de onda de espalhamento no método SMC são realizadas no nível estático-troca (static-exchange, SE) e no nível estático-troca mais polarização (static-exchange plus polarisation, SEP).

Na aproximação estático-troca (SE), o espaço de configurações é construído através da seguinte relação:

$$
\left|\chi_{m}\right\rangle=\mathcal{A}_{N+1}\left[\left|\Phi_{0}\right\rangle \otimes\left|\phi_{m}\right\rangle\right]
$$

onde $\left|\Phi_{0}\right\rangle$ é o estado fundamental da molécula alvo neutra obtido através do método Hartree-Fock, $\left|\phi_{m}\right\rangle$ é o orbital de espalhamento, e $\mathcal{A}$ é o antisimetrizador de $N+1$ elétrons. Nesta aproximação, não há resposta dinâmica dos estados do alvo, sendo que este é apenas representado pelo estado fundamental, impedindo a interação da nuvem eletrônica com o 
elétron incidente, ou seja, os elétrons do alvo formam uma nuvem eletrônica congelada e que não reage à presença do campo elétrico do elétron incidente. Nos processos de espalhamento em energias acima de $\sim 20 \mathrm{eV}$, essa aproximação é razoável devido ao elétron incidente possuir velocidade suficiente para atravessar a nuvem eletrônica sem provocar distorções significativas, mas para colisões em energias mais baixas, o elétron incidente interage com a nuvem eletrônica por um maior tempo provocando maiores distorções, o que torna a aproximação estático-troca inadequada nestes casos.

Na aproximação estático-troca mais polarização (SEP), o espaço de configurações é construido de forma que:

$$
\left|\chi_{i m}\right\rangle=\mathcal{A}_{N+1}\left[\left|\Phi_{i}\right\rangle \otimes\left|\phi_{m}\right\rangle\right]
$$

Nesse nível de aproximação, a função de onda de espalhamento possui flexibilidade e reage à presença do elétron incidente, com os elétrons do alvo podendo sofrer excitações virtuais, ou seja, a nuvem eletrônica poderá sofrer deformações pela presença do elétron incidente. Com isso, interações de polarização de longo alcance e correlação eletrônica (interação de curto alcance) passam a ser consideradas nos cálculos. As configurações são construídas assim como no método de interação de configurações (Configuration Interaction, CI), permitindo excitações virtuais simples com um elétron deixando um orbital ocupado (buraco) e sendo promovido para um orbital desocupado (partícula). Excitações do tipo singleto e tripleto são permitidas para descrição da função de onda da molécula alvo, no entanto, apenas funções de onda de espalhamento do tipo dubleto são consideradas no espaço de configurações.

Para a construção do espaço de configurações costuma-se utilizar orbitais virtuais modificados (modified virtual orbitals, MVOs) (36), como orbitais de partícula e de espalhamento, ao invés dos orbitais virtuais canônicos. Os orbitais virtuais canônicos além de não descreverem bem os estados excitados, por terem sido gerados pelo campo de $N$ elétrons, são excessivamente difusos, o que os torna pouco eficiente para os cálculos numéricos. Os MVOs são construídos através da remoção de um número par $\mathrm{n}$ de elétrons mais energéticos dos $N / 2$ orbitais, permitindo a diagonalização do operador de Fock para o campo do cátion $+\mathrm{n}$, gerando orbitais mais compactos e que descrevem de forma mais eficiente os efeitos de correlação eletrônica.

\subsection{Métodos de Estrutura eletrônica}

Os métodos de estrutura eletrônica se prestam a descrever estados ligados de átomos e moléculas através da solução do Hamiltoniano de $N$ elétrons e $M$ núcleos (Equação 2.55) por meio da equação de Schrödinger $H|\Psi\rangle=E|\Psi\rangle$. Contudo, a solução da equação de Schrödinger é muito complexa para sistemas envolvendo muitos elétrons, e para que seja 
possível solucionar estes problemas, uma série de aproximações costumam ser consideradas durante os cálculos. A aproximação Born-Oppenheimer parte do princípio de que os núcleos atômicos são muito mais massivos do que os elétrons e, consequentemente, possuem energia cinética muito mais baixa, permitindo que o Hamiltoniano molecular seja separado em componentes nucleares e eletrônicas, e que a função de onda molecular seja desacoplada em duas soluções distintas, sendo uma referente a solução do movimento dos núcleos e outra referente a solução do movimento eletrônico com dependência paramétrica das coordenadas nucleares (Equação 2.56).

$$
\begin{gathered}
H=-\sum_{A=1}^{M} \frac{1}{2 M_{A}} \nabla_{A}^{2}-\sum_{i=1}^{N} \frac{1}{2} \nabla_{i}^{2}-\sum_{i=1}^{N} \sum_{A=1}^{M} \frac{Z_{A}}{\left|\vec{r}_{i}-\vec{R}_{A}\right|}+\sum_{i=1}^{N} \sum_{j>i}^{N} \frac{1}{\left|\vec{r}_{i}-\vec{r}_{j}\right|}+\sum_{A=1}^{M} \sum_{B>A}^{M} \frac{Z_{A} Z_{B}}{\left|\vec{R}_{A}-\vec{R}_{B}\right|} \\
\Psi(\vec{r}, \vec{R})=\Psi_{\text {nuc }}(\vec{R}) \Psi_{\text {ele }}(\vec{r} \mid \vec{R}) .
\end{gathered}
$$

Com a aproximação Born-Oppenheimer é possível descrever o problema eletrônico mantendo os núcleos fixos. O Hamiltoniano eletrônico pode ser escrito conforme a equação a seguir:

$$
H_{\text {ele }}=-\sum_{i=1}^{N} \frac{1}{2} \nabla_{i}^{2}-\sum_{i=1}^{N} \sum_{A=1}^{M} \frac{Z_{A}}{\left|\vec{r}_{i}-\vec{R}_{A}\right|}+\sum_{i=1}^{N} \sum_{j>i}^{N} \frac{1}{\left|\vec{r}_{i}-\vec{r}_{j}\right|} .
$$

O objetivo central dos métodos de estrutura eletrônica é solucionar o $H_{\text {ele }}$, e para isso, uma série de métodos, com abordagem ab initio ou semi-empírica, foram desenvolvidos e alguns desses métodos serão abordados nas próximas subseções.

\subsubsection{Método Hartree-Fock}

O método Hartree-Fock baseia-se na descrição da função de onda molecular através de um determinante de Slater de $N$ elétrons,

$$
\Phi_{0}=\frac{1}{\sqrt{N !}}\left|\begin{array}{ccccc}
\chi_{1}\left(\vec{x}_{1}\right) & \chi_{1}\left(\vec{x}_{2}\right) & \chi_{1}\left(\vec{x}_{3}\right) & \ldots & \chi_{1}\left(\vec{x}_{N}\right) \\
\chi_{2}\left(\vec{x}_{1}\right) & \chi_{2}\left(\vec{x}_{2}\right) & \chi_{2}\left(\vec{x}_{3}\right) & \ldots & \chi_{2}\left(\vec{x}_{N}\right) \\
\ldots & \ldots & \ldots & \ldots & \ldots \\
\chi_{N}\left(\vec{x}_{1}\right) & \chi_{N}\left(\vec{x}_{2}\right) & \chi_{N}\left(\vec{x}_{3}\right) & \ldots & \chi_{N}\left(\vec{x}_{N}\right)
\end{array}\right| .
$$

As funções $\chi_{i}\left(\vec{x}_{i}\right)$ são funções de uma partícula com coordenadas espaciais e spin, denominados como spin-orbitais moleculares. Esses spin-orbitais são definidos de forma que: $\chi_{a}\left(\vec{x}_{1}\right)=\phi_{p}\left(\vec{r}_{1}\right) \alpha(1)$ ou $\chi_{a}\left(\vec{x}_{1}\right)=\phi_{p}\left(\vec{r}_{1}\right) \beta(1)$, sendo $\alpha$ e $\beta$ spin up e down, respectivamente. O funcional de energia é definido como:

$$
E[\chi]=\left\langle\Phi_{0}\left|H_{\text {ele }}\right| \Phi_{0}\right\rangle=\sum_{i}^{N} h_{i}+\frac{1}{2} \sum_{i}^{N} \sum_{j}^{N}\left(J_{i j}-K_{i j}\right),
$$


com a integral de uma partícula,

$$
h_{i}=\left\langle\chi_{i}\left(\vec{x}_{i}\right)\left|-\frac{1}{2} \nabla_{i}^{2}-\sum_{A=1}^{M} \frac{Z_{A}}{\left|\vec{r}_{i}-\vec{R}_{A}\right|}\right| \chi_{i}\left(\vec{x}_{i}\right)\right\rangle,
$$

e as integrais de duas partículas,

$$
J_{i j}=\left\langle\chi_{i}\left(\vec{x}_{i}\right) \chi_{j}\left(\vec{x}_{j}\right)\left|\frac{1}{\left|\vec{r}_{i}-\vec{r}_{j}\right|}\right| \chi_{i}\left(\vec{x}_{i}\right) \chi_{j}\left(\vec{x}_{j}\right)\right\rangle
$$

e

$$
K_{i j}=\left\langle\chi_{i}\left(\vec{x}_{i}\right) \chi_{j}\left(\vec{x}_{j}\right)\left|\frac{1}{\left|\vec{r}_{i}-\vec{r}_{j}\right|}\right| \chi_{j}\left(\vec{x}_{i}\right) \chi_{i}\left(\vec{x}_{j}\right)\right\rangle
$$

Os spin-orbitais moleculares formam um conjunto de funções ortonormais entre si. Com isso, o vínculo da equação 2.63 é incorporado ao funcional de energia (Equação 2.59) através dos multiplicadores de Lagrange e o princípio variacional é aplicado na equação 2.64. O princípio variacional garante que o valor esperado do Hamiltoniano será um limite superior para a energia exata do estado fundamental, ou seja, o melhor conjunto de spin-orbitais moleculares são aqueles que levam o valor médio do Hamiltoniano a um mínimo.

$$
\begin{gathered}
\left\langle\chi_{i} \mid \chi_{j}\right\rangle=\delta_{i j}, \\
\delta L[\chi]=\delta\left(E[\chi]-\sum_{i, j} \epsilon_{j, i}\left(\left\langle\chi_{i} \mid \chi_{j}\right\rangle-\delta_{i j}\right)\right)=0 .
\end{gathered}
$$

A solução da equação 2.64 permite a obtenção do operador de Fock (Equação 2.66) e da equação canônica de Hartree-Fock (Equação 2.65).

$$
\begin{gathered}
\mathcal{F}\left(\vec{x}_{i}\right) \chi_{i}\left(\vec{x}_{i}\right)=\epsilon_{i} \chi_{i}\left(\vec{x}_{i}\right), \\
\mathcal{F}\left(\vec{x}_{i}\right)=h\left(\vec{x}_{i}\right)+\sum_{j}^{N}\left[\mathcal{J}_{j}\left(\vec{x}_{i}\right)-\mathcal{K}_{j}\left(\vec{x}_{i}\right)\right] .
\end{gathered}
$$

Com o operador de Coulomb, $\mathcal{J}_{j}\left(\vec{x}_{i}\right)$, e o operador de troca, $\mathcal{K}_{j}\left(\vec{x}_{i}\right)$, definidos nas equações 2.67 e 2.68 ,

$$
\mathcal{J}_{j}\left(\vec{x}_{i}\right) \chi_{i}\left(\vec{x}_{i}\right)=\left\langle\chi_{j}\left(\vec{x}_{j}\right)\left|\frac{1}{\left|\vec{r}_{i}-\vec{r}_{j}\right|}\right| \chi_{j}\left(\vec{x}_{j}\right)\right\rangle \chi_{i}\left(\vec{x}_{i}\right)
$$


e

$$
\mathcal{K}_{j}\left(\vec{x}_{i}\right) \chi_{i}\left(\vec{x}_{i}\right)=\left\langle\chi_{j}\left(\vec{x}_{j}\right)\left|\frac{1}{\left|\vec{r}_{i}-\vec{r}_{j}\right|}\right| \chi_{i}\left(\vec{x}_{j}\right)\right\rangle \chi_{j}\left(\vec{x}_{i}\right)
$$

com a energia Hartree-Fock dada por:

$$
E_{H F}=\sum_{i} \epsilon_{i}-\frac{1}{2} \sum_{i}^{N} \sum_{j>i}^{N}\left(\mathcal{J}_{i j}-\mathcal{K}_{i j}\right) .
$$

A equação de Hartree-Fock (Equação 2.65) contabiliza a média da energia de repulsão elétron-elétron duas vezes, e a $E_{H F}$ (Equação 2.69) contém um termo que subtrai a média da energia elétron-elétron excedente (37). A equação 2.65 acarreta em um conjunto de equações integro-diferenciais acopladas tornando sua implementação computacional inviável. Uma estratégia adotada para implementar o método é obter a equação de HartreeFock-Roothaan (38) que se baseia na expansão dos orbitais moleculares num conjunto de funções bases conhecidas.

$$
\phi_{p}(\vec{r})=\sum_{\gamma=1}^{k} C_{\gamma p} g_{\gamma}(\vec{r})
$$

Substituindo a equação 2.70 na equação 2.65 , multiplicando ambos os lados por $g_{\alpha}^{\star}\left(\vec{r}_{1}\right)$ e integrando, obtém-se a equação de Hartree-Fock-Roothaan.

$$
\mathcal{F}_{\alpha \gamma} C_{\gamma p}=\epsilon_{p} \sum_{\gamma} S_{\alpha \gamma} C_{\gamma p}
$$

com

$$
S_{\alpha \gamma}=\left\langle g_{\alpha}\left(\vec{r}_{i}\right) \mid g_{\gamma}\left(\vec{r}_{i}\right)\right\rangle
$$

e

$$
F_{\alpha \gamma}=\left\langle g_{\alpha}\left(\vec{r}_{i}\right)\left|\mathcal{F}\left(\vec{r}_{i}\right)\right| g_{\gamma}\left(\vec{r}_{i}\right)\right\rangle
$$

Na equação 2.74, o primeiro termo $h_{\alpha \gamma}$ representa a integral de um elétron e os demais representam as integrais de dois elétrons.

$$
F_{\alpha \gamma}=h_{\alpha \gamma}+\sum_{\lambda, \sigma} P_{\sigma, \lambda}\left[\langle\alpha \lambda \mid \gamma \sigma\rangle-\frac{1}{2}\langle\alpha \lambda \mid \sigma \gamma\rangle\right]
$$

onde

$$
h_{\alpha, \gamma}=\left\langle g_{\alpha}\left(\vec{r}_{i}\right)|h| g_{\gamma}\left(\vec{r}_{i}\right)\right\rangle \text {, }
$$




$$
P_{\sigma, \lambda}=2 \sum_{q} C_{\sigma q} C_{\lambda q}^{*}
$$

A equação de Hartree-Fock-Roothaan é resolvida em sua forma matricial através de um campo autoconsistente (self-consistent field, SCF) com um críterio de parada de convergência pré definido. Maiores detalhes de sua implementação podem ser encontrados no texto da referência (37). A definição da função de onda molecular através de um determinante de Slater acarreta na perda de parte da correlação eletrônica com respeito ao operador de Coulomb. Essa definição impõe que cada elétron se movimenta sob ação de um campo médio dos outros $N-1$ elétrons, fazendo uso da aproximação de campo médio. A correlação de Fermi está totalmente incluída no termo de troca, portanto, quando se diz que o método Hartree Fock não considera correlação eletrônica, essa correlação é referente à correlação de Coulomb e à correlação devido à dispersão de London. Para recuperar parte dessa correlação, métodos pós Hartree-Fock foram propostos e dois deles, teoria de perturbação de Möller-Plesset e Coupled Cluster, serão discutidos a seguir.

\subsubsection{Teoria de Perturbação Möller-Plesset}

A teoria de perturbação Möller-Plesset é um dos muitos métodos que visam recuperar os efeitos de correlação dinâmica, não contabilizados no método Hartree-Fock, de um sistema atômico ou molecular por meio da teoria perturbativa de Rayleigh-Schrödinger (39). O Hamiltoniano não perturbado é definido pela soma das contribuições dos $N$ elétrons no operador de Fock (Equação 2.66),

$$
H^{(0)}=\sum_{i}^{N} \mathcal{F}\left(\vec{x}_{i}\right)=\sum_{i}^{N}\left(h\left(\vec{x}_{i}\right)+\sum_{j}^{N}\left[\mathcal{J}_{j}\left(\vec{x}_{i}\right)-\mathcal{K}_{j}\left(\vec{x}_{i}\right)\right]\right) .
$$

Com a definição de $H^{(0)}$, o termo de perturbação $\delta H=H-H^{(0)}$ é escrito conforme equação 2.78 , onde admite-se que a perturbação seja pequena,

$$
\delta H=\sum_{i}^{N} \sum_{j>i}^{N} \frac{1}{\left|\vec{r}_{i}-\vec{r}_{j}\right|}-\sum_{i}^{N}\left(\sum_{j}^{N}\left[\mathcal{J}_{j}\left(\vec{x}_{i}\right)-\mathcal{K}_{j}\left(\vec{x}_{i}\right)\right]\right) .
$$

O primeiro termo da forma final de $\delta H$ na equação 2.78 é a interação elétron-elétron completa e o segundo termo soma duas vezes a interação de repulsão de um elétron com os demais, assim como na equação de Hartree-Fock (Equação 2.65). Com o termo de perturbação definido, são calculadas as correções, sendo o termo de ordem zero:

$$
\left\langle\phi_{0}|H| \phi_{0}\right\rangle=E_{0}^{(0)}=\sum_{i} \epsilon_{i}
$$


A correção de ordem 1 restaura a energia Hartree-Fock,

$$
\begin{gathered}
\left\langle\phi_{0}|\delta H| \phi_{0}\right\rangle=E_{0}^{(1)}=-\frac{1}{2} \sum_{i}^{N} \sum_{j>i}^{N}\left(J_{i j}-K_{i j}\right), \\
E_{0}^{(0)}+E_{0}^{(1)}=\sum_{i} \epsilon_{i}-\frac{1}{2} \sum_{i}^{N} \sum_{j>i}^{N}\left(\mathcal{J}_{i j}-\mathcal{K}_{i j}\right)=E_{H F} .
\end{gathered}
$$

A correção de ordem 2 é dada por:

$$
\begin{gathered}
E_{M P 2}=E_{H F}+E_{0}^{(2)}, \\
\left\langle\phi_{0}|\delta H| \phi_{1}\right\rangle=E_{0}^{(2)}=\sum_{i<j} \sum_{r<s} \frac{\left|\left\langle\phi_{0}|\delta H| \phi_{i j}^{r s}\right\rangle\right|^{2}}{E_{0}^{(0)}-E_{i j}^{r s}} .
\end{gathered}
$$

Os índices de $\phi_{i j}^{r s}$ na equação 2.83 representam determinantes duplamente excitados pela troca dos spin-orbitais moleculares ocupados $i, j$ por spin-orbitais moleculares virtuais $r, s$. O método é expansível até ordens mais altas, no entanto, devido ao aumento do custo computacional, outros métodos, como o Coupled Cluster, passam a ser mais interessantes e mais eficientes para recuperar a correlação eletrônica.

\subsubsection{Coupled Cluster}

O Coupled Cluster baseia-se na subdivisão do sistema de muitos elétrons em clusters de poucos elétrons. Inicialmente calculam-se todas as interações entre os elétrons do cluster e, em seguida, entre os elétrons dos diferentes clusters. A função de onda molecular, equação 2.84, incorpora um termo exponencial dependente do operador de cluster $T$ a solução Hartree-Fock $\Phi_{0}$.

$$
\Phi=\exp (T) \Phi_{0}
$$

O operador de cluster pode ser decomposto em $N$ operadores de clusters de forma que:

$$
T=T_{1}+T_{2}+\ldots+T_{N}
$$

onde $T_{1}$ é o operador que representa todas as excitações simples de um spin orbital $i$ ocupado para um spin orbital $r$ desocupado,

$$
T_{1}=\sum_{i} \sum_{r} t_{r}^{i} a_{r}^{\dagger} a_{i}
$$


$T_{2}$ representa todas as excitações duplas de spins orbitais $i, j$ ocupados para spin orbitais virtuais $r, s$,

$$
T_{2}=\frac{1}{4} \sum_{i, j} \sum_{r, s} t_{r s}^{i j} a_{r}^{\dagger} a_{s}^{\dagger} a_{j} a_{i}
$$

e $T_{n}$ é o operador de todas as n excitações de spins orbitais ocupados $i_{n}$ para spins orbitais virtuais $r_{n}$.

$$
T_{n}=\frac{1}{(n !)^{2}} \sum_{i_{1}, i_{2}, \ldots, i_{n}} \sum_{r_{1}, r_{2}, \ldots, r_{n}} t_{r_{1}, r_{2}, \ldots, r_{n}}^{i_{1}, i_{2}, \ldots, i_{n}} a_{r_{1}}^{\dagger} a_{r_{2}}^{\dagger} \ldots a_{r_{n}}^{\dagger} a_{i_{n}} \ldots a_{i_{2}} a_{i_{1}} .
$$

O formalismo de segunda quantização foi utilizado nas equações 2.86, 2.87 e 2.88, sendo $a$ e $a^{\dagger}$, respectivamente, os operadores de aniquilação e criação, e os coeficientes $t$ denominados como amplitudes de cluster. A equação de Schrödinger pode ser escrita conforme equação 2.89 com energias de acordo com a equação 2.90 .

$$
\begin{gathered}
H \exp (T) \Phi_{0}=E \exp (T) \Phi_{0}, \\
E=\frac{\left\langle\Phi_{0}|\exp (-T) H \exp (T)| \Phi_{0}\right\rangle}{\left\langle\Phi_{0} \mid \Phi_{0}\right\rangle} .
\end{gathered}
$$

Escolhendo o caso particular CCSD, que limita a expansão à excitações simples e duplas, as equações obtidas através do método são:

$$
\begin{gathered}
\left\langle\Phi_{0}\left|\exp \left(-\left(T_{1}+T_{2}\right)\right) H \exp \left(\left(T_{1}+T_{2}\right)\right)\right| \Phi_{0}\right\rangle=E \\
\left\langle\Phi_{i}^{r}\left|\exp \left(-\left(T_{1}+T_{2}\right)\right) H \exp \left(\left(T_{1}+T_{2}\right)\right)\right| \Phi_{0}\right\rangle=0 \\
\left\langle\Phi_{i j}^{r s}\left|\exp \left(-\left(T_{1}+T_{2}\right)\right) H \exp \left(\left(T_{1}+T_{2}\right)\right)\right| \Phi_{0}\right\rangle=0 .
\end{gathered}
$$

Normalmente, os cálculos coupled cluster são realizados até o nível CCSD devido ao seu alto custo computacional. Quando necessário, as contribuições das excitações triplas são incluídas de forma aproximativa através da teoria de perturbação, sendo este modelo denominado $\operatorname{CCSD}(\mathrm{T})$ (39). Neste trabalho foi feito uso do $\operatorname{CCSD}(\mathrm{T})$ para a obtenção de energias dos estados ligados por dipolo, que são estados bastante difusos, com energia na ordem de meV, e que precisam de bases mais difusas e métodos mais robustos para serem descritos apropriadamente.

\subsubsection{Métodos Multiconfiguracionais}

Os métodos multiconfiguracionais foram desenvolvidos para solucionar problemas em que a representação da função de onda molecular, por apenas um determinante 
de Slater, não permite uma descrição adequeada das interações eletrônicas. Problemas envolvendo estados excitados e quasi-degenerados, quebras de ligações, estados de transição e intermediários frequentemente precisam ser descritos com uma função de onda molecular mais complexa, em que diferentes arranjos de configurações eletrônicas são consideradas (40). A inclusão de um maior número de configurações eletrônicas permite que a correlação não dinâmica, denominada correlação estática, necessária para descrever esses fenômenos adequadamente, seja recuperada. O método SCF multiconfiguracional (Multi-Configurational Self-Consistent Field, MCSCF) parte da representação da função de onda molecular como configurações construídas através de combinações lineares de determinantes de Slater, assim como no método de Interação de Configurações (CI), com a diferença de que as configurações também são otimizadas ao invés de apenas os coeficientes CI.

$$
\Phi=\sum_{i}^{m} c_{i} \phi_{i}
$$

$\mathrm{Na}$ equação 2.94, os coeficientes $c_{i}$ estão associados às $m$-configurações $\phi_{i}$, sendo $\phi_{i}$ representado por combinações de determinantes de Slater que possuem a mesma simetria e spin do estado estudado. O Hamiltoniano eletrônico, com as regras de segunda quantização, pode ser escrito da seguinte forma:

$$
H=\sum_{i, j}\langle i|h| j\rangle a_{i}^{\dagger} a_{j}+\frac{1}{2} \sum_{i, j, k, l}\langle i j \mid k l\rangle a_{i}^{\dagger} a_{j}^{\dagger} a_{l} a_{k}
$$

onde $a_{i}^{\dagger}$ e $a_{i}$ são, respectivamente, os operadores de criação e aniquilação. A energia é dada por:

$$
E=\sum_{i, j} h_{i j} D_{i j}+\frac{1}{2} \sum_{i, j, k, l} P_{i j k l}(i j \mid k l)
$$

com

$$
\begin{gathered}
D_{i j}=\sum_{m, n} c_{m}^{*} c_{n}\left\langle\phi_{m}\left|E_{i j}\right| \phi_{n}\right\rangle, \\
P_{i j k l}=\left\langle\phi_{m}\left|E_{i j} E_{k l}-\delta_{j k} E_{i l}\right| \phi_{n}\right\rangle, \\
E_{p q}=a_{p \alpha}^{\dagger} a_{q \alpha}+a_{p \beta}^{\dagger} a_{q \beta} .
\end{gathered}
$$

Nas equações 2.96, 2.97 e 2.98, $h_{i j}$ e $(i j \mid k l)$ são, respectivamente, integrais de um e dois elétrons, $D_{i j}$ é um elemento da matriz de densidade de um elétron e $P_{i j k l}$ é um elemento 
da matriz de densidade de dois elétrons. A obtenção das funções de onda e dos autovalores usualmente é realizada através da definição da equação 2.96 em termos de parâmetros variacionais da função de onda e através da solução da seguinte equação:

$$
\sum_{j}\left\langle\phi_{i}|H| \phi_{j}\right\rangle c_{j}-\epsilon c_{i}=0
$$

com os vínculos:

$$
\begin{gathered}
\sum_{i} c_{i}^{2}=1, \\
\left\langle\phi_{i} \mid \phi_{j}\right\rangle=\delta_{i j}
\end{gathered}
$$

O parâmetro $\epsilon$ da equação 2.100 é um multiplicador de Lagrange. Existem diversos métodos que podem ser utilizados para otimizar os parâmetros variacionais sendo os princípais e mais utilizados o método Newton-Raphson e o método super-CI (41).

Contudo, o uso do método MCSCF é bastante complexo pois as configurações da equação 2.94 devem ser escolhidas cuidadosamente de forma que seja o mais flexível possível para que os efeitos de correlação estática possam ser incorporados. A escolha incorreta das configurações pode levar a resultados errados, o que é um fator complicador para a usabilidade do método. Uma forma automática de gerar essas configurações e reduzir o problema na escolha dos orbitais do espaço ativo é com o uso do método CASSCF, que será descrito a seguir.

\subsubsection{Método CASSCF}

O método CASSCF (Complete active space self-consistent field) é uma modificação do método MCSCF para que as configurações da equação 2.94 possam ser escolhidas de maneira automática através de um critério pré-estabelecido. Esse critério baseia-se na sub-divisão do espaço de configurações em quatro subespaços (41). Esses subespaços são definidos como espaço dos orbitais congelados, dos orbitais inativos, dos orbitais ativos e dos orbitais virtuais. O espaço dos orbitais congelados é composto por orbitais moleculares de caroço mais internos e que possuem caráter atômico. Esses orbitais são mantidos duplamente ocupados por todo o processo e não precisam ser otimizados durante os cálculos MCSCF, pois eles não contribuem em processos reativos ou de excitação e de ionização do sistema em estudo. O espaço dos orbitais inativos é composto por orbitais que permanecem duplamente ocupados e que também não contribuem para os processos físicos e químicos. No entanto, esses orbitais precisam ser otimizados para uma melhor descrição do sistema. O espaço dos orbitais ativos é composto pelos orbitais que participam diretamente dos processos físicos e químicos. Nesse espaço todas as possíveis ocupações 
eletrônicas são permitidas e os orbitais sempre serão otimizados durante os cálculos. O espaço dos orbitais virtuais possuem orbitais que não serão populados durante os cálculos.

A escolha do espaço ativo é a etapa mais importante para a aplicação do método e varia conforme o fenômeno a ser estudado. Caso o interesse seja o estudo de excitações e ionizações de compostos orgânicos, o espaço ativo ideal deve conter todos os orbitais $\pi$ e $\pi^{*}$, os orbitais que apresentam pares isolados, para descrever excitações do tipo $\mathrm{n} \rightarrow$ $\pi^{*}$, e os orbitais de Rydberg (41). Para dissociações, os orbitais $\sigma$ e $\sigma^{*}$ na coordernada dissociativa a ser estudada devem ser incluídos juntamente com os orbitais $\pi$ e $\pi^{*}$. O número de configurações do método escala conforme a equação

$$
N_{C A S}=\frac{2 S+1}{n+1}\left(\frac{n+1}{N / 2-S}\right)\left(\frac{n+1}{N / 2+S+1}\right)
$$

sendo $S$ o spin total, $N$ o número de elétrons no espaço ativo e $n$ o número de orbitais no espaço ativo. O grande número de configurações (Equação 2.103) é um fator limitante para o tamanho do espaço ativo visto que o custo computacional aumenta rapidamente conforme o número de configurações cresce, tornando o cálculo inviável para espaços ativos muito grandes e com muitos elétrons.

O método CASSCF também permite que múltiplos estados eletrônicos sejam otimizados simultaneamente através do uso da técnica de state-averaged CASSCF (SACASSCF) $(42,43)$. Os orbitais são otimizados de acordo com a energia média

$$
E_{\text {med }}=\sum_{i} \omega_{i} E_{i}
$$

no qual $\omega_{i}$ são os pesos das energias dos $i$-estados incluídos na média.

\subsubsection{Método CASPT2}

O método CASPT2 (Complete active space second-order perturbation theory) visa a recuperar a correlação eletrônica dinâmica, não considerada no método CASSCF, através de métodos perturbativos multiconfiguracionais (41) até segunda ordem. O método baseiase na teoria de perturbação de Rayleigh-Schrödinger, assim como a teoria de perturbação de Möller-Plesset, mas com uma função de onda de referência $\Phi_{0}$ multiconfiguracional, do tipo CASSCF. Da teoria de perturbação de Rayleigh-Schrödinger pode-se extrair as correções de energia até segunda ordem, que são da forma:

$$
\begin{aligned}
& E_{0}^{(0)}=\left\langle\Phi_{0}\left|H_{0}\right| \Phi_{0}\right\rangle, \\
& E_{0}^{(1)}=\left\langle\Phi_{0}|\delta H| \Phi_{0}\right\rangle,
\end{aligned}
$$




$$
E_{0}^{(2)}=\left\langle\Phi_{0}|\delta H| \Phi_{1}\right\rangle
$$

onde $\delta H$ é uma pequena perturbação obtida pela diferença Hamiltoniano total e do Hamiltoniano de ordem $0\left(\delta H=H-H_{0}\right), \Phi_{0}$ e $\Phi_{1}$ são, respectivamente, a função de onda CASSCF de ordem 0 e a função de onda corrigida em primeira ordem. O Hamiltoniano de ordem zero pode ser representado da seguinte forma:

$$
\boldsymbol{H}_{0}=\boldsymbol{P}_{0} \boldsymbol{F} \boldsymbol{P}_{0}+\boldsymbol{P}_{S D} \boldsymbol{F} \boldsymbol{P}_{S D}+\boldsymbol{P}_{X} \boldsymbol{F} \boldsymbol{P}_{X}
$$

no qual $\boldsymbol{P}_{0}$ é um operador de projeção no espaço de configurações de referência, $\boldsymbol{P}_{S D}$ é o operador de projeção no espaço de configurações interagente, isto é, no espaço formado por todas as configurações com excitações simples e duplas em relação ao espaço CAS, $\boldsymbol{P}_{X}$ é o projetor do espaço de configurações que não interage com as funções de referência, $\boldsymbol{F}$ é um operador de Fock generalizado definido como um operador efetivo de um elétron composto pela soma dos elementos de matriz $f_{p q}$ e do operador de excitação com média sobre os spins $E_{p q}$, conforme equações 2.109 à 2.111 (44).

$$
\boldsymbol{F}=\sum_{p, q} f_{p q} E_{p q}
$$

onde

$$
\begin{gathered}
f_{p q}=h_{p q}+\sum_{r, s} D_{r s}\left[\langle p r \mid q s\rangle-\frac{1}{2}\langle p q \mid r s\rangle\right] \\
E_{p q}=\sum_{\sigma} a_{p \sigma}^{\dagger} a_{q \sigma} .
\end{gathered}
$$

Na correção de primeira ordem, somente os termos que interagem diretamente com a função de onda de referência CAS são incluidos, isto é, os termos referentes ao espaço de configurações da projeção $\boldsymbol{P}_{S D}$.

$$
\left|\Phi_{1}\right\rangle=\sum_{i=1}^{m} c_{i}\left|\phi_{i}\right\rangle=-\sum_{i=1}^{m} \frac{\left\langle\phi_{i}|\delta H| \Phi_{0}\right\rangle}{E_{i}^{(0)}-E_{0}^{(0)}}\left|\phi_{i}\right\rangle .
$$

Nas ordens subsequentes, os termos além do espaço de projeção $\boldsymbol{P}_{S D}$ voltam a ser incorporados e a correção da energia de segunda ordem é dada por:

$$
E_{0}^{(2)}=\sum_{i}^{m} c_{i}\left\langle\Phi_{0}|\delta H| \phi_{i}\right\rangle=-\sum_{i}^{m} \frac{\left|\left\langle\Phi_{0}|\delta H| \phi_{i}\right\rangle\right|^{2}}{E_{i}^{(0)}-E_{0}^{(0)}}
$$


Por fim, a função de onda normalizada com a correção de primeira ordem incorporada é:

$$
|\Phi\rangle=\sqrt{\omega}\left|\Phi_{0}\right\rangle+\sqrt{1-\omega}\left|\Phi_{1}\right\rangle
$$

onde $\omega$ é o peso da função de onda de referência CAS. O peso $\omega$ de cada estado eletrônico deve ser semelhante para que haja balanceamento dos efeitos de correlação eletrônica entre os estados. A existência de um estado com $\omega$ muito menor que os demais indica a presença de estados intrusos. Os estados intrusos são estados originados da expansão em primeira ordem da função de onda (Equação 2.114) e que possuem energia muito próximas a energia do estado de referência (44). Consequentemente, esses estados apresentam denominadores pequenos ou negativos na correção das energias em segunda ordem (Equação 2.113) e inviabilizam o uso do método. O problema dos estados intrusos pode ser tratado através do aumento do espaço ativo com a inclusão dos orbitais que descrevem o estado intruso, ou da técnica level shift, nos casos em que as interações entre o estado intruso e os estados da função de onda de referência sejam pequenas. Detalhes sobre a técnica level shift podem ser vistos na referência (41).

\subsubsection{Teoria do funcional da densidade}

A teoria do funcional da densidade (Density Functional Theory, DFT) descreve a estrutura eletrônica de um sistema através de um funcional de densidade eletrônica $\rho(\vec{r})$, ao invés de utilizar aproximações na função de onda molecular, como os métodos mencionados anteriormente. Essa abordagem permite reduzir a dimensionalidade de um problema de $N$ partículas, que é representado por funções de ondas $3 N$ dimensionais (à parte o spin), em um problema de um funcional da densidade de 3 dimensões (45). Com isso, problemas envolvendo sistemas grandes, que não poderiam ser estudados, devido ao alto custo computacional necessário para aplicação dos métodos ab initio pós-Hartree-Fock, podem ser estudados através do DFT.

Os pilares da DFT são os teoremas de Hohenberg-Kohn (46) e o formalismo de Kohn-Sham (47). De acordo com essa teoria, a energia do estado fundamental pode ser determinada pela densidade eletrônica. A DFT visa correlacionar a energia eletrônica com a densidade eletrônica permitindo que a energia do Hamiltoniano eletrônico (Equação 2.57) seja descrita pelo funcional

$$
E[\rho]=T_{s}[\rho]+V_{n e}[\rho]+J[\rho]+E_{x c}[\rho]
$$

onde $T_{s}[\rho]$ é o funcional de energia cinética no referencial de um sistema de partículas não interagentes, sob ação de um potencial local efetivo $v_{e f}$, obtido através das equações 
de Kohn-Sham e da aproximação de função de onda por um determinante de Slater, e que possui mesma densidade eletrônica que o sistema interagente (48),

$$
\begin{gathered}
H^{K S}=-\frac{1}{2} \nabla^{2}+v_{e f}(r), \\
T_{s}[\rho]=\left\langle\phi_{i}\left|-\frac{1}{2} \nabla^{2}\right| \phi_{i}\right\rangle,
\end{gathered}
$$

$V_{n e}[\rho]$ é o funcional de interação elétron-núcleo expresso em termos do potencial externo devido aos núcleos,

$$
V_{n e}[\rho]=\int \rho(\vec{r}) v(\vec{r}) d \vec{r}
$$

$J[\rho]$ é o termo de Coulomb da interação elétron-elétron

$$
J[\rho]=\frac{1}{2} \iint \frac{\rho(\vec{r}) \rho\left(\vec{r}^{\prime}\right)}{\left|r-r^{\prime}\right|} d \vec{r} d \vec{r}^{\prime}
$$

e $E_{x c}[\rho]$ é o funcional de correlação e troca

$$
E_{x c}[\rho]=\left(T[\rho]-T_{s}[\rho]\right)+\left(V_{e e}[\rho]-J[\rho]\right)
$$

Na equação 2.120, $V_{e e}$ é a energia de repulsão elétron-elétron e $T[\rho]$ é a energia cinética exata para o sistema de elétrons que interagem. A formulação da DFT não apresenta nenhuma aproximação e, caso todos os funcionais da equação 2.115 fossem conhecidos, a energia obtida seria exata. No entanto, o funcional $E_{x c}[\rho]$, de correlação e troca, não pode ser obtido de forma exata. Com isso, uma série de funcionais foram e ainda são desenvolvidos com o objetivo de aproximar o funcional de correlação e troca. Neste trabalho foi utilizado o funcional B3LYP durante os cálculos de otimizações de geometrias. 


\section{Resultados}

Neste capítulo, os resultados obtidos para as moléculas de G e 8-oxoG são apresentados e analisados. Inicialmente é realizada uma descrição geral sobre os procedimentos aplicados nos cálculos para ambas as moléculas e então apresentadas as seções de choque para o espalhamento de um elétron por G e 8-oxoG, os estados ligados por dipolo e os limiares de excitação eletrônica. Por fim, um estudo comparativo entre a G e 8-oxoG é apresentado, com base nas seções de choque de DEA, acoplamentos não adiabáticos entre estados aniônicos e limiares de dissociação, visando a compreender se a lesão pode produzir mais radicais ao interagir com elétrons de baixas energias e, consequentemente, produzir um efeito protetor às células sadias quando expostas a radiação ionizante.

\subsection{Procedimentos Numéricos}

Nesta seção, são apresentados os procedimentos numéricos aplicados nos cálculos realizados neste trabalho. Em sequência, são informados detalhes sobre a descrição do alvo molecular e os cálculos de espalhamento. Por fim, são descritos os procedimentos utilizados nos cálculos auxiliares de estrutura eletrônica.

As otimizações das geometrias para o mínimo do estado fundamental das moléculas neutras foram realizadas com a programa GAMESS (49) utilizando DFT com o funcional B3LYP e a base aug-cc-pVTZ (B3LYP/aug-cc-pVTZ). A geometria das moléculas de 8-oxoG e $\mathrm{G}$ foram planificadas impedindo a piramidização do grupo $\mathrm{NH}_{2}$ ligado ao anel hexagonal, permitindo explorar a decomposição por simetria (grupo de simetria $\mathrm{C}_{s}$ ) nos cálculos de espalhamento. Para a 8-oxoG também foram realizados cálculos sem a imposição de planaridade na geometria (grupo de simetria $\mathrm{C}_{1}$ ). Seções de choque para a molécula de $\mathrm{G}$ nas geometrias $\mathrm{C}_{1}$ e $\mathrm{C}_{s}$ foram publicadas anteriormente por Winstead e Mckoy, tendo sido observados apenas uma diminuição de $0.1 \sim 0.2 \mathrm{eV}$ na energia das ressonâncias $\pi^{*}$ na aproximação SE quando comparado com o cálculo na geometria planar. Este resultado motiva o uso da planaridade para reduzir os custos computacionais sem perdas significativas na caracterização dos ânions transientes, visto que a estrutura da 8-oxoG é semelhante à G com alterações apenas no anel pentagonal com a substituição de um Hidrogênio $(\mathrm{H})$ ligado ao Carbono $(\mathrm{C})$ por um Oxigênio $(\mathrm{O})$ e a adição de um $\mathrm{H}$ ligado a um Nitrogênio $(\mathrm{N})$. As coordenadas e geometrias otimizadas podem ser observadas nas Tabelas A1, A2, A3, e nas Figuras 3 e 4 .

O estado fundamental do alvo molecular foi calculado no nível Hartree Fock restrito utilizando o pacote GAMESS customizado para utilização dos pseudopotenciais de Bachelet, Hamann e Schlüter (BHS) (33). As funções de base foram descritas com 


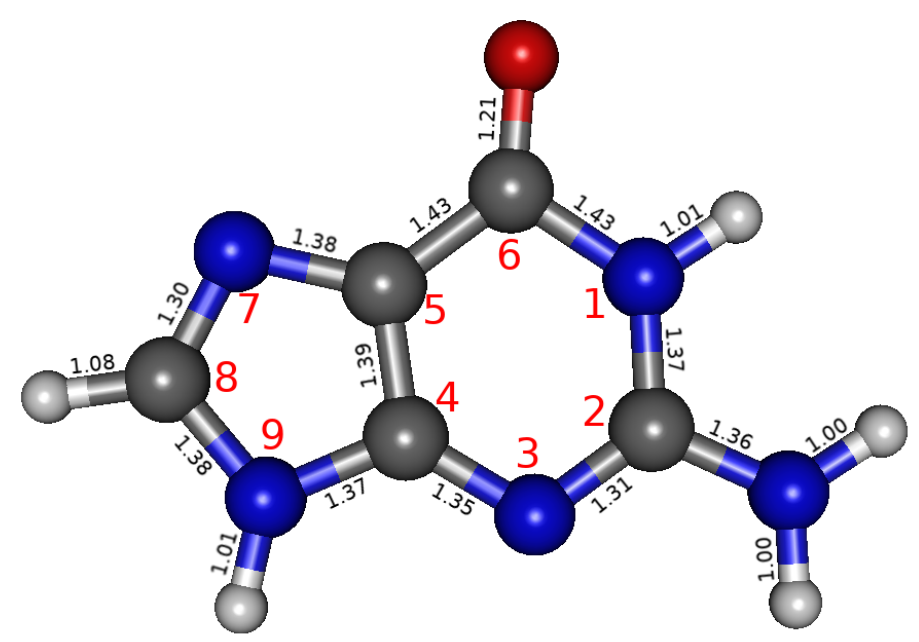

Figura 3 - Estrutura planarizada da molécula de Guanina otimizada com o método B3LYP/aug-cc-pVTZ. O átomo de Oxigênio está representado em vermelho, Nitrogênio em azul, Carbono em cinza e Hidrogênio em branco. Os comprimentos de ligação (em Å) e a convenção de numeração dos átomos nos anéis também são indicados.

parâmetros específicos para cálculos com pseudopotenciais através de funções gaussianas cartesianas otimizadas do tipo 5s5p2d para cada átomo de C, N, O (expoentes na Tabela A4) e com as funções de base de Dunning (50), 4s/3s, para os átomos de $\mathrm{H}$ (expoentes na Tabela A5). Essa base para a G possui um total de 367 orbitais atômicos contraídos que se reduzem a 345 com a eliminação dos orbitais esfericamente simétricos do tipo $d_{x x}+d_{y y}+d_{z z}$, e para 8-oxoG consiste no total de 399 funções de orbitais atômicos contraídos que se reduzem para 375 .

As estimativas do número de configurações de polarização para os cálculos SEP foram realizadas através do critério proposto por Winstead e McKoy (51) para minimizar o risco de subcorrelação ou supercorrelação das energias de ressonâncias, que ocorrem quando a inclusão dos efeitos de correlação-polarização é desbalenceada para mais (supercorrelação) ou para menos (subcorrelação), em relação à descrição Hartree-Fock do alvo molecular. Esse critério considera a inclusão das configurações obtidas de todas as excitações simples do alvo que preservam simetria e spin, multiplicadas por MVOs compatíveis com o caráter da ressonância. Nos cálculos realizados neste trabalho, o número de configurações considerado foi estimado através de todas as excitações do tipo singleto possíveis acopladas com os três primeiros orbitais de espalhamento do tipo $\pi^{*}$. Entretanto, o uso das configurações obtidas por este critério costuma subestimar a correlação eletrônica fazendo com que as posições das ressonâncias sejam superestimadas. Foi verificado, em diferentes estudos previamente realizados pelo grupo, que a inclusão das excitações com acoplamento tripleto, além dos estados singletos preconizados por Winstead e McKoy, melhora a descrição das 

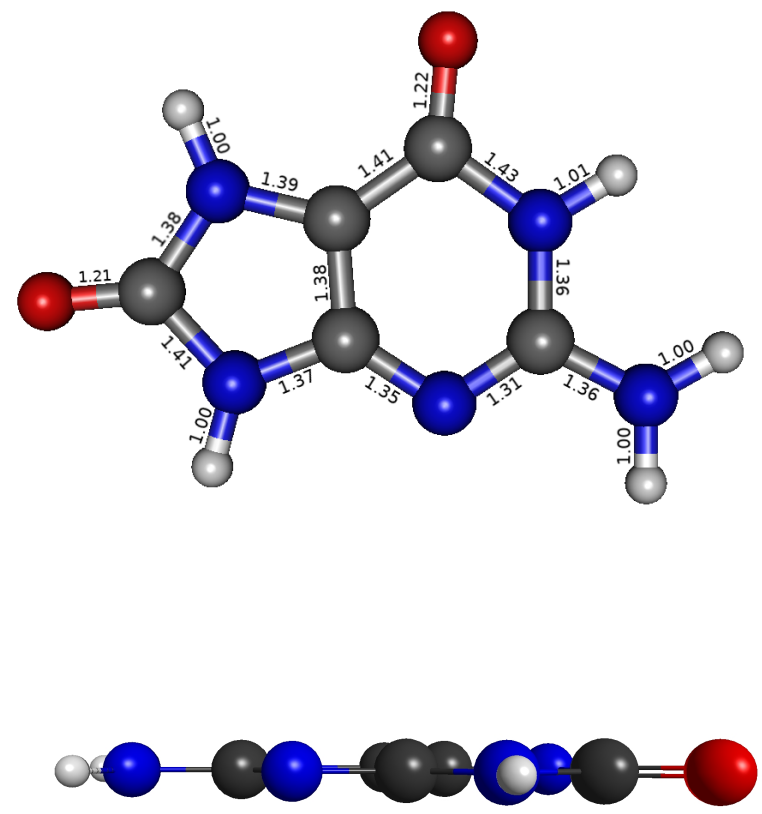

$\mathrm{C}_{s}$
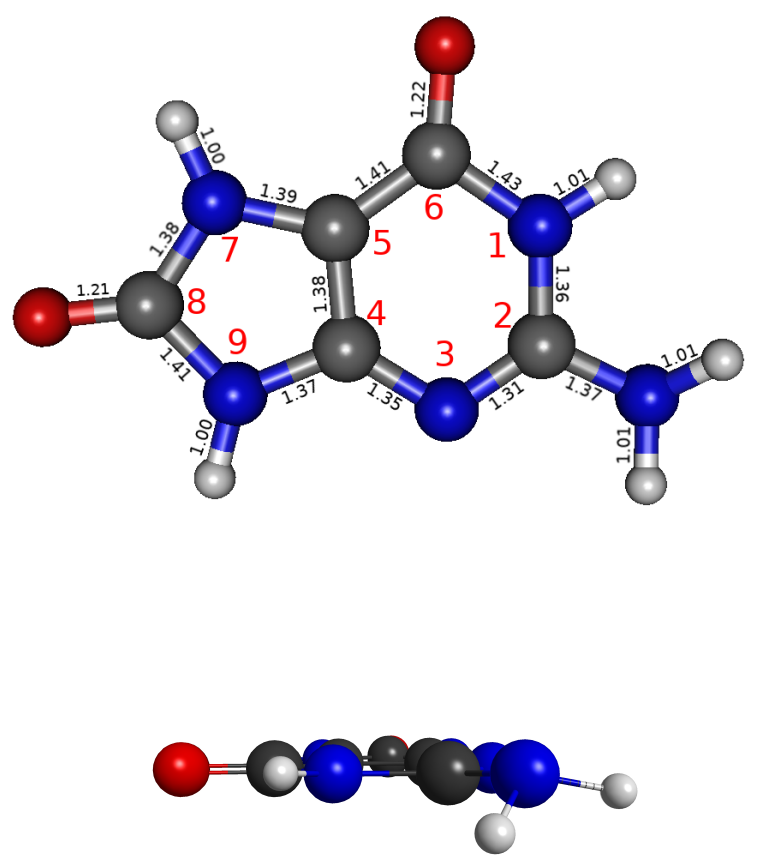

$\mathrm{C}_{1}$

Figura 4 - Estrutura planarizada (esquerda) e não planarizada (direita) da molécula de 8oxoG otimizada com o método B3LYP/aug-cc-pVTZ. O átomo de Oxigênio está representado em vermelho, Nitrogênio em azul, Carbono em cinza e Hidrogênio em branco. Os comprimentos de ligação (em Å) e a convenção de numeração dos átomos nos anéis também são indicados.

energias das ressonâncias em relação aos dados experimentais obtidos por espectroscopia de transmissão eletrônica (Electron Transmission Spectroscopy, ETS). O critério de corte de energia (52) permite a inclusão das excitações com acoplamento tripleto e é definido por $\epsilon_{\text {particula }}-\epsilon_{\text {buraco }}+\epsilon_{\text {espalhamento }}<\Delta$, sendo $\epsilon$ a energia dos orbitais subscritos. Neste trabalho, o espaço de configurações foi definido através do critério de corte de energia (52), de forma a reproduzir, aproximadamente, o número de configurações definido pelo critério de Winstead e McKoy. As posições e larguras das ressonâncias foram obtidas através de ajustes de mínimos quadrados com a formula de Breit-Wigner (26).

As energias das ressonâncias $\pi^{*}$ também foram estimadas por meio de uma relação semi empírica (6) através da otimização de geometria com MP2/6-31g(d) e do cálculo de energia no nível Hartree Fock na mesma base. Nesse procedimento, a energia de captura eletrônica (vertical attachment energy, VAE) é estimada por meio de uma correção linear da energia de um orbital virtual (virtual orbital energy, VOE), segundo VAE $=0.64795 \times$ VOE - 1.4298 (em eV). Outros cálculos com métodos de estrutura eletrônica também foram 
realizados com o objetivo de caracterizar o momento de dipolo, estado ligado por dipolo (dipole bound state, DBS), acoplamentos não adiabáticos entre estados aniônicos, limiar de excitação eletrônica e de dissociação. Os valores de momento de dipolo foram obtidos com o método B3LYP/aug-cc-pVTZ. A energia do DBS em relação ao estado fundamental da molécula neutra foi obtida no nível CCSD(T)/aug-cc-pVDZ+6s6p, sendo 6s6p um conjunto de funções de base difusas adicionais, com centros localizados no átomo mais próximo ao polo positivo do momento de dipolo. Os expoentes das funções difusas foram obtidos pelo procedimento even tempered descrito por Skurski et al. (53), que consiste em sucessivas divisões por 4 do menor coeficiente de funções de base para o átomo de $\mathrm{H}$ da base aug-cc-pVDZ.

Os limiares de excitação eletrônica da 8-oxoG e da G foram estimados com o código OpenMolcas (54) utilizando cálculos CASSCF com correção de segunda ordem CASPT2, correspondendo à energia vertical de excitação do primeiro estado tripleto. Nestes cálculos foram considerados espaços ativo com 18 elétrons e 13 orbitais $(18,13)$ para ambas as moléculas, utilizando a base ANO (Atomic Natural Orbital) com contração 4s3p1d para os átomos de $\mathrm{C}, \mathrm{N}$ e $\mathrm{O}$ e 2s1p para os átomos de $\mathrm{H}$. Os acoplamentos não adiabáticos entre estados $\pi^{*} / \sigma^{*}$ foram estimados em nível CASSCF através de um espaço ativo com 10 (11) elétrons e 10 orbitais para a molécula neutra (ânion) com a base cc-pVDZ, e média sobre estados (state-averaged) de 8 estados das moléculas. Os acoplamentos não adiabaticos entre estados $\pi^{*}$ foram estimados com um espaço ativo com 8 (9) elétrons e 8 orbitais para a molécula neutra (ânion). Todos os cálculos multiconfiguracionais foram realizados com imaginary shift de 0.2 para evitar estados intrusos e IPEA nulo (44). Os orbitais utilizados no espaço ativo dos cálculos estão disponíveis no Apêndice B onde os orbitais das Figuras B1 e B3 são os orbitais de espaço ativo utilizados nos cálculos de limiar de excitação eletrônica, respectivamente para G e 8-oxoG, e os orbitais das Figuras B2 e B4, são respectivamente para G e 8-oxoG, os orbitais de espaço ativo utilizados para os cálculos de acoplamentos não adiabáticos e das aproximações das energias de ressonâncias por SA-CASSCF/MS-CASPT2.

Por fim, os limiares de dissociação foram obtidos pelo método composto G4(MP2) ${ }^{1}$, que é comumente utilizado para o cálculo de grandezas termoquímicas com alta acurácia. Os limiares de dissociação foram obtidos pela diferença entre a energia dos produtos da dissociação por DEA $\left(E_{[A-B]^{\bullet /-}}+E_{B^{-/} \bullet}\right)$ e a energia da molécula neutra $E_{A}$. Para comparações com os resultados experimentais, foram utilizados os limiares de dissociação

1 O método G4(MP2), pertencente a classe de métodos Gaussian-N (55), foi desenvolvido com o objetivo de produzir resultados de energia molecular de forma mais acurada baseando-se numa série de combinações de diferentes cálculos com métodos ab-initio. Cálculos com métodos mais robustos que incluí mais correlação eletrônica como $\operatorname{CCSD}(\mathrm{T})$ e QCISD(T), com bases pequenas e menos difusas, são combinados com cálculos com métodos menos robustos que incluí menos correlação eletrônica como MP2 ou MP4, com bases muito grandes e bem difusas para aproximar a energia de cálculos mais custosos. Para as demais correções necessárias, o método utiliza-se de parâmetros empiricos denominados como termos de Higher Level Correction (HLC). 
a partir do cálculo da energia livre de Gibbs, que considera a contribuição entrópica, e para comparação com os resultados teóricos foram utilizados os limiares de dissociação com as energias calculadas com a correção de energia vibracional de ponto zero.

$$
E_{\text {diss }}=E_{[A-B]^{\bullet /-}}+E_{B^{-/ \bullet}}-E_{A}
$$

\subsection{Estados Aniônicos}

Nesta seção, são apresentados os resultados de seção de choque integral para o espalhamento de elétrons por G e 8-oxoG, os cálculos de estado de ligado por dipolo e do limiar de excitação eletrônica para cada molécula. Os resultados para a G são apresentados primeiramente e comparados com resultados publicados em trabalhos anteriores. Posteriormente, são apresentados os resultados para a 8-oxoG e comparados com os resultados discutidos previamente para a $\mathrm{G}$.

\subsubsection{Guanina}

O cálculo Hartree Fock para o estado fundamental do alvo gerou 345 orbitais moleculares sendo 28 orbitais duplamente ocupados pelos elétrons de valência e 317 orbitais virtuais (os elétrons de caroço foram descritos utilizando os pseudopotenciais BHS). Com estes, foram gerados orbitais moleculares modificados (MVOs) no campo de um cátion com carga +8 . O espaço de configurações da $\mathrm{G}$ foi construído com o critério de corte de energia $\Delta=-1.81$ Hartree, utilizando MVOs como orbitais partícula (excitações virtuais do alvo) e de espalhamento, resultando em 16528 configurações na representação irredutível $A^{\prime \prime}$. Cálculos de seção de choque integral publicados anteriormente $(51,56,57)$ não encontraram ressonâncias com assinaturas claras na componente $A^{\prime}$ da seção de choque integral (integral cross section, ICS) em energias abaixo do limiar de excitação eletrônica. Portanto, apenas a seção de choque integral para a representação irredutível $A^{\prime \prime}$ foi calculada.

A seção de choque integral elástica obtida nas aproximações SE e SEP são mostradas na Figura 5. As posições e larguras das ressonâncias nas aproximações SE e SEP são apresentadas na Tabela 1. Na aproximação SE, as energias obtidas para as ressonâncias de forma $\pi^{*}$ foram $3.50 \mathrm{eV}, 3.76 \mathrm{eV}, 5.14 \mathrm{eV}$ e $9.78 \mathrm{eV}$. O caráter das ressonâncias é ilustrado pelos orbitais virtuais compactos mostrados na Figura 6, onde são enumerados em ordem crescente de energia. As posições das ressonâncias nos cálculos SE estão de acordo com trabalhos anteriores realizados por Winstead e McKoy (51), e Nunes et al. (56) na mesma aproximação. Entretanto, ambos os trabalhos não conseguiram localizar a ressonância $\pi_{2}^{*}$ nesta aproximação por ser muito próxima à ressonância $\pi_{1}^{*}$. Winstead e Mckoy identificaram as ressonâncias $\pi_{1}^{*}$ e $\pi_{2}^{*}$ como uma única ressonância de forma 
assimétrica e no trabalho de Nunes et al., no qual foi utilizado o mesmo método com pseudopotenciais deste trabalho, a base $5 \mathrm{~s} 4 \mathrm{p} 2 \mathrm{~d}$ e/ou a quadratura numérica da função de Green, utilizadas nos cálculos de seção de choque, podem não ter sido suficientes para distinguir os dois picos. Com a inclusão de polarização, as energias das ressonâncias $\pi^{*}$ se estabilizaram, sendo deslocadas para $0.97 \mathrm{eV}, 1.47 \mathrm{eV}, 2.65 \mathrm{eV}$ e $6 \mathrm{eV}$, sendo compatíveis com os resultados obtidos por Nunes et al. com diferenças menores ou iguais a $0.1 \mathrm{eV}$ para as três primeiras ressonâncias. Os valores obtidos também são comparáveis com as estimativas por relação de escala (Scaled VOEs) para as três primeiras ressonâncias com diferença de cerca de $\sim 0.3 \mathrm{eV}$ nas ressonâncias $\pi_{1}^{*}$ e $\pi_{3}^{*}$. As posições das ressonâncias medidas por ETS (58) foram $0.46 \mathrm{eV}, 1.37 \mathrm{eV}$ e $2.36 \mathrm{eV}$. Os resultados deste trabalho estão em bom acordo para os estados $\pi_{2}^{*}$ e $\pi_{3}^{*}$ e apresentam uma maior divergência na posição da ressonância $\pi_{1}^{*}$, de $\sim 0.5 \mathrm{eV}$. Entretanto, segundo os autores, o tautômero enol apresenta maior contribuição para o espectro na temperatura em que o experimento foi realizado $(\sim 571 \mathrm{~K})$, embora os cálculos apresentados neste trabalho e nos trabalhos anteriores considerem o tautômero keto. Os valores obtidos diferem consideravelmente se comparados com os resultados de Dora et al. (57), que obtiveram as ressonâncias nas energias $1.83 \mathrm{eV}, 3.3 \mathrm{eV}, 4.25 \mathrm{eV}$ e $7.36 \mathrm{eV}$ com o método de matriz R, enquanto Winstead e Mckoy (51) obtiveram 1.55 eV, 2.4 eV e 3.75 eV. O cálculo de Winstead e Mckoy (51) utiliza um critério de polarização que não inclui configurações do tipo tripleto no espaço de configurações que, conforme mencionado anteriormente, costuma subestimar a correlação eletrônica implicando na obtenção de energias mais altas. Dora et al. (57) reportaram outro resultado utilizando uma aproximação denominada uncontracted close-coupling (u-CC), voltada à descrição de canais de excitação eletrônica, que tende a subestimar a correlação para as ressonâncias de forma. Nesse caso, a posição da ressonância $\pi_{1}^{*}, 0.97 \mathrm{eV}$, concorda bem com o presente resultado, embora haja divergências significativas de $\sim 1 \mathrm{eV}$ para $\pi_{2}^{*}$ e $\pi_{3}^{*}$, e $\sim 0.4 \mathrm{eV}$ para $\pi_{4}^{*}$.

O momento de dipolo da $\mathrm{G}$ obtido neste trabalho foi de $6.88 \mathrm{D}$, compatível com o resultado obtido com o método Hartree Fock/6-31**, 6.83 D (59), e apresentando uma discrepância de $1.3 \mathrm{D}$ para o resultado experimental de $5.50 \mathrm{D}$ em solução de dioxano (59). Párkányi et al. (59) associaram essa discrepância à baixa solubilidade das purinas, que é um fator que dificulta a determinação experimental do momento de dipolo. O limite crítico para que uma molécula possa formar um DBS através da captura de um elétron em um orbital difuso próximo ao polo positivo do momento de dipolo é de 2.0-2.5 D (60), indicando que a $\mathrm{G}$ pode apresentar um DBS. O valor obtido para o DBS foi -91 meV, sendo o orbital SOMO (Singly Occupied Molecular Orbital) indicado na Figura 7. O resultado obtido está de acordo com o estudo de Haranczyk et al. (61), que obtiveram -65 meV na aproximação CCSD(T)/aug-cc-pVDZ com bases difusas 5s5p localizadas no H ligado ao átomo $\mathrm{N}_{9}$ e no átomo $\mathrm{N}_{7}$.

O limiar de excitação eletrônica da G neutra foi obtido por métodos multicon- 


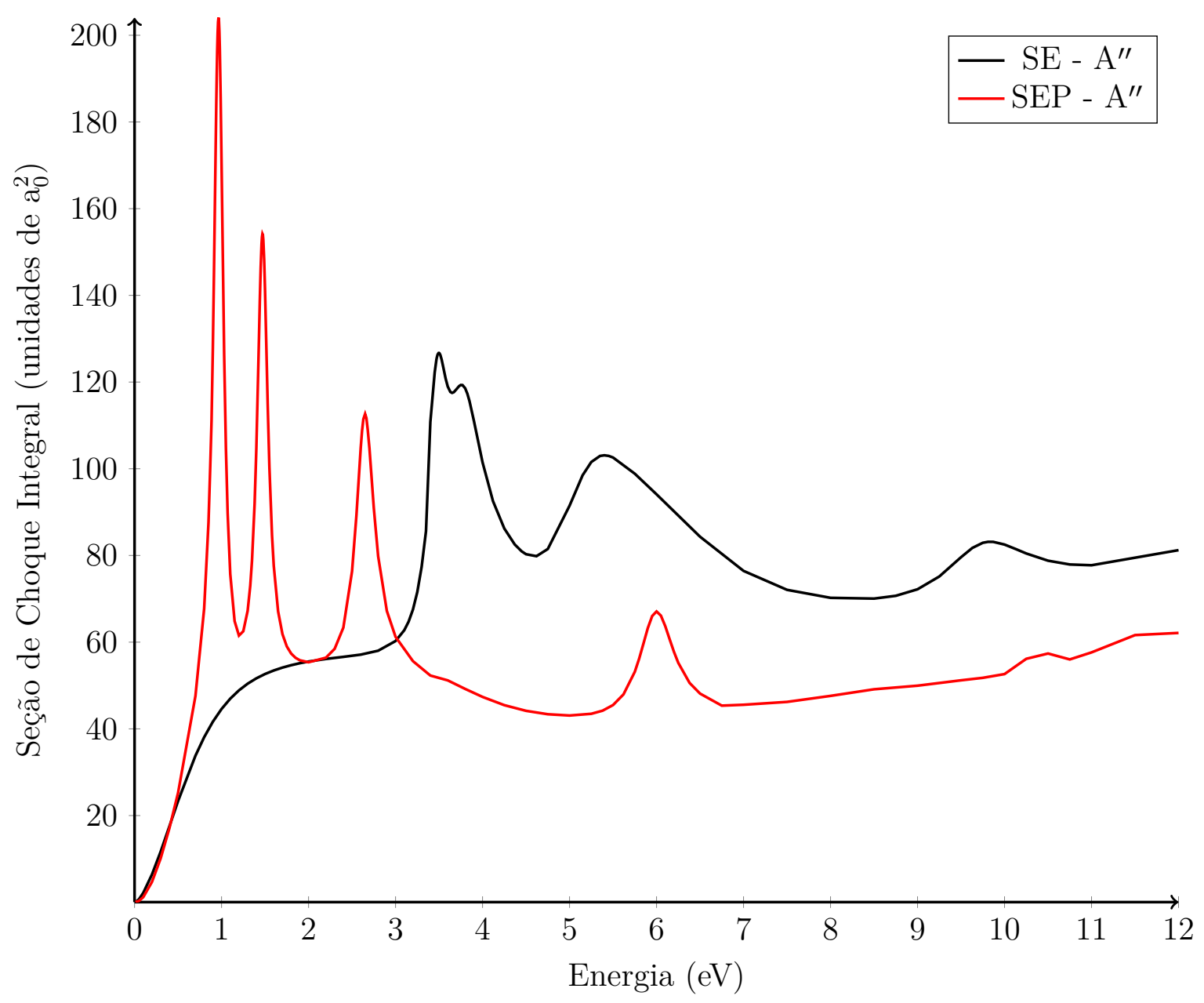

Figura 5 - Componente $A^{\prime \prime}$ da seção de choque integral para o espalhamento elástico de elétrons por Guanina. As curvas preta e vermelha correspondem a cálculos realizados nas aproximações $\mathrm{SE}$ e SEP, respectivamente.

figuracionais. As ressonâncias acima desse limiar podem apresentar caráter misto com acoplamentos com estados excitados da molécula não considerados, em razão da aproximação elástica utilizada, que desconsidera os canais de excitação eletrônica. A falta desses acoplamentos tende a superestimar as energias das ressonâncias com caráter misto de forma e caroço excitado. O valor obtido para a energia de excitação do primeiro estado tripleto foi de $4.02 \mathrm{eV}$ com caráter predominante $\pi_{7} \rightarrow \pi_{1}^{*}$ (Figura B1). Para a excitação singleto correspondente foi obtido o valor de $4.61 \mathrm{eV}$, que é compatível com o resultado de $4.76 \mathrm{eV}$ obtido por Fülscher et al. e próximo aos resultados experimentais de 4.4-4.5 eV (62). Conclui-se que não deve haver acoplamentos com estados excitados desconsiderados nos cálculos de espalhamento para as ressonâncias $\pi_{1}^{*}, \pi_{2}^{*}$ e $\pi_{3}^{*}$ na $\mathrm{G}$, visto que a energia destas ressonâncias estão abaixo do limiar de excitação eletrônica. A energia da ressonância $\pi_{4}^{*}$ pode estar superestimada devido ao número de canais incluídos no cálculo de espalhamento. 

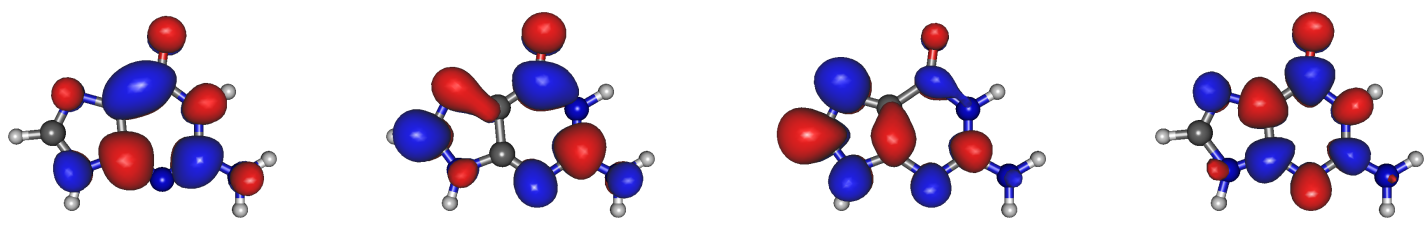

$\pi_{1}^{*}$

$\pi_{2}^{*}$

$\pi_{3}^{*}$

$\pi_{4}^{*}$

Figura 6 - Orbitais virtuais com caráter $\pi^{*}$ da Guanina obtidos no nível HF/6-31g(d) utilizando a geometria planar $\left(\mathrm{C}_{s}\right)$. Todos os orbitais foram obtidos com isovalor de 0.03 .

\begin{tabular}{ccccc}
\hline Aproximação & $\pi_{1}^{*}$ & $\pi_{2}^{*}$ & $\pi_{3}^{*}$ & $\pi_{4}^{*}$ \\
\hline SE & 3.50 & 3.76 & $5.14(0.78)$ & $9.78(1.15)$ \\
SEP & $0.97(0.13)$ & $1.47(0.15)$ & $2.65(0.25)$ & $6.00(0.49)$ \\
SE(56) & $3.5(0.51)$ & - & $5.30(0.7)$ & 9.7 \\
SEP(56) & 0.90 & 1.55 & 2.75 & - \\
SMC SEP(51) & 1.55 & 2.4 & 3.75 & - \\
R-Matrix - SEP(57) & 1.83 & 3.3 & 4.25 & 7.36 \\
R-Matrix - u-CC(57) & 0.97 & 2.41 & 3.78 & 6.41 \\
Scaled VOE & 1.21 & 1.38 & 2.37 & 5.16 \\
ETS-enol(58) & 0.46 & 1.37 & 2.36 & - \\
\hline SA-CASSCF(9,8)/cc-pVDZ & 3.12 & 3.98 & 5.30 & 8.40 \\
MS-CASPT2(9,8)/cc-pVDZ & 2.03 & 2.49 & 3.48 & 6.31 \\
MS-CASPT2(11,10)/ANO-L-VDZP & 1.19 & 1.53 & 2.55 & 5.33 \\
\hline
\end{tabular}

Tabela 1 - Posições e larguras (informadas entre parênteses) das ressonâncias obtidas para a molécula de Guanina, em unidades de eV. Os resultados deste trabalho são apresentados nas aproximações SE e SEP.
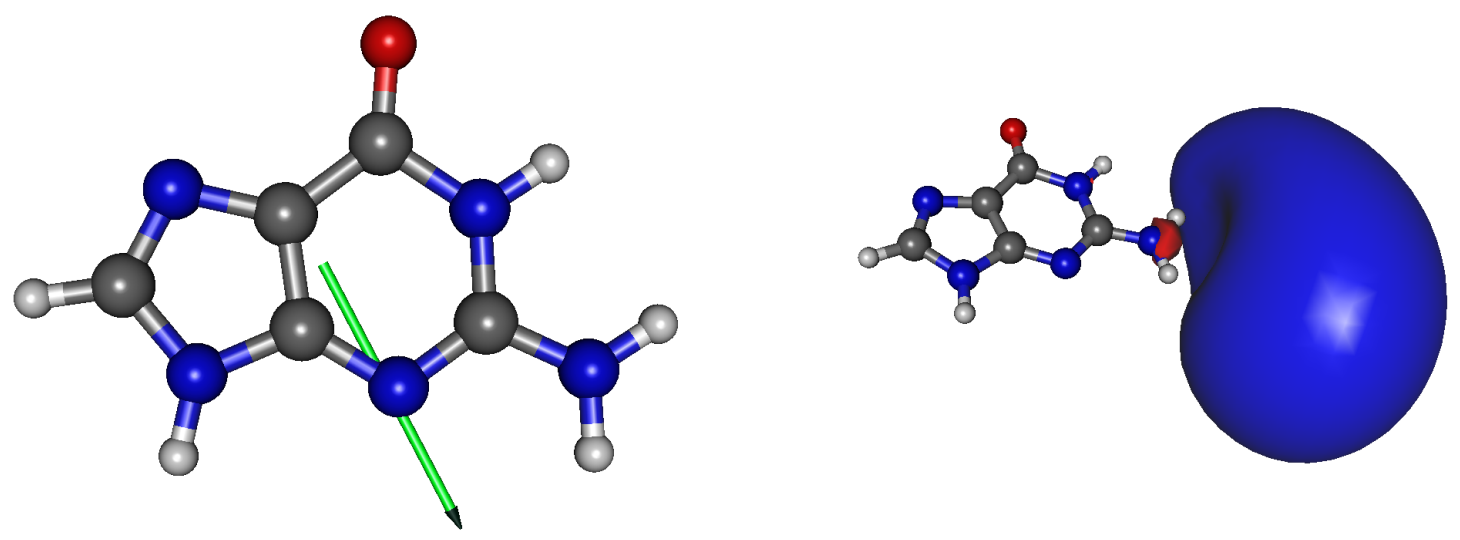

Figura 7 - Vetor momento de dipolo (esquerda) e orbital SOMO do DBS para a molécula de Guanina (direita). Orbital obtido com isovalor de 0.008. 


\subsubsection{8-oxo-guanina}

O cálculo Hartree Fock para o estado fundamental do alvo gerou 375 orbitais moleculares sendo 31 duplamente ocupados pelos elétrons de valência e 344 orbitais virtuais (os elétrons de caroço foram descritos utilizando os pseudopotenciais BHS). Com estes, foram gerados MVOs, que foram utilizados como orbitais de partícula e de espalhamento nas aproximações SE e SEP, com o campo do cátion de carga +4 . O espaço de configurações da 8-oxoG foi construído com o critério de corte $\Delta=-0.20$ Hartree para a geometria planar $\left(\mathrm{C}_{s}\right)$, no qual resultou em 18944 configurações com simetria $A^{\prime}$ e 19312 configurações com simetria $A^{\prime \prime}$. Para o cálculo com a geometria pertencente ao grupo $\mathrm{C}_{1}$ foi utilizado $\Delta=-0.24$ Hartree como critério de corte resultando em 32349 configurações entre os orbitais moleculares.

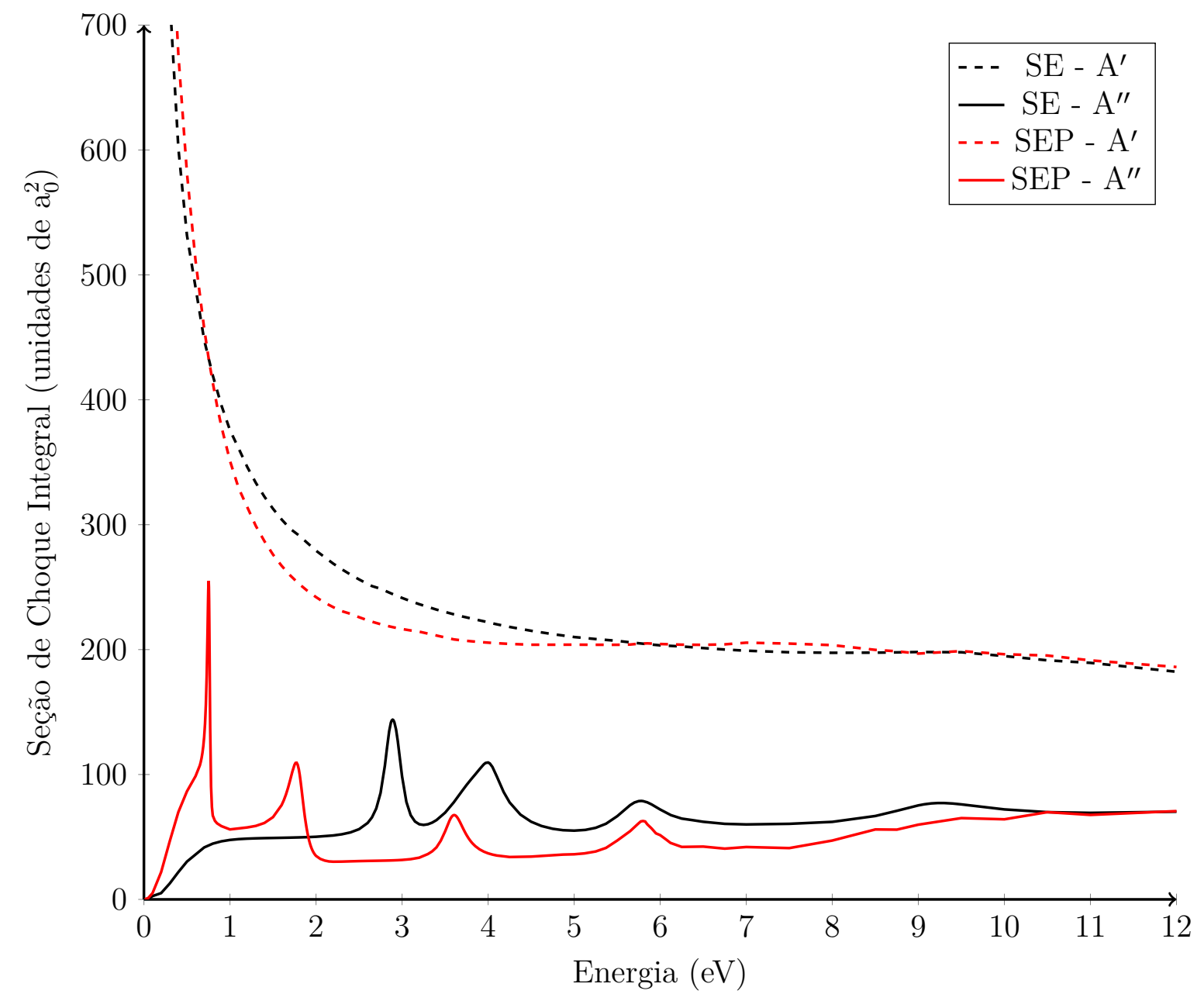

Figura 8 - Componente $A^{\prime}$ (curva tracejada) e $A^{\prime \prime}$ da seção de choque integral para o espalhamento elástico de elétrons por 8-oxoG. As curvas preta e vermelha correspondem a cálculos realizados nas aproximações SE e SEP, respectivamente.

A seção de choque integral elástica obtida nas aproximações SE e SEP e as ressonâncias encontradas podem ser observadas na Figura 8, para a geometria planar $\left(\mathrm{C}_{s}\right)$ e Figura 9, para a geometria pertencente ao grupo $\mathrm{C}_{1}$. As posições e larguras de 


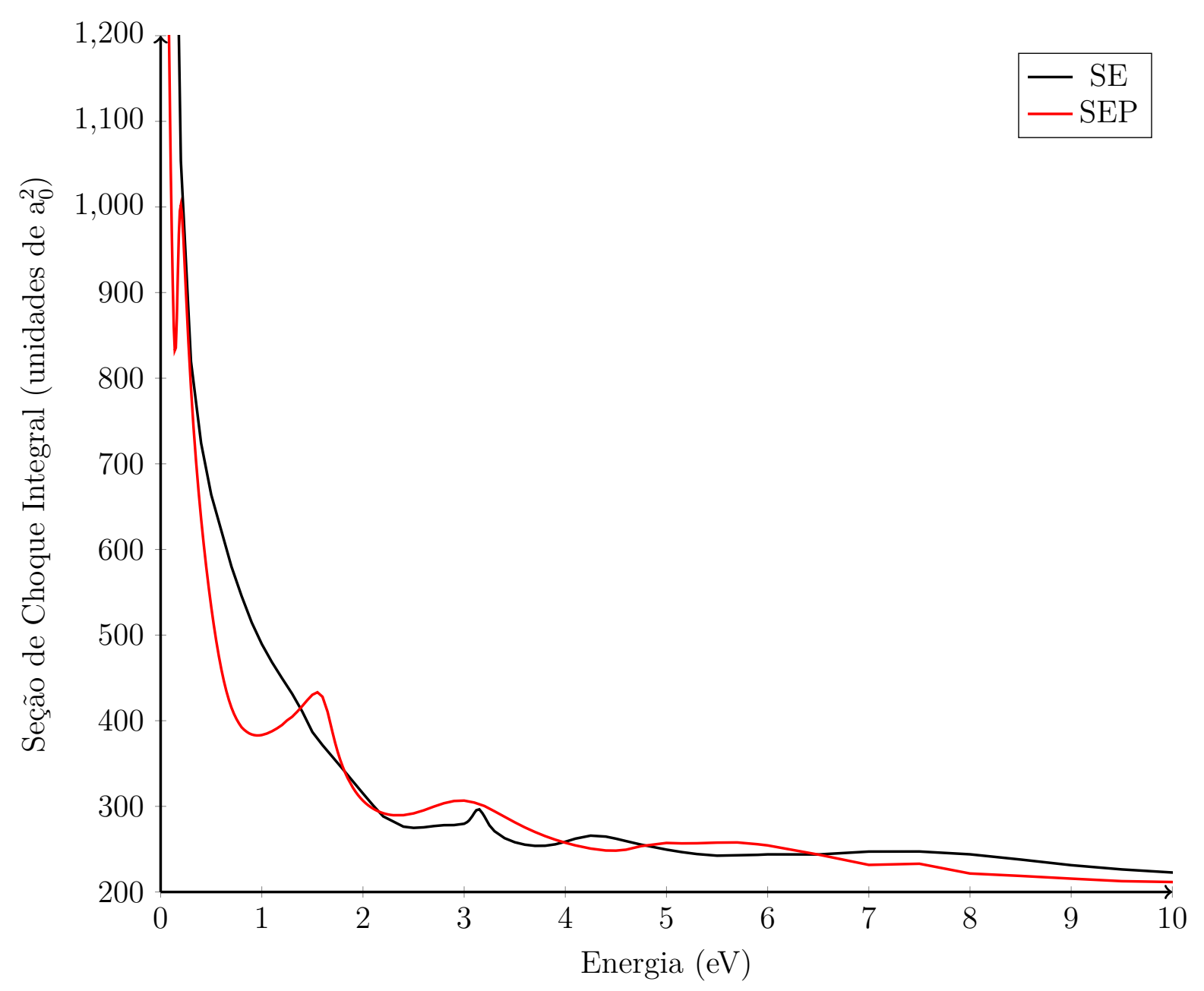

Figura 9 - Seção de choque integral para o espalhamento elástico de elétrons por 8oxoG utilizando a geometria pertencente ao grupo $\mathrm{C}_{1}$. As curvas preta e vermelha correspondem a cálculos realizados nas aproximações SE e SEP, respectivamente.

cada ressonância na aproximação SE e SEP, para ambas as geometrias, estão presentes na Tabela 2. As posições das ressonâncias $\pi^{*}$ obtidas na aproximação SE foram $2.89 \mathrm{eV}$, $4.00 \mathrm{eV}, 5.76 \mathrm{eV}$ e $9.71 \mathrm{eV}$ para os cálculos de seção de choque com a geometria planar $\left(\mathrm{C}_{s}\right)$. Para a geometria não planarizada $\left(\mathrm{C}_{1}\right)$, a decomposição por simetria não é possível, fazendo com que a contribuição de background associada à interação dipolar $\left(\sim \mu / r^{2}\right)$ fique super-imposta às assinaturas das ressonâncias. O momento de dipolo da 8-oxoG é considerável ( 7 D), implicando grande magnitude para a contribuição do background e tornando difícil atribuir as posições das ressonâncias, particularmente na aproximação SE, que sobrestima posições e larguras. Com base nas seções de choque e na análise do pseudo-espectro da Hamiltoniana de espalhamento representada na base das configurações, é possível atribuir as energias $\sim 3.1 \mathrm{eV}$ e $\sim 4.3 \mathrm{eV}$ para as ressonâncias $\pi_{1}^{*}$ e $\pi_{2}^{*}$ na geometria $\mathrm{C}_{1}$. Em energias mais altas, a análise do pseudo-espectro não se mostrou útil, sendo possível identificar apenas uma estrutura larga na seção de choque, em torno de $7.5 \mathrm{eV}$. O caráter das ressonâncias é ilustrado pelos orbitais virtuais compactos mostrados na Figura 10, onde 
são enumerados em ordem crescente de energia. Na aproximação SEP, as energias obtidas foram $0.75 \mathrm{eV}, 1.77 \mathrm{eV}, 3.61 \mathrm{eV}$ e $5.71 \mathrm{eV}$ para as ressonâncias obtidas para a geometria planar $\left(\mathrm{C}_{s}\right)$ apresentando razoável compatibilidade com as duas primeiras ressonâncias estimadas por relação de escala, com divergência de $\sim 0.4 \mathrm{eV}$ para a segunda ressonância mas com diferenças de $\sim 1 \mathrm{eV}$ para as duas últimas ressonâncias. As ressonâncias $\pi_{3}^{*}$ e $\pi_{4}^{*}$ podem possuir contribuições de ressonâncias de caroço excitado e, consequentemente, suas energias podem estar superestimadas. Para a geometria $\mathrm{C}_{1}$, as assinaturas das ressonâncias tornam-se mais claras na aproximação SEP, em relação ao cálculo SE, pois a estabilização torna os picos mais estreitos. As posições das ressonâncias na aproximação SEP são 0.2 $\mathrm{eV}, 1.56 \mathrm{eV}, 3.00 \mathrm{eV}$ e $5.4 \mathrm{eV}$ apresentando estabilização em todas as ressonâncias se comparado com o cálculo em geometria planar, com as ressonâncias $\pi_{1}^{*}$ e $\pi_{3}^{*}$ sendo mais afetadas pela planarização da geometria com divergência de $\sim 0.6 \mathrm{eV}$ e as ressonâncias $\pi_{2}^{*}$ e $\pi_{4}^{*}$ com diferença de $\sim 0.3 \mathrm{eV}$. O aumento da largura na geometria não planarizada deve estar relacionado à ausência de regras de seleção de momento angular, que deve afetar a decomposição em ondas parciais das ressonâncias. Em particular, a contribuição da onda $s$ $(l=0)$ é proibida por simetria na componente $\mathrm{A}^{\prime \prime}$ do cálculo $\mathrm{C}_{s}$, embora haja contribuição no cálculo $\mathrm{C}_{1}$. A ausência de barreira centrífuga na onda $s$ tende a alargar as ressonâncias, diminuindo seu tempo de vida. As energias apresentam razoável concordância com as estimativas por relação de escala (Scaled VOE) possuindo divergência máxima de 0.4 $\mathrm{eV}$ para as três primeiras ressonâncias e $\sim 0.7 \mathrm{eV}$ para quarta ressonância. Os orbitais virtuais compactos da Figura 10 possuem caráter semelhante apresentando diferença significativa apenas no grupo $\mathrm{NH}_{2}$, onde ocorre a piramidização. As ressonâncias obtidas nas seções de choque representam a formação dos mesmos estados transientes do ânion apesar de haver divergências quanto às posições. A seção de choque integral da 8-oxoG na geometria planar apresenta ressonâncias com assinaturas mais claras. Embora o espectro de ressonâncias obtidos com as geometrias $\mathrm{C}_{1}$ e $\mathrm{C}_{s}$ sejam compatíveis, a planarização facilita significativamente a interpretação das seções de choque, nessa medida justificando o procedimento utilizado nos estudos anteriores da $\mathrm{G}(56,51,57)$.

O limiar de excitação eletrônica para 8-oxoG neutra foi obtido através de cálculos multiconfiguracionais. O valor obtido para a energia mínima de excitação foi de $3.35 \mathrm{eV}$, com caráter predominante $\pi_{8} \rightarrow \pi_{1}^{*}$ (Figura B3). Para a excitação singleto correspondente, a energia obtida foi $4.23 \mathrm{eV}$, que também foi o resultado que $\mathrm{Lu}$ et al. (63) obtiveram experimentalmente. Portanto, as posições das ressonâncias $\pi_{3}^{*}$ e $\pi_{4}^{*}$, obtidas com a geometria planarizada $\mathrm{C}_{s}$, podem possuir caráter misto e estarem superestimadas pela falta de acoplamentos com estados excitados do alvo.

Nesse ponto é interessante comparar os estados ressonantes obtidos para as moléculas de G e 8-oxoG. Do ponto de vista metodológico, a comparação mais consistente será entre os cálculos SEP da geometria planarizada, pois não foi realizado o cálculo na geometria $\mathrm{C}_{1}$ para a $\mathrm{G}$. As posições e larguras de ressonâncias nos cálculos SEP (Tabelas 
1 e 2) são compatíveis apresentando discrepâncias menores que 0.3 eV, com exceção à ressonância $\pi_{3}^{*}$, que apresenta discrepância de $\sim \mathrm{eV}$ na posição. A estabilização das ressonâncias $\pi_{1}^{*}$ e $\pi_{4}^{*}$ e a desestabilização das ressonâncias $\pi_{2}^{*}$ e $\pi_{3}^{*}$ na 8-oxoG é indicada tanto pelos cálculos de espalhamento quanto pela lei de escala empírica (Scaled VOE). A distância entre as ressonâncias $\pi_{1}^{*}$ e $\pi_{2}^{*}$ é consideravelmente menor na $\mathrm{G}(\sim 0.5 \mathrm{eV})$ do que na 8-oxoG $(\sim 1 \mathrm{eV})$. Em relação aos resultados obtidos para a 8-oxoG na geometria não planarizada, observa-se uma estabilização ainda mais acentuada para as ressonâncias $\pi_{1}^{*}$ e $\pi_{4}^{*}$. Quanto às larguras, é esperado que a estabilização seja acompanhada de aumento dos tempos de vida. Isso é observado na comparação entre $\mathrm{G}$ e 8-oxoG planarizadas, mas não com a 8-oxoG não planarizada, provavelmente em razão dos acoplamentos de momento angular, conforme discutido anteriormente. Esse efeito de alargamento das ressonâncias também seria esperado para a G não planarizada. Portanto, com base na comparação entre os resultados obtidos com as geometrias planarizadas, este estudo aponta que o tempo de vida da ressonância $\pi_{1}^{*}$ seria maior na 8-oxoG do que na $G$, o que em princípio favoreceria a dissociação iniciada pela formação do estado $\pi_{1}^{*}$ na forma oxidada.

Em relação aos orbitais virtuais compactos (Figuras 6 e 10), pode-se observar que os orbitais $\pi_{1}^{*}$ e $\pi_{4}^{*}$ são semelhantes na $\mathrm{G}$ e na 8-oxoG, tendo apenas um leve aumento na densidade eletrônica do orbital virtual $\pi_{1}^{*}$ na 8-oxoG na coordenada $\mathrm{C}_{8}-\mathrm{N}_{9}$ do anel pentagonal próxima ao grupo carbonila onde ocorre a oxidação. No orbital $\pi_{2}^{*}$ há maior densidade eletrônica no anel hexagonal da 8-oxoG enquanto na $\mathrm{G}$ a densidade eletrônica está mais delocalizada, e no orbital $\pi_{3}^{*}$, a densidade eletrônica está mais localizada no anel pentagonal na 8-oxoG. A diferença de densidade eletrônica nos orbitais $\pi_{2}^{*}$ e $\pi_{3}^{*}$, quando comparado com a $\mathrm{G}$, sugere que a formação dos ânions transientes na 8-oxoG em baixas energias possa preferencialmente apresentar processos de degradação da estrutura cíclica no anel hexagonal em energias mais baixas do que a degradação do anel pentagonal.

\begin{tabular}{ccccc}
\hline Aproximação & $\pi_{1}^{*}$ & $\pi_{2}^{*}$ & $\pi_{3}^{*}$ & $\pi_{4}^{*}$ \\
\hline SE & $\sim 3.15$ & $\sim 4.3$ & $\sim 7.5$ & - \\
SE - $C_{s}$ & $2.89(0.23)$ & $4.00(0.55)$ & $5.76(0.64)$ & $9.21(1.33)$ \\
SEP & $\sim 0.2(0.09)$ & $1.56(0.44)$ & $3.00(1.31)$ & $\sim 5.4$ \\
SEP - $C_{s}$ & $0.75(0.03)$ & $1.77(0.21)$ & $3.61(0.32)$ & $5.78(0.47)$ \\
Scaled VOE & 0.59 & 1.25 & 2.79 & 4.71 \\
Scaled VOE - $C_{s}$ & 0.76 & 1.44 & 2.85 & 4.81 \\
\hline SA-CASSCF $(9,8) /$ cc-pVDZ & 2.86 & 4.08 & 7.05 & 7.84 \\
MS-CASPT2(9,8)/cc-pVDZ & 1.67 & 2.46 & 4.78 & 5.71 \\
MS-CASPT2(11,10)/ANO-L-VDZP & 0.84 & 1.58 & 3.46 & 4.87 \\
\hline
\end{tabular}

Tabela 2 - Posições e larguras (informadas entre parênteses) das ressonâncias obtidas para a molécula de 8-oxoG, em unidades de eV. Os resultados da seção de choque integral de espalhamento elástico são apresentados nas aproximações SE (SE $\left.C_{s}\right)$ e $\operatorname{SEP}\left(\mathrm{SEP}-C_{s}\right)$. 


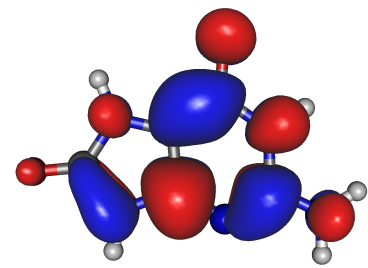

$\pi_{1}^{*}-\mathrm{C}_{s}$

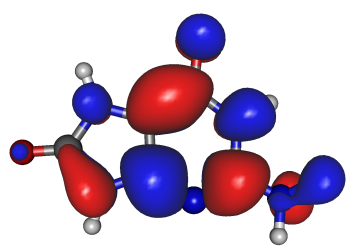

$\pi_{1}^{*}-\mathrm{C}_{1}$

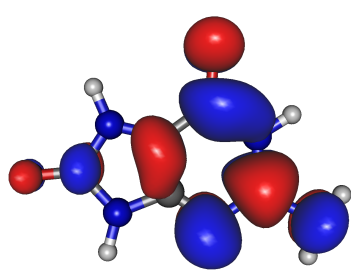

$\pi_{2}^{*}-\mathrm{C}_{s}$

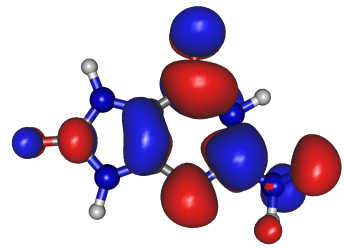

$\pi_{2}^{*}-\mathrm{C}_{1}$

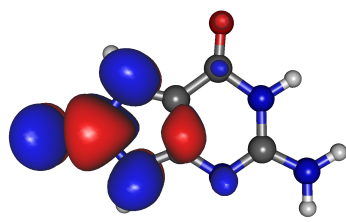

$\pi_{3}^{*}-\mathrm{C}_{s}$

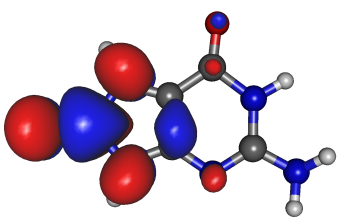

$\pi_{3}^{*}-\mathrm{C}_{1}$

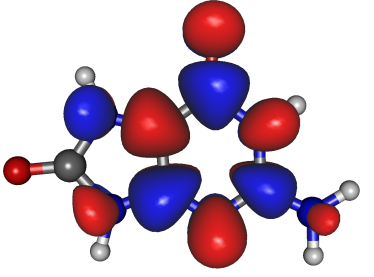

$\pi_{4}^{*}-\mathrm{C}_{s}$

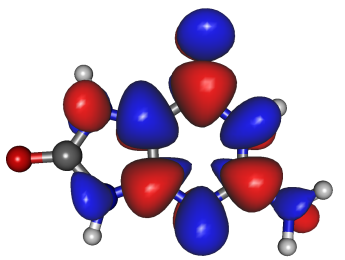

$\pi_{4}^{*}-\mathrm{C}_{1}$

Figura 10 - Orbitais virtuais com caráter $\pi^{*}$ da 8-oxoG obtidos no nível HF/6-31g(d), na geometria planar $\left(\mathrm{C}_{s}\right)$ da 8-oxoG (cima) e na geometria da 8-oxoG pertencente ao grupo $\mathrm{C}_{1}$ (baixo). Todos os orbitais foram obtidos com isovalor de 0.03 .

A 8-oxoG apresenta momento de dipolo de 7.15 D (6.73 D na geometria $\mathrm{C}_{1}$ ), que é comparável com o momento de dipolo da G $(6.88 \mathrm{D})$. Apesar da 8-oxoG também não apresentar estados ligados de valência, a 8-oxoG também apresenta um DBS. O DBS foi obtido com a adição das 6s6p funções difusas no $\mathrm{N}$ do grupo $\mathrm{NH}_{2}$, que está localizado na direção do vetor momento de dipolo conforme pode ser visto na Figura 11 com o orbital SOMO indicado ao lado. Os resultados obtidos foram -174 meV para o cálculo com aproximação de geometria plana $\left(\mathrm{C}_{s}\right)$ e $-146 \mathrm{meV}$ na geometria pertencente ao grupo $\mathrm{C}_{1}$, apresentando uma estabilização do DBS quando considerada a aproximação de geometria plana. A 8-oxoG também apresenta um DBS mais estável que a $\mathrm{G}$ (-91 meV), e com vetor momento de dipolo da 8-oxoG mais paralelo ao grupo $\mathrm{NH}_{2}$. 

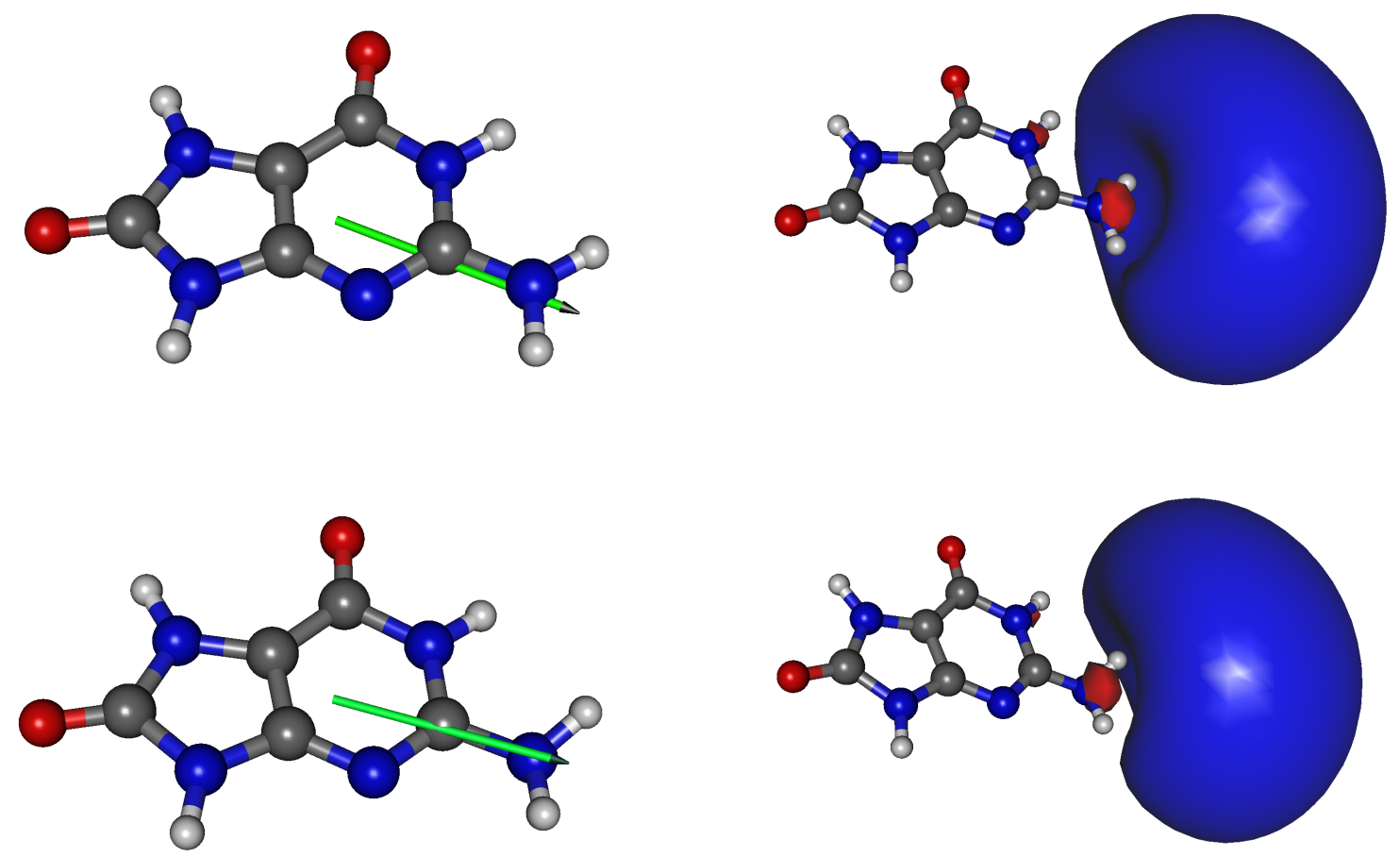

Figura 11 - Vetor momento de dipolo (esquerda) e orbital SOMO do DBS (direita) para a molécula de 8-oxoG na geometria planarizada $\mathrm{C}_{s}$ (cima) e na geometria pertencente ao grupo $\mathrm{C}_{1}$ (baixo). Orbitais obtidos com isovalor de 0.008.

\subsection{Captura eletrônica dissociativa}

Nesta seção, são discutidos aspectos relacionados ao processo de DEA dado que as ressonâncias foram caracterizadas para a 8-oxoG e G, na aproximação de núcleos fixos, na seção anterior. O estudo foi realizado com base nos resultados apresentados, em métodos de estrutura eletrônica (em princípio inadequados ao estudo de ressonâncias) para estimar acoplamentos não adiabáticos, e em cálculos auxiliares de limiares de dissociação, buscando obter algum entendimento sobre processos dissociativos induzidos por DEA. Na discussão a seguir, as energias dos acoplamentos serão expressas em relação ao mínimo de energia do estado fundamental das moléculas neutras, permitindo uma comparação consistente com as energias das ressonâncias.

Cálculos de estados ligados com métodos multiconfiguracionais, SA-CASSCF/MSCASPT2, com a base cc-pVDZ e orbitais de espaço ativo representados pelas Figuras B2 $(G)$ e B4(8-oxoG), foram realizados para estimar as energias das ressonâncias para a $G$ (Tabela 1) e para 8-oxoG (Tabela 2). Apesar dos cálculos de estados ligados não incluírem a autoionização, as posições de energia obtidas através do método SA-CASSCF/cc-pVDZ são compatíveis com as posições de energia obtidas pelo método SMC na aproximação $\mathrm{SE}$, para as ressonâncias com energia abaixo do limiar de excitação eletrônica ( $\pi_{1}^{*}$ à $\pi_{3}^{*}$ 
para $\mathrm{G}, \pi_{1}^{*}$ e $\pi_{2}^{*}$ para 8-oxoG), enquanto os resultados com MS-CASPT2, na mesma base, apresentam posições de energia mais altas quando comparados com o método SMC na aproximação SEP. Contudo, os cálculos MS-CASPT2/ANO-L-VDZP apresentam boa concordância com os resultados obtidos pelo método SMC na aproximação SEP. Com o objetivo de estimar acoplamentos não adiabáticos entre os estados $\pi_{1}^{*}$ e $\pi_{2}^{*}$, cálculos de interseções cônicas (conical intersection, CI) foram realizados para a G e 8-oxoG. Foi encontrado um acoplamento $\left(\pi_{1}^{*} / \pi_{2}^{*}\right)$ para $\mathrm{G}$ e não foram encontrados acoplamentos entre os estados $\pi_{1}^{*}$ e $\pi_{2}^{*}$ para 8-oxoG. A geometria da interseção $\left(\pi_{1}^{*} / \pi_{2}^{*}\right)$ apresenta a rotação do grupo $\mathrm{NH}_{2}$ e mantém a planaridade dos anéis da $\mathrm{G}$ (Figura 12). A energia do acoplamento não adiabático em relação ao estado fundamental é de $3.82 \mathrm{eV}$, que está abaixo da estimativa da ressonância $\pi_{2}^{*}(3.98 \mathrm{eV})$ pelo mesmo método (SA-CASSCF $(9,8) /$ cc-pVDZ), e consequentemente, pode ser acessada através da formação do estado $\pi_{2}^{*}$ visto que este possui energia vibracional mais alta que o acoplamento não adiabático. Francés-Monerris et al. (64) também reportaram a existência de um acoplamento $\pi_{1}^{*} / \pi_{2}^{*}$ encontrado nos cálculos de caminho de energia mínima (Minimum Energy Path, MEP) para a G. No entanto, Francés-Monerris et al. (64), utilizando o método SA-CASSCF/ANO-L-VDZP, não conseguiram encontrar uma geometria de mínimo estável para o ânion formado por captura eletrônica no orbital $\pi_{2}^{*}$, não tendo sido possível estimar a energia vibracional necessária para que esse cruzamento fosse alcançado. Nesse trabalho, também não houve êxito na tentativa de obter a energia adiabática de formação do ânion no orbital $\pi_{2}^{*}$. Cruzamentos singleto-dubleto (singlet-doublet crossings, SDC) entre o estado fundamental $\mathrm{S}_{0}$ e o estado aniônico $\pi_{1}^{*}$ também foram obtidos para G e 8-oxoG. Os SDC são aproximações para os acoplamentos não adiabáticos $\left(\mathrm{DBS} / \pi_{1}^{*}\right)$ pois se espera que a curva de energia do estado fundamental e do DBS sejam muitos próximas, tal como indicado pelas energias de ligação dos DBSs discutidas anteriormente. Na G, a geometria do cruzamento (Figura 12) apresenta um deslocamento do grupo $\mathrm{NH}_{2}$ para fora do plano e distorções no anel hexagonal na região próxima ao grupo $\mathrm{NH}_{2}$. O cruzamento ocorre em $2.42 \mathrm{eV}$ do estado fundamental e possui energia mais baixa do que a estimativa da ressonância $\pi_{1}^{*}(3.12 \mathrm{eV})$ no mesmo nível de cálculo (SA-CASSCF $(9,8)$ /cc-pVDZ), o que permite que esse cruzamento possa ser acessado através da formação do estado aniônico $\pi_{1}^{*}$. Para a 8-oxoG (Figura 13), a geometria do cruzamento também apresenta o deslocamento do grupo $\mathrm{NH}_{2}$ para fora do plano e distorções no anel hexagonal. No entanto, na 8-oxoG, também ocorrem maiores distorções no anel pentagonal e nos H's ligados a este anel. A energia do cruzamento é $1.80 \mathrm{eV}$, e portanto abaixo da energia estimada para a formação do ânion no orbital $\pi_{1}^{*}$ no mesmo nível de cálculo $(2.86 \mathrm{eV})$, possibilitando que este cruzamento seja acessado através da formação do estado aniônico $\pi_{1}^{*}$. 

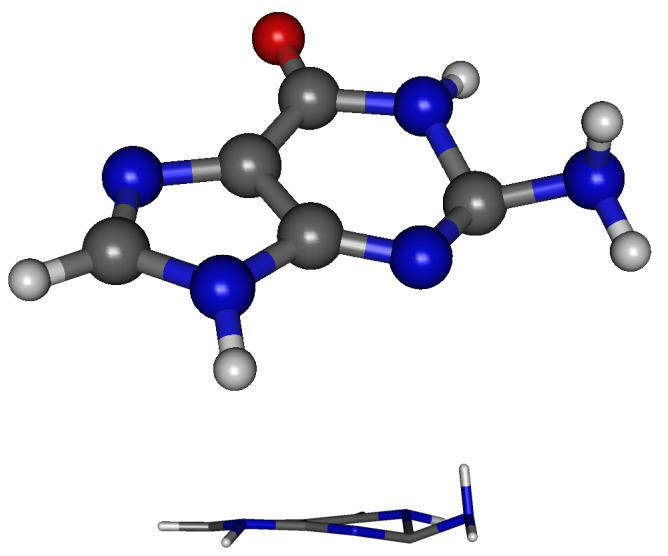

SA-CASSCF $(9,8) /$ cc-pVDZ - $2.42 \mathrm{eV}$
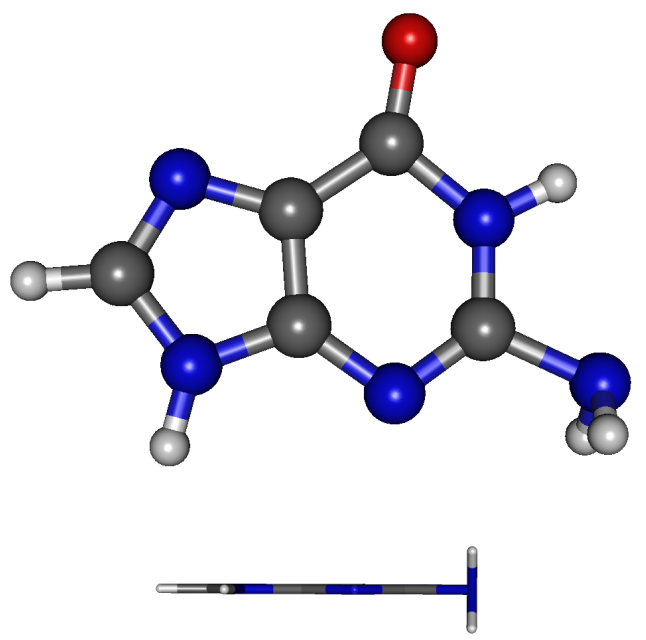

SA-CASSCF $(9,8) / c c-p V D Z-3.82 \mathrm{eV}$

Figura 12 - Geometria da interseção cônica DBS $/ \pi_{1}^{*}$ estimada com base no acoplamento $\mathrm{S}_{0} / \pi_{1}^{*}$ (esquerda) e $\pi_{1}^{*} / \pi_{2}^{*}$ (direita) obtida por $\operatorname{CASSCF}(9,8) /$ cc-pVDZ para G.

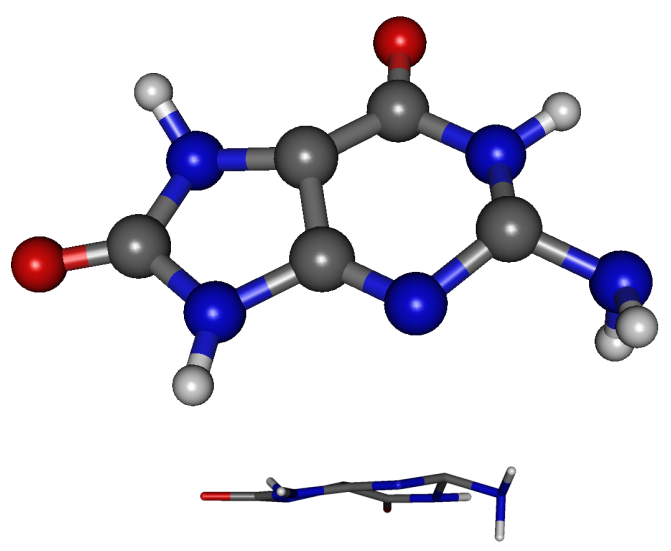

SA-CASSCF $(9,8) / c c-p V D Z-1.80 \mathrm{eV}$

Figura 13 - Geometria da interseção cônica DBS/ $\pi_{1}^{*}$ estimada com base no acoplamento $\mathrm{S}_{0} / \pi_{1}^{*}$ obtida por $\operatorname{CASSCF}(9,8) /$ cc-pVDZ para 8-oxoG.

O acoplamento não adiabático $\pi_{1}^{*} / \pi_{2}^{*}$ na $\mathrm{G}$ indica que a formação da ressonância $\pi_{2}^{*}$ pode transferir população eletrônica para o orbital $\pi_{1}^{*}$, possibilitando que acoplamentos $\pi_{1}^{*} / \sigma^{*}$ com energias mais altas que a formação da ressonância $\pi_{1}^{*}$ sejam acessados, e cruzamentos $\mathrm{S}_{0} / \pi_{1}^{*}$ na $\mathrm{G}$ e 8-oxoG indicam a existência de acoplamentos não adiabáticos $\mathrm{DBS} / \pi_{1}^{*}$ que podem levar à transferência de população eletrônica para o orbital DBS a partir da formação da ressonância $\pi_{1}^{*}$, assim permitindo que níveis vibracionais de 
altas energias do DBS sejam acessados e possam resultar em processos dissociativos. O acoplamento $\mathrm{DBS} / \pi_{1}^{*}$ acontece em energia significativamente mais baixa na 8 -oxoG do que na $\mathrm{G}$, o que em princípio favoreceria o decaimento na forma oxidada.

Medidas de intensidade de DEA para a $\mathrm{G}$ foram reportadas por Abdoul-Carime (24), e os principais resultados são resumidos na Tabela 3, onde são indicados os fragmentos de dissociação, a energia dos picos em que ocorrem, e a intensidade (contagens por segundo, cps). São observadas três reações, produzindo os ânions [G-H]- (eliminação de H), [G$\left.\mathrm{NH}_{2}\right]^{-}$(eliminação de $\mathrm{NH}_{2}$ ) e $\mathrm{OCN}^{-}$(abertura de anel) em energias compatíveis com as ressonâncias $\pi_{1}^{*}(\sim 1 \mathrm{eV})$ e $\pi_{2}^{*}(\sim 1.5 \mathrm{eV})$. Há ainda fragmentação em energias mais altas, 2.0 $\mathrm{eV}$ e $2.9 \mathrm{eV}$, com formação de $\mathrm{OCN}^{-}$e $\mathrm{CN}^{-}$, cuja interpretação com base nos resultados deste trabalho é mais difícil, de forma que a discussão que segue irá se concentrar nos fragmentos formados em energias mais baixas. As medidas de intensidade de DEA para a $\mathrm{G}$ mostram que a intensidade do produto $[\mathrm{G}-\mathrm{H}]^{-}(\mathrm{m} / \mathrm{z}=150)$ apresenta menor intensidade que os fragmentos aniônicos $\mathrm{OCN}^{-}(\mathrm{m} / \mathrm{z}=42)$ e $\mathrm{CN}^{-}(\mathrm{m} / \mathrm{z}=26)$, e esta a uma ordem de grandeza abaixo da intensidade de eliminação de $\mathrm{H}$ nas demais nucleobases (24). Também é observado que o fragmento $\left[\mathrm{G}-\mathrm{NH}_{2}\right]^{-}(\mathrm{m} / \mathrm{z}=135)$ possui sinal consideravelmente mais intenso que a eliminação de $\mathrm{H}$ (Tabela 3).

\begin{tabular}{cccc}
\hline $\mathrm{m} / \mathrm{z}$ & Fragmento & Energia $(\mathrm{eV})$ & Intensidade do sinal (cps) \\
\hline 26 & $\mathrm{CN}^{-}$ & 2.0 & 98 \\
42 & $\mathrm{OCN}^{-}$ & 0.6 & 18 \\
42 & $\mathrm{OCN}^{-}$ & 1.7 & 96 \\
42 & $\mathrm{OCN}^{-}$ & 2.9 & 58 \\
135 & {$\left[\mathrm{G}-\mathrm{NH}_{2}\right]^{-}$} & 0.5 & 46 \\
135 & {$\left[\mathrm{G}-\mathrm{NH}_{2}\right]^{-}$} & 1.4 & 23 \\
150 & {$[\mathrm{G}-\mathrm{H}]^{-}$} & 0.9 & 4 \\
150 & {$[\mathrm{G}-\mathrm{H}]^{-}$} & 1.7 & 12 \\
\hline
\end{tabular}

Tabela 3 - Resumo dos resultados experimentais das medidas de intensidade de DEA para espalhamento de elétrons por G. São indicados os fragmentos, a relação massa/carga $(\mathrm{m} / \mathrm{z})$ que os caracteriza, a energia em que ocorrem as máximas intensidades de detecção, e as intensidades (cps).

A eliminação de $\mathrm{H}$ e $\mathrm{NH}_{2}$ sugere a existência de ressonâncias $\sigma^{*}$ com caráter antiligante na região de ligações $\mathrm{N}-\mathrm{H}$ e C-NH . No entanto, essas ressonâncias em geral são largas e têm assinaturas obscurecidas pelo background associado à interação dipolar, ao menos na geometria da molécula neutra $(51,57)$. É prática corriqueira recorrer a orbitais virtuais obtidos com bases compactas para obter indicação indireta dessas ressonâncias. $\mathrm{Na}$ Figura 14, os orbitais virtuais A'-LUMO, A'-LUMO+2 e A'-LUMO+3 apresentam contribuições $\sigma^{*}$ em múltiplas coordenadas $\mathrm{N}-\mathrm{H}$ enquanto os orbitais $\mathrm{A}^{\prime}$-LUMO+1 e 
A'-LUMO+4 são localizados na ligação $\mathrm{N}_{9}-\mathrm{H}$ e $\mathrm{C}_{8}-\mathrm{H}$.

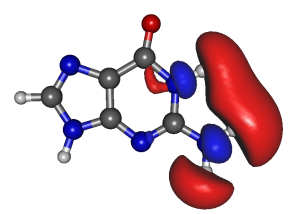

$\sigma_{N-H}^{*}\left(\mathrm{~A}^{\prime}-\mathrm{LUMO}\right)$

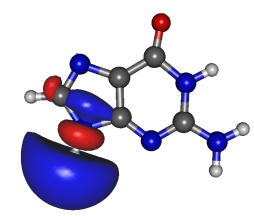

$\sigma_{N-H}^{*}\left(\mathrm{~A}^{\prime}-\mathrm{LUMO}+1\right)$

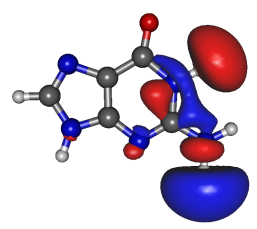

$\sigma_{N-H}^{*}\left(\mathrm{~A}^{\prime}-\mathrm{LUMO}+2\right)$

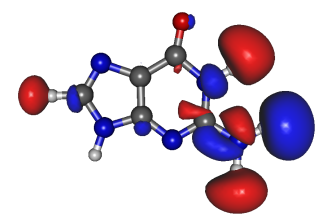

$$
\sigma_{N-H}^{*}\left(\mathrm{~A}^{\prime}-\mathrm{LUMO}+3\right)
$$

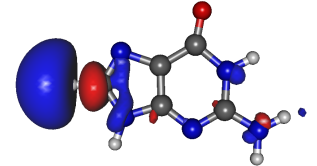

$\sigma_{C-H}^{*}\left(\mathrm{~A}^{\prime}-\mathrm{LUMO}+4\right)$

Figura 14 - Orbitais virtuais com caráter $\sigma^{*}$ da Guanina obtidos no nível HF $/ 6-31 \mathrm{~g}(\mathrm{~d})$, na geometria planarizada $\left(\mathrm{C}_{s}\right)$.

O fragmento (G-H)- apresenta picos em $0.9 \mathrm{eV}$ e $1.7 \mathrm{eV}$ (Tabela 3) e os limiares de eliminação de $\mathrm{H}$ a partir das ligações N-H (Tabela 4) variam entre $0.94 \mathrm{eV}$ e $1.17 \mathrm{eV}$ em temperatura zero, enquanto $0.65 \mathrm{eV}$ a $0.87 \mathrm{eV}$ em temperatura ambiente (energia livre, $\Delta \mathrm{G})$. Os resultados são compatíveis com o limiar de dissociação experimental de $\sim 0.5 \mathrm{eV}(65)$ e compatíveis com a dissociação iniciada pelas ressonâncias $\pi_{1}^{*}(0.97 \mathrm{eV})$ ou $\pi_{2}^{*}(1.47 \mathrm{eV})$. Francés-Monerris et al. (64) realizaram cálculos multiconfiguracionais em busca de acoplamentos não adiabáticos que pudessem levar à eliminação de $\mathrm{H}$ nas nucleobases canônicas, encontrando o acoplamento $\pi_{1}^{*} / \sigma_{N_{1}-H}^{*}(\sim 2.3 \mathrm{eV})$ e cruzamentos com estados vibracionais excitados do DBS $(1.4 \sim 2.1 \mathrm{eV})$, obtidos de forma aproximada através de cruzamentos (SDC). Estes acoplamentos foram associados ao pico localizado em $1.7 \mathrm{eV}$ nas medidas de intensidade de DEA. As estimativas dos acoplamentos não adiabáticos realizadas neste trabalho com $\operatorname{SA}-\mathrm{CASSCF}(11,10)$ (espaço ativo indicado na Figura B2), com a base cc-pVDZ, indicam a existência de um acoplamento $\pi_{1}^{*} / \sigma_{N_{9}-H}^{*}$ em energias próximas ao acoplamento $\pi_{1}^{*} / \sigma_{N_{1}-H}^{*}$ (Tabela 5). Os acoplamentos $\pi^{*} / \sigma^{*}$ possuem energias altas comparadas às energias das ressonâncias $\pi_{1}^{*}$ e $\pi_{2}^{*}$ no mesmo nível de cálculo (SACASSCF $(9,8) /$ cc-pVDZ na Tabela 1), e provavelmente são inacessíveis. Os cruzamentos $\mathrm{DBS} / \sigma^{*}$ são mais acessíveis, assim como o acoplamento DBS $/ \pi^{*}$ discutido anteriormente. Assim, é esperado que o decaimento $\pi^{*} \rightarrow$ DBS prevaleça sobre o decaimento $\pi^{*} \rightarrow \sigma^{*}$, particularmente no caso da $\pi_{1}^{*}$. O DBS pode em princípio levar à eliminação de $\mathrm{H}$ pelo acoplamento DBS $/ \sigma^{*}$. 
O mecanismo dissociativo também pode operar através do acoplamento entre ressonâncias $\sigma_{N-H}^{*}$ com ressonâncias vibracionais de Feshbach. A energia do estado ligado por dipolo da $\mathrm{G}$, obtida na seção anterior, é de $-0.091 \mathrm{eV}$ e a energia da frequência harmônica de estiramento da coordenada N-H da molécula neutra é $0.46 \mathrm{eV}$. Assumindo que a frequência de estiramento N-H seja próxima na molécula neutra e no DBS, pode-se estimar as energias dos níveis vibracionais excitados do estado ligado por dipolo através de um modelo harmônico. O nível vibracional $\nu=1(0.37 \mathrm{eV})$ é fechado pois possui energia abaixo do limiar de dissociação, enquanto $\nu=2(0.83 \mathrm{eV})$ é permitido energeticamente e possui energia próxima ao pico de $0.9 \mathrm{eV}$ observado nas medidas de intensidade de DEA (Tabela 3). O pico em 1.7 eV é compatível com o nível vibracional $\nu=4(1.75 \mathrm{eV})$. O limiar de dissociação de $\mathrm{H}$ na coordenada $\mathrm{C}-\mathrm{H}$ é de $2.72 \mathrm{eV}(\Delta \mathrm{G}=2.43 \mathrm{eV})$ e não deve contribuir para eliminação de $\mathrm{H}$, em consistência com os dados experimentais mostrados na Tabela 3.

\begin{tabular}{|c|c|c|c|}
\hline $\begin{array}{c}\text { Fragmento } \\
\text { aniônico }\end{array}$ & Radical & $\begin{array}{c}\text { Limiar de } \\
\text { dissociação - } \\
\Delta \mathrm{G}(\mathrm{eV})\end{array}$ & $\begin{array}{c}\text { Limiar de } \\
\text { dissociação - } \\
0 \mathrm{~K}(\mathrm{eV})\end{array}$ \\
\hline$(\mathbf{G}-\mathbf{H})^{-}$ & $\mathbf{H}$ & 2.43 & 2.72 \\
\hline$(\mathrm{G}-\mathrm{H})^{-}$ & $\mathbf{H}$ & 0.65 & 0.94 \\
\hline$(\mathrm{G}-\mathrm{H})^{-}$ & $\mathbf{H}$ & 0.87 & 1.17 \\
\hline$(\mathbf{G}-\mathbf{H})^{-}$ & $\mathbf{H}$ & 0.67 & 0.96 \\
\hline$(\mathrm{G}-\mathrm{H})^{-}$ & $\mathbf{H}$ & 0.69 & 0.98 \\
\hline$\left(\mathbf{G}-\mathbf{N H}_{2}\right)^{-}$ & $\mathbf{N H}_{2}$ & 1.71 & 2.19 \\
\hline$\left(\mathbf{G}-\mathbf{N H}_{2}\right)^{-}$ & $\mathbf{N H}_{2}$ & 0.40 & 0.87 \\
\hline
\end{tabular}

Tabela 4 - Limiares de dissociação de Hidrogênio e $\mathrm{NH}_{2}$ com correção entrópica (coluna 3) e com correção de ponto zero (coluna 4) para a molécula de Guanina 


\begin{tabular}{ccccc}
\hline & $\left(\pi_{1}^{*} / \sigma^{*}\right)_{C I}$ & $\left(\pi_{2}^{*} / \sigma^{*}\right)_{C I}$ & $\left(\pi_{3}^{*} / \sigma^{*}\right)_{C I}$ & $\left(S_{0} / \sigma^{*}\right)_{S D C}$ \\
\hline$\sigma_{N_{1}-H}^{*}$ & 4.15 & 4.41 & - & 3.09 \\
$\sigma_{N_{9}-H}^{*}$ & 3.88 & 4.28 & - & 3.45 \\
$\sigma_{C-N H_{2}}^{*}$ & 4.53 & 5.42 & 5.99 & 4.02 \\
\hline
\end{tabular}

Tabela 5 - Energias estimadas para acoplamentos não adiabáticos na $\mathrm{G}$, em eV, no nível SA-CASSCF $(11,10)$ /cc-pVDZ, em relação ao estado fundamental.

A formação do ânion $\left[\mathrm{G}-\mathrm{NH}_{2}\right]^{-}$possui picos em $0.5 \mathrm{eV}$ e $1.4 \mathrm{eV}$ (Tabela 3) podendo ser iniciada através de acoplamentos $\pi_{1}^{*} / \sigma_{N H_{2}}^{*}$ e $\pi_{2}^{*} / \sigma_{N H_{2}}^{*}$. Contudo, essa dissociação não deve ocorrer de forma trivial visto que o limiar para a abstração do grupo $\mathrm{NH}_{2}$ é 2.19 $\mathrm{eV}(\Delta \mathrm{G}=1.71 \mathrm{eV})$, que é incompatível com os picos obtidos nas medidas de intensidade de DEA (Tabela 3). Como a ligação N-H é mais fraca que a ligação C-H, uma reação de recombinação com a abstração do grupo $\mathrm{NH}_{2}$ e a migração do $\mathrm{H}$ ligado ao $\mathrm{N}_{1}$ para o $\mathrm{C}_{2}$, com o elétron extra permancendo na molécula para estabilizar o ânion, possui limiar de dissociação de $0.87 \mathrm{eV}(\Delta \mathrm{G}=0.40 \mathrm{eV})$, que é compatível com o pico em $0.5 \mathrm{eV}$. A coordenada $\mathrm{C}-\mathrm{NH}_{2}$ foi estirada em 0.2 bohr e 0.4 bohr através de cálculos $\mathrm{HF} / 6-31 \mathrm{~g}(\mathrm{~d})$ para a molécula neutra com o objetivo de observar o comportamento dos orbitais virtuais compactos. Os orbitais A'-LUMO e A'-LUMO+2 da Figura 14 evoluem para orbitais que possuem contribuições antiligantes nas coordenadas $\mathrm{N}_{1}-\mathrm{H}$ e $\mathrm{C}-\mathrm{NH}_{2}$, o que é um indício de que esta reação pode ocorrer. Também pode-se observar que o orbital A'-LUMO na Figura 15 apresenta caráter mais difuso e está próximo do orbital DBS (Figura 7), a despeito da falta de funções de base difusas no cálculo, sugerindo um possível acoplamento com estados vibracionais excitados do DBS como rota desta dissociação. Os acoplamentos $\pi^{*} / \sigma_{C-N H_{2}}^{*}$ (Tabela 5) possuem energias mais altas do que as ressonâncias no mesmo nível de cálculo (SA-CASSCF $(9,8) /$ cc-pVDZ na Tabela 1) e também devem ser inacessíveis.

O processo dissociativo pode ocorrer através da formação da ressonância $\pi_{1}^{*}$ que durante a relaxação vibracional pode permitir o acoplamento $\pi_{1}^{*}$ DBS, que subsequentemente se acoplaria aos estados $\sigma_{N_{1}-H}^{*}$ e $\sigma_{C-N H_{2}}^{*}$. De forma alternativa, a energia da frequência harmônica do estiramento $\mathrm{C}_{-} \mathrm{NH}_{2}$ é $0.21 \mathrm{eV}$ para o estado fundamental da molécula neutra. Assumindo que essa energia é igual para o estado ligado por dipolo, que possui energia de $-0.091 \mathrm{eV}$, pode-se estimar os níveis vibracionais excitados do DBS através do modelo harmônico. Para os níveis vibracionais $\nu=1(0.12 \mathrm{eV})$ e $\nu=2(0.33$ eV), a dissociação é proibida energeticamente pois as energias estão abaixo do limiar de dissociação. O nível $\nu=3(0.54 \mathrm{eV})$ é permitido energeticamente e está próximo ao pico obtido nos resultados de seção de choque de DEA (Tabela 3). O acoplamento não adiabático $\pi_{1}^{*} / \pi_{2}^{*}$ pode indicar uma possível rota dessa dissociação a partir da formação da ressonância $\pi_{2}^{*}$, o que pode explicar o pico em $1.4 \mathrm{eV}$. Haranczyk et al. (61) reportaram que a estrutura molecular na geometria de energia mínima do ânion formado por captura 
$\mathrm{A}^{\prime}-\mathrm{LUMO}$

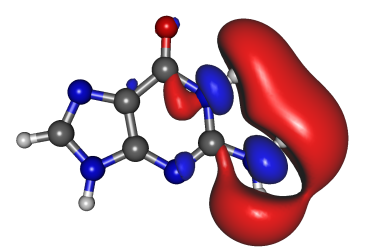

0 bohr

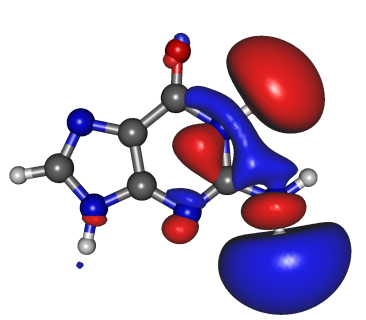

0 bohr

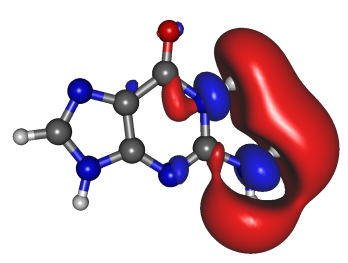

$0.2 \mathrm{bohr}$

$\mathrm{A}^{\prime}-\mathrm{LUMO}+2$

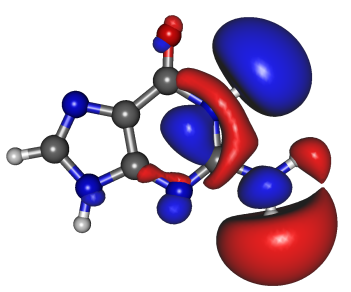

$0.2 \mathrm{bohr}$

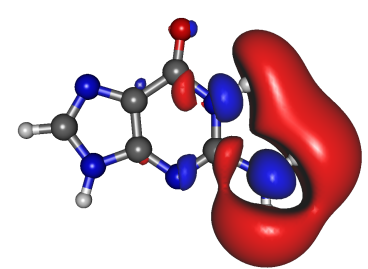

$0.4 \mathrm{bohr}$

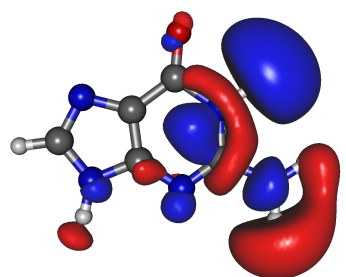

$0.4 \mathrm{bohr}$

Figura 15 - Evolução dos orbitais A'-LUMO e A'-LUMO+2 da Figura 14 com o estiramento da coordenada $\mathrm{C}-\mathrm{NH}_{2}$. Orbitais gerados com valor de contorno de isosuperfície de 0.03 .

eletrônica no orbital $\pi_{1}^{*}$ apresenta importantes deformações no anel hexagonal da G e que o grupo $\mathrm{NH}_{2}$ é fortemente rotacionado para fora do plano da molécula, o que corrobora com a participação da ressonância $\pi_{1}^{*}$ no processo dissociativo do grupo $\mathrm{NH}_{2}$ e indica a sua participação nos processos dissociativos das reações de recombinação dos fragmentos de maior intensidade $\mathrm{OCN}^{-}$e $\mathrm{CN}^{-}$. A formação de $\mathrm{CN}^{-}$e $\mathrm{OCN}^{-}$envolve reações mais complexas, com abertura de anéis, e não serão discutidas neste trabalho.

Neste ponto é interessante realizar uma discussão comparativa entre aspectos relevantes da $\mathrm{G}$ e 8-oxoG que possam indicar dissociações pelo mecanismo de DEA. Como ainda não foram publicados resultados de medidas de intensidade de DEA para a 8-oxoG, o estudo foi realizado através da comparação dos resultados apresentados anteriormente com limiares de dissociação obtidos para $\mathrm{H}$ e $\mathrm{NH}_{2}$ e acoplamentos não adiabáticos.

Os orbitais virtuais compactos foram obtidos para 8-oxoG com o objetivo de buscar evidências indiretas da formação de ressonâncias $\sigma^{*}$ com contribuição antiligante nas ligações $\mathrm{C}_{-} \mathrm{NH}_{2}$ e N-H, que normalmente não apresentam assinatura clara na seção de choque devido a intensidade do background associado à interação dipolar. A 8-oxoG apresenta orbitais moleculares antiligantes em ligações N-H (Figura 16) mais delocalizadas do que a G (Figura 14), não apresentando orbitais moleculares com contribuição antili- 
gante predominante em uma ligação específica. Os orbitais A'-LUMO e A'-LUMO+3 são semelhantes aos respectivos orbitais na $\mathrm{G}$ e o orbital A'-LUMO+2 apresenta semelhanças na densidade eletrônica no anel hexagonal com o respectivo orbital na G.

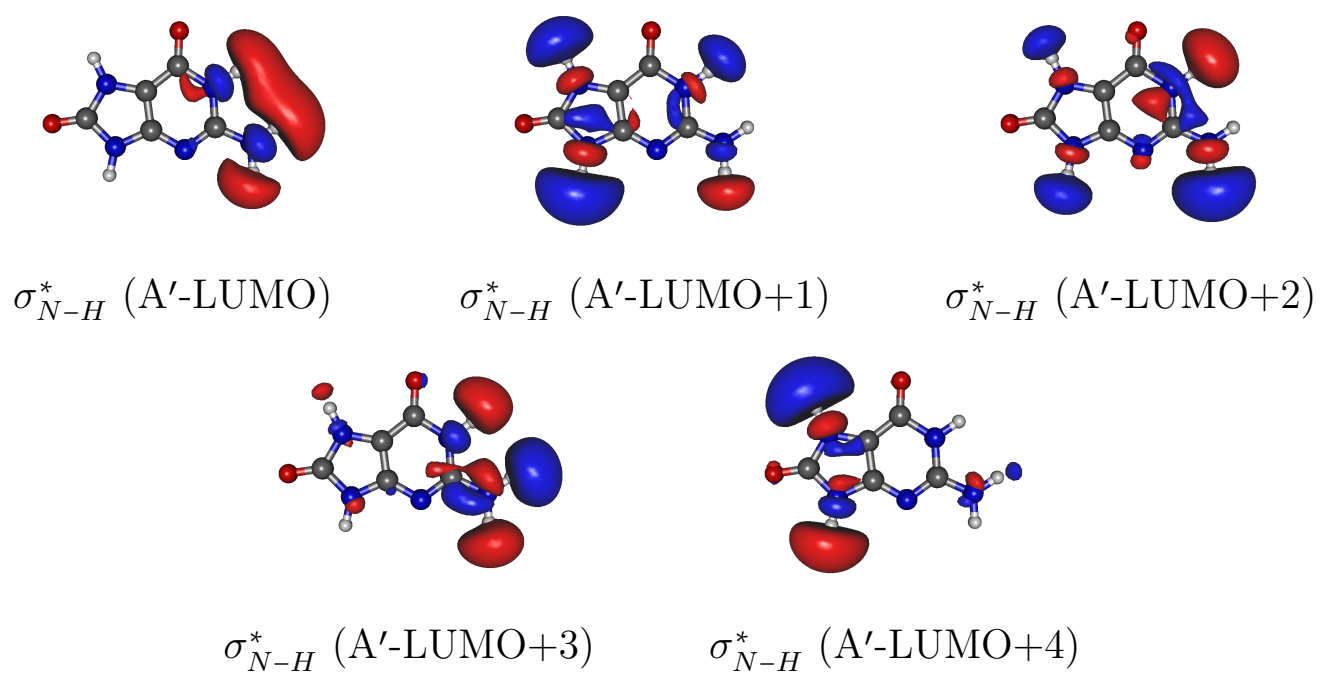

Figura 16 - Orbitais virtuais com caráter $\sigma^{\star}$ da 8-oxoG obtidos no nível HF/6-31g(d), na geometria planarizada $\left(\mathrm{C}_{s}\right)$.

Os limiares de eliminação de $\mathrm{H}$ variam entre $0.62 \mathrm{eV}$ a $1.31 \mathrm{eV}$ em temperatura zero, enquanto $0.33 \mathrm{eV}$ a $1.03 \mathrm{eV}$, em temperatura ambiente $(\Delta \mathrm{G})$ (Tabela 6), apresentando, de forma geral, menores limiares de reação em comparação a G (Tabela 4). Os limiares são compatíveis com dissociação iniciada pela formação das ressonâncias $\pi_{1}^{*}(\sim 0.7 \mathrm{eV})$ e $\pi_{2}^{*}$ $(\sim 1.8 \mathrm{eV})$ da geometria planarizada. Em relação à geometria não planarizada, os limiares de dissociação seriam incompatíveis com a ressonância $\pi_{1}^{*}(\sim 0.2 \mathrm{eV})$ e só seriam acessíveis por acoplamento $\pi^{*} / \sigma^{*}$ a partir da ressonância $\pi_{2}^{*}(\sim 1.6 \mathrm{eV})$, sugerindo que, de fato, a eliminação de $\mathrm{H}$ em energias menores que $\sim 1.6 \mathrm{eV}$, caso ocorra, seria devido a acoplamentos de ressonâncias vibracionais de Feshbach com estados $\sigma_{N-H}^{*}$, provavelmente em ligações $\mathrm{N}-\mathrm{H}$ próximas ao orbital SOMO do DBS (Figura 11). As interseções cônicas $\pi^{*} / \sigma_{N_{1}-H}^{*}$ (Tabela 7), obtidas com SA-CASSCF/MS-CASPT2, apontam para energias mais altas que as estimativas das ressonâncias pelo mesmo método (Tabela 2) e não devem ser acessadas. O acoplamento $\left(S_{0} / \sigma_{N_{1}-H}^{*}\right)$ indica a possibilidade de uma interseção cônica entre estados DBS e $\sigma_{N_{1}-H}^{*}$ e o acoplamento $\pi_{1}^{*} / \mathrm{DBS}(\sim 1.8 \mathrm{eV})$, calculado anteriormente, permitiria que estados vibracionais de alta energia possam ser acessados através da formação da ressonância $\pi_{1}^{*}$. A energia da frequência harmônica do estiramento $\mathrm{N}_{1}-\mathrm{H}$ é $0.45 \mathrm{eV}$ para o estado fundamental da molécula neutra. Assumindo que essa energia é igual para o estado ligado por dipolo, que possui energia de $-0.146 \mathrm{eV}$, pode-se estimar os níveis vibracionais excitados do DBS através do modelo harmônico. O nível $\nu=1(0.3 \mathrm{eV})$ é energeticamente proibido pois possui energia abaixo do limiar de dissociação, os níveis vibracionais a partir de $\nu=2(0.75 \mathrm{eV})$ podem apresentar acoplamentos entre ressonâncias $\sigma_{N-H}^{*}$ e ressonâncias vibracionais de Feshbach e levar a eliminação de H. 


\begin{tabular}{|c|c|c|c|}
\hline $\begin{array}{c}\text { Fragmento } \\
\text { aniônico }\end{array}$ & Radical & $\begin{array}{c}\text { Limiar de } \\
\text { dissociação - } \\
\Delta \mathrm{G}(\mathrm{eV})\end{array}$ & $\begin{array}{c}\text { Limiar de } \\
\text { dissociação - } \\
0 \mathrm{~K}(\mathrm{eV})\end{array}$ \\
\hline $\begin{array}{c}\text { (8-oxoG - } \\
\mathrm{H})^{-}\end{array}$ & $\mathbf{H}$ & 0.69 & 0.99 \\
\hline $\begin{array}{c}\text { (8-oxoG - } \\
\mathrm{H})^{-}\end{array}$ & $\mathbf{H}$ & 0.33 & 0.62 \\
\hline $\begin{array}{c}\text { (8-oxoG - } \\
\mathrm{H})^{-}\end{array}$ & $\mathbf{H}$ & 1.03 & 1.31 \\
\hline $\begin{array}{c}\text { (8-oxoG - } \\
\mathrm{H})^{-}\end{array}$ & $\mathbf{H}$ & 0.42 & 0.73 \\
\hline $\begin{array}{c}\text { (8-oxoG - } \\
\mathbf{H})^{-}\end{array}$ & $\mathbf{H}$ & 0.63 & 0.94 \\
\hline $\begin{array}{c}(8-\mathrm{oxoG}- \\
\left.\mathrm{NH}_{2}\right)^{-}\end{array}$ & $\mathbf{N H}_{2}$ & 1.44 & 1.92 \\
\hline $\begin{array}{c}(8-\mathrm{oxoG}- \\
\left.\mathrm{NH}_{2}\right)^{-}\end{array}$ & $\mathbf{N H}_{2}$ & $\sim 0$ & 0.48 \\
\hline
\end{tabular}

Tabela 6 - Limiares de dissociação de Hidrogênio e $\mathrm{NH}_{2}$ com correção entrópica (coluna 3) e com correção de ponto zero (coluna 4) para a molécula de 8-oxoG

A eliminação direta do radical de $\mathrm{NH}_{2}$ apresenta limiar de dissociação próximo ao encontrado na $\mathrm{G}$, de $1.92 \mathrm{eV}(\Delta \mathrm{G}=1.44 \mathrm{eV})$ e a reação recombinativa análoga a proposta para a $\mathrm{G}$, com abstração do grupo $\mathrm{NH}_{2}$ e migração do $\mathrm{H}$ ligado ao $\mathrm{N}_{1}$ para o $\mathrm{C}_{2}$, possui limiar de dissociação de $0.48 \mathrm{eV}(\Delta \mathrm{G}=\sim 0 \mathrm{eV})$. Assim como para os limiares de dissociação de $\mathrm{H}$, as energias dos limiares são mais baixas do que na $\mathrm{G}$ e o limiar de dissociação da reação recombinativa $(0.48 \mathrm{eV})$ seria incompatível com a ressonância $\pi_{1}^{*}$ $(\sim 0.2 \mathrm{eV})$ obtida sem aproximações de geometria planar, novamente indicando que, caso essa reação ocorra, o mecanismo envolveria a participação de ressonâncias vibracionais de Feshbach. As interseções cônicas (Tabela 7) também apresentam energias mais altas do que as ressonâncias estimadas pelo mesmo nível de cálculo e são provavelmente inacessíveis. A frequência harmônica do estiramento da ligação $\mathrm{C}^{-\mathrm{NH}_{2}}$ é $0.21 \mathrm{eV}$ e, assumindo que essa energia é igual para o estado ligado por dipolo, o primeiro nível $\nu=1(0.1 \mathrm{eV})$ já seria permitido energeticamente e acoplamentos entre ressonâncias vibracionais de Feshbach e ressonâncias $\sigma_{\mathrm{C}-\mathrm{NH}_{2}}^{*}$ poderiam ocorrer. 


\begin{tabular}{ccccc}
\hline & $\left(\pi_{1}^{*} / \sigma^{*}\right)_{C I}$ & $\left(\pi_{2}^{*} / \sigma^{*}\right)_{C I}$ & $\left(\pi_{3}^{*} / \sigma^{*}\right)_{C I}$ & $\left(S_{0} / \sigma^{*}\right)_{S D C}$ \\
\hline$\sigma_{N_{1}-H}^{*}$ & 3.64 & 4.01 & - & 2.67 \\
$\sigma_{C-N H_{2}}^{*}$ & 4.01 & 4.98 & - & - \\
\hline
\end{tabular}

Tabela 7 - Energias estimadas para acoplamentos não adiabáticos na 8-oxoG, em eV, no nível SA-CASSCF $(11,10) /$ cc-pVDZ, em relação ao estado fundamental. 


\section{Considerações Finais}

Este trabalho desenvolveu um estudo das ressonâncias da G e 8-oxoG através da teoria de espalhamento, e uma análise de aspectos que podem ser relevantes em processos dissociativos induzidos pelo mecanismo de captura eletrônica dissociativa (DEA). Para isto, cálculos de seção de choque integral para espalhamento de elétrons de baixas energias (0-12 eV) por G e 8-oxoG foram realizados com o Método Multicanal de Schwinger (SMC) utilizando os pseudopotenciais de Bachelet, Hamann e Schlüter (BHS) e foram obtidos posições e larguras para as ressonâncias de forma. Para a $G$, foram encontradas quatro ressonâncias de forma com caráter $\pi^{*}$, tanto na aproximação SE como na aproximação SEP. Os resultados obtidos para as ressonâncias na $\mathrm{G}$ são compatíveis com os resultados publicados anteriormente $(51,56,57)$ com uma segunda ressonância na aproximação SE e uma quarta ressonância na aproximação SEP que só haviam sido encontradas nos cálculos com o método de matriz R por Dora et al (57). Para a 8-oxoG, na aproximação SE, foram encontradas quatro ressonâncias de forma nos cálculos com geometria planar que estão associadas com a formação de ânions metaestáveis com caráter $\pi^{*}$, no entanto, apenas as ressonâncias $\pi_{1}^{*}$ e $\pi_{2}^{*}$ foram identificadas na geometria não planar, com divergência na posição de cerca de $0.3 \mathrm{eV}$ em relação as ressonâncias em geometria planar. Na aproximação SEP, foram encontradas quatro ressonâncias de forma com caráter $\pi^{*}$ para os cálculos com geometria planar e não planar, e também foi observado o aumento das larguras e o deslocamento das ressonâncias para menores energias em cerca de $0.3 \sim 0.6$ eV no cálculo com geometria não planar, em relação ao cálculo com geometria planar. Contudo, concluiu-se que as ressonâncias encontradas em ambos os cálculos da 8-oxoG correspondem aos mesmos processos de captura eletrônica em orbitais $\pi^{*}$. Os resultados apresentam estabilização das ressonâncias $\pi_{1}^{*}$ e $\pi_{4}^{*}$ e desestabilização das ressonâncias $\pi_{2}^{*}$ e $\pi_{3}^{*}$ da 8-oxoG em relação a $\mathrm{G}$, e indicam maior tempo de vida para o ânion de 8-oxoG, o que favorece dissociações iniciadas pela formação de estados $\pi^{*}$. Os limiares de excitação eletrônica foram obtidos para a 8-oxoG e $\mathrm{G}$, e através deles concluiu-se que as ressonâncias $\pi_{3}^{*}$ e $\pi_{4}^{*}$ da 8-oxoG podem conter acoplamentos com estados excitados desconsiderados enquanto apenas a ressonância $\pi_{4}^{*}$ na $\mathrm{G}$ pode conter esses acoplamentos e consequentemente, possuir energia superestimada.

O estado ligado por dipolo (DBS) da 8-oxoG e da G também foi caracterizado para as moléculas com aproximação de geometria planar, e não planar para 8-oxoG. A aproximação de geometria planar estabiliza o DBS em $30 \mathrm{meV}$ mantendo os orbitais SOMO sem alterações significativas. A 8-oxoG possui momento de dipolo mais alinhado ao grupo $\mathrm{NH}_{2}$ e também possui um DBS mais estável (-174 meV) do que a $\mathrm{G}(-91 \mathrm{meV})$.

As dissociações por DEA da G foram discutidas em comparação com as medidas de 
intensidade de DEA, obtida experimentalmente por Abdoul-Carime et al. (24), com base nas ressonâncias obtidas neste trabalho, e em cálculos de estrutura eletrônica suplementares com métodos ab-initio e semi-empirícos, para estimar limiares de dissociação e acoplamentos não adiabáticos. Os principais fragmentos aniônicos detectados em energia abaixo do limiar de excitação eletrônica foram: $\mathrm{CN}^{-}(\mathrm{m} / \mathrm{z}=26)$, $\mathrm{OCN}^{-}(\mathrm{m} / \mathrm{z}=42),\left(\mathrm{G}-\mathrm{NH}_{2}\right)^{-}(\mathrm{m} / \mathrm{z}=$ $135),(\mathrm{G}-\mathrm{H})^{-}(\mathrm{m} / \mathrm{z}=150)$. Os ânions $\mathrm{OCN}^{-}, \mathrm{CN}^{-}$são provenientes da degradação da estrutura cíclica da G e são formados por rupturas de múltiplas coordenadas e de uma série de recombinações, e consequentemente, sua interpretação com base nos resultados obtidos neste trabalho é complicada, e não foi realizada. A eliminação de $\mathrm{H}$ deve estar relacionada com acoplamentos entre ressonâncias vibracionais de Feshbach e estados $\sigma_{N-H}^{*}$ e pode ser iniciada através formação das ressonâncias $\pi_{1}^{*}$ e $\pi_{2}^{*}$, que subsequentemente acopla com estados vibracionais de alta energia $\left(\pi^{*} / \mathrm{DBS}\right)$, que permite que acoplamentos DBS $/ \sigma^{*}$ sejam acessados. A eliminação de $\mathrm{NH}_{2}$ deve ocorrer através de uma reação de recombinação com a abstração do grupo $\mathrm{NH}_{2}$ acompanhada pela migração do $\mathrm{H}$ da ligação $\mathrm{N}_{1}-\mathrm{H}$ para o $\mathrm{C}_{2}$. Esse processo deve ocorrer através da formação da ressonância $\pi_{1}^{*}$ e do acoplamento $\pi_{1}^{*}$ DBS, permitindo que acoplamentos com estados $\sigma_{N_{1}-H}^{*}$ e $\sigma_{C-N H_{2}}^{\star}$ sejam acessados. Esse mecanismo, a princípio, é possível através da formação da ressonância $\pi_{2}^{*}$ com o acoplamento $\pi_{2}^{*} / \pi_{1}^{*}$.

Por fim, os limiares de eliminação de $\mathrm{H}$ e $\mathrm{NH}_{2}$ e interseções cônicas entre estados $\pi^{*}$ e $\sigma^{*}$ com contribuição antiligante nas ligações $\mathrm{N}_{1}-\mathrm{H}$ e C- $\mathrm{NH}_{2}$ foram analisados para 8-oxoG e comparados com os resultados da $\mathrm{G}$ em razão de não existirem resultados publicados de medidas de intensidade de DEA para a 8-oxoG. Os limiares de dissociação na 8-oxoG, de forma geral, apresentaram menores energias do que na G. Em comparação com as ressonâncias obtidas sem a aproximação de geometria planar, a ressonância $\pi_{1}^{*}$ apresenta menor energia do que a estimativa dos limiares de dissociação, e consequentemente, não deve contribuir para o processo dissociativo por acoplamentos $\pi^{*} / \sigma^{*}$. As eliminações para os dois fragmentos em energias menores que $\sim 1.6 \mathrm{eV}$ só seriam possíveis através de acoplamentos entre ressonâncias $\sigma^{*}$ com ressonâncias vibracionais de Feshbach. As interseções cônicas $\pi^{*} / \sigma_{N_{1}-H}^{*}$ e $\pi^{*} / \sigma_{C-N H_{2}}^{*}$ também não são acessíveis. Contudo, é esperado que haja a participação do acoplamento $\pi_{1}^{*}$ DBS em processos dissociativos na 8-oxoG, visto que esse acoplamento é acessível através da estimativa do estado $\pi_{1}^{*}$, no mesmo nível de cálculo. 


\section{Referências}

1 BOYER, M. C. et al. The role of low-energy (20ev) electrons in astrochemistry. Surface Science, v. 652, p. 26 - 32, 2016. ISSN 0039-6028. Insights into Surface Phenomena: In Honor of John T. Yates Jr. Disponível em: <http://www.sciencedirect.com/science/ article/pii/S0039602816001084> . Citado na página 11.

2 WINSTEAD, C.; MCKOY, V. Electron-molecule collisions in low-temperature plasmas. the role of theory. Advances in Atomic Molecular and Optical Physics - ADVAN ATOM MOL OPT PHYS, v. 43, p. 111-145, 12 2000. Citado na página 11.

3 CHRISTOPHOROU, L. G.; OLTHOFF, J. K. Electron interactions with plasma processing gases: present status and future needs. Applied Surface Science, v. 192, n. 1, p. 309 - 326, 2002. ISSN 0169-4332. Advance in Low Temperature RF Plasmas. Disponível em: < http://www.sciencedirect.com/science/article/pii/S0169433202000338> . Citado na página 11.

4 THORMAN, R. M. et al. The role of low-energy electrons in focused electron beam induced deposition: four case studies of representative precursors. Beilstein Journal of Nanotechnology, v. 6, p. 1904-1926, 2015. ISSN 2190-4286. Citado na página 11.

5 JAGAU, T.-C.; BRAVAYA, K. B.; KRYLOV, A. I. Extending quantum chemistry of bound states to electronic resonances. Annual Review of Physical Chemistry, v. 68, n. 1, p. 525-553, 2017. PMID: 28463649. Disponível em: <https://doi.org/10.1146/annurev-physchem-052516-050622>. Citado na página 11.

6 STAlEY, S. W.; STRNAD, J. T. Calculation of the energies of .pi.* negative ion resonance states by the use of koopmans' theorem. The Journal of Physical Chemistry, v. 98, n. 1, p. 116-121, 1994. Disponível em: <https://doi.org/10.1021/j100052a020>. Citado 2 vezes nas páginas 11 e 43.

7 BOUDAIFFA, B. et al. Resonant formation of dna strand breaks by low-energy (3 to $20 \mathrm{ev)} \mathrm{electrons.} \mathrm{Science,} \mathrm{American} \mathrm{Association} \mathrm{for} \mathrm{the} \mathrm{Advancement} \mathrm{of}$ Science, v. 287, n. 5458, p. 1658-1660, 2000. ISSN 0036-8075. Disponível em: $<$ https://science.sciencemag.org/content/287/5458/1658>. Citado 2 vezes nas páginas 12 e 13.

8 PAN, X. et al. Dissociative electron attachment to dna. Phys. Rev. Lett., American Physical Society, v. 90, p. 208102, May 2003. Disponível em: < https: //link.aps.org/doi/10.1103/PhysRevLett.90.208102>. Citado na página 13.

9 LOMAX, M.; FOLKES, L.; O’NEILL, P. Biological consequences of radiation-induced dna damage: Relevance to radiotherapy. Clinical oncology (Royal College of Radiologists (Great Britain)), v. 25, 07 2013. Citado na página 13.

10 WARDMAN, P. Chemical radiosensitizers for use in radiotherapy. Clinical Oncology, v. 19, n. 6, p. 397 - 417, 2007. ISSN 0936-6555. Importance of Radiobiology to Cancer Therapy: Current Practice and Future Perspectives. Disponível em: <http://www.sciencedirect.com/science/article/pii/S0936655507005808>. Citado na página 14. 
11 COHEN-JONATHAN, E.; BERNHARD, E. J.; MCKENNA, W. G. How does radiation kill cells? Current Opinion in Chemical Biology, v. 3, n. 1, p. 77 - 83, 1999. ISSN 1367-5931. Disponível em: <http://www.sciencedirect.com/science/article/pii/S1367593199800143>. Citado na página 14.

12 KOSSOSKI, F.; BETTEGA, M. H. F.; VARELLA, M. T. d. N. Shape resonance spectra of uracil, 5-fluorouracil, and 5-chlorouracil. The Journal of Chemical Physics, v. 140, n. 2, p. 024317, 2014. Disponível em: < https://doi.org/10.1063/1.4861589>. Citado 2 vezes nas páginas 14 e 15.

13 MCLAUGHLIN, P. W. et al. Halogenated pyrimidine sensitization of low dose rate irradiation in human malignant glioma. International Journal of Radiation Oncology, Biology, Physics, Elsevier, v. 26, n. 4, p. 637-642, Jul 1993. ISSN 0360-3016. Disponível em: <https://doi.org/10.1016/0360-3016(93)90281-Y>. Citado na página 14.

14 ABDOUL-CARIME, H. et al. Sensitizing dna to secondary electron damage: resonant formation of oxidative radicals from 5-halouracils. Journal of the American Chemical Society, v. 123, n. 22, p. 5354-5355, 2001. PMID: 11457401. Disponível em: $<$ https://doi.org/10.1021/ja003952d>. Citado na página 14.

15 KOPYRA, J. et al. Electron driven reactions in sulphur containing analogues of uracil: the case of 2-thiouracil. Phys. Chem. Chem. Phys., The Royal Society of Chemistry, v. 16, p. 25054-25061, 2014. Disponível em: <http://dx.doi.org/10.1039/C4CP03544E>. Citado na página 14.

16 KOSSOSKI, F.; VARELLA, M. T. d. N. Negative ion states of 5-bromouracil and 5-iodouracil. Phys. Chem. Chem. Phys., The Royal Society of Chemistry, v. 17, p. 17271-17278, 2015. Disponível em: <http://dx.doi.org/10.1039/C5CP01475A>. Citado na página 14.

17 KOSSOSKI, F.; KOPYRA, J.; VARELLA, M. T. d. N. Anion states and fragmentation of 2-chloroadenine upon low-energy electron collisions. Phys. Chem. Chem. Phys., The Royal Society of Chemistry, v. 17, p. 28958-28965, 2015. Disponível em: <http://dx.doi.org/10.1039/C5CP04967A>. Citado na página 14.

18 KOSSOSKI, F.; VARELLA, M. T. d. N. How does methylation suppress the electroninduced decomposition of 1-methyl-nitroimidazoles? The Journal of Chemical Physics, v. 147, n. 16, p. 164310, 2017. Disponível em: <https://doi.org/10.1063/1.5005604>. Citado na página 14.

19 CORNETTA, L. M.; KOSSOSKI, F.; VARELLA, M. T. d. N. Transient anion spectra of the potential radiosensitizers 5-cyanateuracil and 5-thiocyanateuracil. Journal of Chemical Physics, 2017. Citado na página 14.

20 WALLACE, S. S. Biological consequences of free radical-damaged dna bases1, 2 1guest editor: Miral dizdaroglu 2this article is part of a series of reviews on "oxidative dna damage and repair." the full list of papers may be found on the homepage of the journal. Free Radical Biology and Medicine, v. 33, n. 1, p. 1 - 14, 2002. ISSN 0891-5849. Disponível em: <http://www.sciencedirect.com/science/article/pii/S0891584902008274>. Citado na página 15. 
21 NGUYEN, K.; BURROWS, C. J. A prebiotic role for 8-oxoguanosine as a flavin mimic in pyrimidine dimer photorepair. Journal of the American Chemical Society, v. 133, p. 14586-9, 08 2011. Citado na página 15.

22 NGUYEN, K.; BURROWS, C. J. Whence flavins? redox-active ribonucleotides link metabolism and genome repair to the rna world. Accounts of chemical research, v. 45, 10 2012. Citado na página 15.

23 BECKSTEAD, A. et al. Life in the light: Nucleic acid photoproperties as a legacy of chemical evolution. Phys. Chem. Chem. Phys., v. 18, 08 2016. Citado na página 15.

24 ABDOUL-CARIME, H. et al. Decomposition of purine nucleobases by very low energy electrons. The European Physical Journal D, v. 35, p. 399-404, 08 2005. Citado 3 vezes nas páginas 15, 57 e 66 .

25 KANVAH, S. et al. Oxidation of dna: Damage to nucleobases. Accounts of chemical research, v. 43, p. 280-7, 11 2009. Citado na página 15.

26 JOACHAIN, C. Quantum Collision Theory. [S.l.]: North-Holland, 1975. ISBN 9780720402940. Citado 3 vezes nas páginas 17, 25 e 43.

27 LIPPMANN, B. A.; SCHWINGER, J. Variational principles for scattering processes. i. Phys. Rev., American Physical Society, v. 79, p. 469-480, Aug 1950. Disponível em: <https://link.aps.org/doi/10.1103/PhysRev.79.469>. Citado na página 19.

28 GELTMAN, S.; MASSEY, H.; BRUECKNER, K. Topics in Atomic Collision Theory. Elsevier Science, 2013. (Pure and applied physics). ISBN 9781483277028. Disponível em: $<$ https://books.google.com.br/books?id=P8E4BQAAQBAJ $>$. Citado na página 21.

29 LIMA, M. A. P.; MCKOY, V. Aspects of the schwinger multichannel variational formulation. Phys. Rev. A, American Physical Society, v. 38, p. 501-503, Jul 1988. Disponível em: <https://link.aps.org/doi/10.1103/PhysRevA.38.501>. Citado na página 22 .

30 COSTA, R. F. da et al. Recent advances in the application of the schwinger multichannel method with pseudopotentials to electron-molecule collisions. The European Physical Journal D, v. 69, n. 6, p. 159, Jun 2015. ISSN 1434-6079. Disponível em: <https://doi.org/10.1140/epjd/e2015-60192-6>. Citado 2 vezes nas páginas 23 e 24.

31 SILVA, A. J. R. da et al. Schwinger multichannel method: A study of a feshbach resonance in e- $\mathrm{h}_{2}$ collisions. Phys. Rev. A, American Physical Society, v. 41, p. 2903-2905, Mar 1990. Disponível em: < https://link.aps.org/doi/10.1103/PhysRevA.41.2903>. Citado na página 24.

32 SAKURAI, J.; NAPOLITANO, J. Modern Quantum Mechanics. Cambridge University Press, 2017. ISBN 9781108422413. Disponível em: <https://books.google.com.br/books? id=010yDwAAQBAJ $>$. Citado na página 24.

33 BACHELET, G. B.; HAMANN, D. R.; SCHLÜTER, M. Pseudopotentials that work: From h to pu. Phys. Rev. B, American Physical Society, v. 26, p. 4199-4228, Oct 1982. Disponível em: < https://link.aps.org/doi/10.1103/PhysRevB.26.4199>. Citado 2 vezes nas páginas 26 e 41. 
34 BetTeGA, M. H. F.; FERREIRA, L. G.; LIMA, M. A. P. Transferability of local-density norm-conserving pseudopotentials to electron-molecule-collision calculations. Phys. Rev. A, American Physical Society, v. 47, p. 1111-1118, Feb 1993. Disponível em: $<$ https://link.aps.org/doi/10.1103/PhysRevA.47.1111>. Citado na página 26.

35 BETTEGA, M. H. F. et al. Note on the generation of gaussian bases for pseudopotential calculations. International Journal of Quantum Chemistry, v. 60, p. 821-824, 1996. Disponível em: < https://doi.org/10.1002/(SICI)1097-461X(1996)60: 4<821::AID-QUA4>3.0.CO;2-Z> C Citado na página 27.

36 BAUSCHLICHER, C. W. The construction of modified virtual orbitals (mvo's) which are suited for configuration interaction calculations. The Journal of Chemical Physics, v. 72, n. 2, p. 880-885, 1980. Disponível em: <https://doi.org/10.1063/1.439243>. Citado na página 28.

37 CASTRO, M. A.; CANUTO, S. Métodos de química teórica e modelagem molecular O método Hartree-Fock. [S.l.]: Editora Livraria da Física, 2007, 1-27 p. Citado 2 vezes nas páginas 31 e 32.

38 ROOTHAAN, C. C. J. New developments in molecular orbital theory. Rev. Mod. Phys., American Physical Society, v. 23, p. 69-89, Apr 1951. Disponível em: <https://link.aps.org/doi/10.1103/RevModPhys.23.69>. Citado na página 31.

39 CASTRO, M. A.; CANUTO, S. Métodos de química teórica e modelagem molecular Métodos Perturbativos para a obtenção de correlação eletrônica. [S.l.]: Editora Livraria da Física, 2007, 113-144 p. Citado 2 vezes nas páginas 32 e 34.

40 SCHMIDT, M. W.; GORDON, M. S. The construction and interpretation of mcscf wavefunctions. Annual Review of Physical Chemistry, v. 49, n. 1, p. 233-266, 1998. PMID: 15012429. Disponível em: <https://doi.org/10.1146/annurev.physchem.49.1.233>. Citado na página 35.

41 BORIN, A. C. Métodos de química teórica e modelagem molecular - Métodos Multiconfiguracionais para o estudo de estrutura eletrônica. [S.l.]: Editora Livraria da Física, 2007, 171-207 p. Citado 3 vezes nas páginas 36, 37 e 39.

42 WERNER, H.; MEYER, W. A quadratically convergent mcscf method for the simultaneous optimization of several states. The Journal of Chemical Physics, v. 74, n. 10, p. 5794-5801, 1981. Disponível em: <https://doi.org/10.1063/1.440892>. Citado na página 37.

43 WERNER, H.; MEYER, W. A quadratically convergent multiconfiguration-selfconsistent field method with simultaneous optimization of orbitals and ci coefficients. The Journal of Chemical Physics, v. 73, n. 5, p. 2342-2356, 1980. Disponível em: < https://doi.org/10.1063/1.440384>. Citado na página 37.

44 ZOBEL, J. P.; NOGUEIRA, J. J.; GONZáLEZ, L. The ipea dilemma in caspt2. Chem. Sci., The Royal Society of Chemistry, v. 8, p. 1482-1499, 2017. Disponível em: <http://dx.doi.org/10.1039/C6SC03759C>. Citado 3 vezes nas páginas 38, 39 e 44.

45 COHEN, A. J.; MORI-SÁNCHEZ, P.; YANG, W. Challenges for density functional theory. Chemical Reviews, American Chemical Society, v. 112, n. 1, p. 289-320, Jan 2012. 
ISSN 0009-2665. Disponível em: <https://doi.org/10.1021/cr200107z> . Citado na página 39.

46 HOHENBERG, P.; KOHN, W. Inhomogeneous electron gas. Phys. Rev., American Physical Society, v. 136, p. B864-B871, Nov 1964. Disponível em: <https://link.aps.org/doi/10.1103/PhysRev.136.B864>. Citado na página 39.

47 KOHN, W.; SHAM, L. J. Self-consistent equations including exchange and correlation effects. Phys. Rev., American Physical Society, v. 140, p. A1133-A1138, Nov 1965. Disponível em: < https://link.aps.org/doi/10.1103/PhysRev.140.A1133>. Citado na página 39.

48 DUARTE HéLIO ANDERSON E ROCHA, W. R. Métodos de química teórica e modelagem molecular - Métodos Multiconfiguracionais para o estudo de estrutura eletrônica. [S.1.]: Editora Livraria da Física, 2007, 73-111 p. Citado na página 40.

49 BARCA, G. M. J. et al. Recent developments in the general atomic and molecular electronic structure system. The Journal of Chemical Physics, v. 152, n. 15, p. 154102, abr. 2020. ISSN 0021-9606, 1089-7690. Disponível em: < http: //aip.scitation.org/doi/10.1063/5.0005188>. Citado na página 41.

50 DUNNING, T. H. Gaussian basis functions for use in molecular calculations. i. contraction of (9s5p) atomic basis sets for the first-row atoms. The Journal of Chemical Physics, v. 53, n. 7, p. 2823-2833, 1970. Disponível em: <https: //doi.org/10.1063/1.1674408>. Citado na página 42.

51 WINSTEAD, C.; MCKOY, V. Interaction of low-energy electrons with the purine bases, nucleosides, and nucleotides of dna. The Journal of Chemical Physics, v. 125, n. 24, p. 244302, 2006. Disponível em: <https://doi.org/10.1063/1.2424456>. Citado 7 vezes nas páginas 42, 45, 46, 48, 51, 57 e 65 .

52 KOSSOSKI, F.; BETTEGA, M. H. F. Low-energy electron scattering from the aza-derivatives of pyrrole, furan, and thiophene. The Journal of Chemical Physics, v. 138, n. 23, p. 234311, 2013. Disponível em: < https://doi.org/10.1063/1.4811218>. Citado na página 43.

53 SKURSKI, P.; GUTOWSKI, M.; SIMONS, J. How to choose a one-electron basis set to reliably describe a dipole-bound anion. J Quantum Chem International Journal of Quantum Chemistry, v. 80, p. 1024-1038, 11 2000. Citado na página 44.

54 AQUILANTE, F. et al. Modern quantum chemistry with [open]molcas. The Journal of Chemical Physics, v. 152, n. 21, p. 214117, 2020. Disponível em: $<$ https://doi.org/10.1063/5.0004835>. Citado na página 44.

55 CURTISS, L. A.; REDFERn, P. C.; RAGHAVACHARI, K. Gn theory. Wiley Interdisciplinary Reviews: Computational Molecular Science, v. 1, n. 5, p. 810-825, 2011. Disponível em: <https://onlinelibrary.wiley.com/doi/abs/10.1002/wcms.59>. Citado na página 44.

56 NUNES, F. et al. Transient negative ion spectrum of the cytosine-guanine pair. The European Physical Journal D, v. 71, 04 2017. Citado 4 vezes nas páginas 45, 48, 51 e 65. 
57 DORA, A. et al. Low-energy electron scattering with the purine bases of dna/rna using the r-matrix method. The Journal of Chemical Physics, v. 136, n. 2, p. 024324, 2012. Disponível em: <https://doi.org/10.1063/1.3675448>. Citado 6 vezes nas páginas $45,46,48,51,57$ e 65 .

58 AFlatOONI, K.; GALLUP, G. A.; BURROW, P. D. Electron attachment energies of the dna bases. The Journal of Physical Chemistry A, v. 102, n. 31, p. 6205-6207, 1998. Disponível em: < https://doi.org/10.1021/jp980865n>. Citado 2 vezes nas páginas 46 e 48.

59 PáRKáNYI, C. et al. Theoretical and experimental dipole moments of purines. Collection of Czechoslovak Chemical Communications, v. 67, 08 2002. Citado na página 46.

60 CRAWFORD, O. H. Negative ions of polar molecules. Molecular Physics, Taylor Francis, v. 20, n. 4, p. 585-591, 1971. Disponível em: <https://doi.org/10.1080/ 00268977100100561>. Citado na página 46.

61 HARANCZYK, M.; GUTOWSKI, M. Valence and dipole-bound anions of the most stable tautomers of guanine. Journal of the American Chemical Society, v. 127, p. 699-706, 02 2005. Citado 2 vezes nas páginas 46 e 60.

62 FüLSCHER, M. P.; SERRANO-ANDRéS, L.; ROOS, B. O. A theoretical study of the electronic spectra of adenine and guanine. Journal of the American Chemical Society, v. 119, n. 26, p. 6168-6176, 1997. Disponível em: <https://doi.org/10.1021/ja964426i>. Citado na página 47.

63 LU, Z. et al. Excited state relaxation of neutral and basic 8-oxoguanine. The Journal of Physical Chemistry B, American Chemical Society, v. 119, n. 26, p. 8293-8301, Jul 2015. ISSN 1520-6106. Disponível em: <https://doi.org/10.1021/acs.jpcb.5b03565>. Citado na página 51.

64 FRANCéS-MONERRIS, A. et al. Complete-active-space second-order perturbation theory (caspt2//casscf) study of the dissociative electron attachment in canonical dna nucleobases caused by low-energy electrons (0-3 ev). The Journal of Chemical Physics, v. 143, n. 21, p. 215101, 2015. Disponível em: < https://doi.org/10.1063/1.4936574>. Citado 2 vezes nas páginas 55 e 58.

65 ABDOUl-CARIME, H.; GOHLKE, S.; ILLENBERGER, E. Site-specific dissociation of dna bases by slow electrons at early stages of irradiation. Phys. Rev. Lett., American Physical Society, v. 92, p. 168103, Apr 2004. Disponível em: <https://link.aps.org/doi/10.1103/PhysRevLett.92.168103>. Citado na página 58. 
Apêndices 


\section{APÊNDICE A - Coordenadas atômicas das moléculas de $G$ e 8-oxoG e coeficientes de} funções de base dos cálculos de espalhamento

\begin{tabular}{cccc}
\hline Átomo & $\mathrm{x}$ & $\mathrm{y}$ & $\mathrm{z}$ \\
\hline $\mathrm{N}$ & 2.0061836511 & 1.4532952623 & 0.0000000000 \\
$\mathrm{~N}$ & 2.0823879366 & -0.7439716251 & 0.0000000000 \\
$\mathrm{~N}$ & -0.2816200506 & -1.2581971399 & 0.0000000000 \\
$\mathrm{~N}$ & -1.6093318169 & 0.6841178478 & 0.0000000000 \\
$\mathrm{~N}$ & -2.5775035881 & -1.4365688035 & 0.0000000000 \\
$\mathrm{C}$ & 2.9016462454 & 0.4011147603 & 0.0000000000 \\
$\mathrm{C}$ & 0.7553826456 & -0.3984424054 & 0.0000000000 \\
$\mathrm{C}$ & 0.6961877517 & 0.9778350746 & 0.0000000000 \\
$\mathrm{C}$ & -1.4556569859 & -0.6713063338 & 0.0000000000 \\
$\mathrm{C}$ & -0.5487854450 & 1.6451202222 & 0.0000000000 \\
$\mathrm{H}$ & 2.4530434117 & -1.6782669856 & 0.0000000000 \\
$\mathrm{H}$ & -2.5301832694 & 1.0979913243 & 0.0000000000 \\
$\mathrm{H}$ & 2.2905883010 & 2.4165781797 & 0.0000000000 \\
$\mathrm{H}$ & -3.5000954628 & -1.0466367012 & 0.0000000000 \\
$\mathrm{H}$ & -2.4647487475 & -2.4334902296 & 0.0000000000 \\
$\mathrm{O}$ & 4.1131939279 & 0.4293011439 & 0.0000000000 \\
$\mathrm{O}$ & -0.8041585048 & 2.8402264092 & 0.0000000000 \\
\hline & & &
\end{tabular}

Tabela A1 - Coordenadas otimizadas da 8-oxoG para a geometria pertencente ao grupo $\mathrm{C}_{s}$ em unidades de Ångström $(\AA)$ obtidas com B3LYP/aug-cc-pVTZ. 
APENDICE A. Coordenadas atômicas das moléculas de G e 8-oxoG e coeficientes de funções de base dos cálculos de espalhamento

\begin{tabular}{cccc}
\hline Átomo & $\mathrm{x}$ & $\mathrm{y}$ & $\mathrm{z}$ \\
\hline $\mathrm{N}$ & 2.0013260241 & 1.4506303702 & -0.0157225967 \\
$\mathrm{~N}$ & 2.0775144530 & -0.7465596348 & 0.0199649763 \\
$\mathrm{~N}$ & -0.2886104271 & -1.2560854452 & 0.0824838856 \\
$\mathrm{~N}$ & -1.6115827032 & 0.6871840039 & 0.1018538696 \\
$\mathrm{~N}$ & -2.5925420800 & -1.4298210738 & 0.2130761759 \\
$\mathrm{C}$ & 2.8968774617 & 0.3974280490 & -0.0232471133 \\
$\mathrm{C}$ & 0.7514385763 & -0.3987074107 & 0.0491830823 \\
$\mathrm{C}$ & 0.6927763545 & 0.9766914537 & 0.0264657873 \\
$\mathrm{C}$ & -1.4586733681 & -0.6675160746 & 0.1146931560 \\
$\mathrm{C}$ & -0.5519768047 & 1.6465663865 & 0.0550463891 \\
$\mathrm{H}$ & 2.4470663645 & -1.6813074965 & 0.0181358559 \\
$\mathrm{H}$ & -2.5305703461 & 1.0982041678 & 0.1791142158 \\
$\mathrm{H}$ & 2.2855717252 & 2.4136077749 & -0.0497263160 \\
$\mathrm{H}$ & -3.4536556123 & -1.0654885896 & -0.1577118478 \\
$\mathrm{H}$ & -2.4428390495 & -2.4138146683 & 0.0601559874 \\
$\mathrm{O}$ & -0.8030654779 & 2.8421021875 & 0.0487735561 \\
$\mathrm{O}$ & 4.1074749076 & 0.4255859980 & -0.0586690645 \\
\hline
\end{tabular}

Tabela A2 - Coordenadas otimizadas da 8-oxoG para a geometria pertencente ao grupo $\mathrm{C}_{1}$ em unidades de Ångström $(\AA)$ obtidas com B3LYP/aug-cc-pVTZ.

\begin{tabular}{cccc}
\hline Átomo & $\mathrm{x}$ & $\mathrm{y}$ & $\mathrm{z}$ \\
\hline $\mathrm{N}$ & -1.790826007 & 0.905956602 & 0.000000000 \\
$\mathrm{~N}$ & -1.513341981 & -1.309906190 & 0.000000000 \\
$\mathrm{~N}$ & 0.902046387 & -1.479236917 & 0.000000000 \\
$\mathrm{~N}$ & 1.898793170 & 0.653526198 & 0.000000000 \\
$\mathrm{~N}$ & 3.196662494 & -1.281910887 & 0.000000000 \\
$\mathrm{C}$ & -2.396074736 & -0.246085510 & 0.000000000 \\
$\mathrm{C}$ & -0.254986302 & -0.778310771 & 0.000000000 \\
$\mathrm{C}$ & -0.445575133 & 0.599082079 & 0.000000000 \\
$\mathrm{C}$ & 1.962366160 & -0.712009770 & 0.000000000 \\
$\mathrm{C}$ & 0.706712482 & 1.453096156 & 0.000000000 \\
$\mathrm{H}$ & -1.735383068 & -2.290891612 & 0.000000000 \\
$\mathrm{H}$ & 2.746036814 & 1.202316907 & 0.000000000 \\
$\mathrm{H}$ & 4.041598371 & -0.744512086 & 0.000000000 \\
$\mathrm{H}$ & 3.250502905 & -2.283501758 & 0.000000000 \\
$\mathrm{H}$ & -3.463229210 & -0.396570134 & 0.000000000 \\
$\mathrm{O}$ & 0.809307654 & 2.662127694 & 0.000000000 \\
\hline
\end{tabular}

Tabela A3 - Coordenadas otimizadas da Guanina para a geometria pertencente ao grupo $\mathrm{C}_{s}$ em unidades de Ångström $(\AA)$ obtidas com B3LYP/aug-cc-pVTZ. 
APENDICE A. Coordenadas atômicas das moléculas de G e 8-oxoG e coeficientes de funções de base dos cálculos de espalhamento

\begin{tabular}{cccc}
\hline Tipo & Carbono & Nitrogênio & Oxigênio \\
\hline s & 12.4962802 & 17.567340 & 16.058780 \\
s & 2.4702861 & 3.423615 & 5.920242 \\
s & 0.6140280 & 0.884301 & 1.034907 \\
s & 0.1840280 & 0.259045 & 0.316843 \\
s & 0.0399821 & 0.055708 & 0.065203 \\
p & 5.2288690 & 7.050692 & 10.141200 \\
p & 1.5920580 & 1.910543 & 2.783023 \\
p & 0.5686120 & 0.579261 & 0.841010 \\
p & 0.2103260 & 0.165395 & 0.232940 \\
p & 0.0722500 & 0.037192 & 0.052211 \\
d & 0.6035920 & 0.403039 & 0.756793 \\
d & 0.1567530 & 0.091192 & 0.180759 \\
\hline
\end{tabular}

Tabela A4 - Expoentes das funções de base tipo gaussianas não contraídas no sistema cartesiano para os átomos de Carbono, Nitrogênio e Oxigênio (unidades atômicas)

\begin{tabular}{ccc}
\hline Tipo & Hidrogênio & $\begin{array}{c}\text { Coeficiente } \\
\text { de Contração }\end{array}$ \\
\hline $\mathrm{s}$ & 13.361500 & 0.130844 \\
$\mathrm{~s}$ & 2.013300 & 0.921539 \\
$\mathrm{~s}$ & 0.453800 & 1.000000 \\
$\mathrm{~s}$ & 0.123300 & 1.000000 \\
\hline
\end{tabular}

Tabela A5 - Expoentes das funções de base tipo gaussianas contraídas e seus respectivos coeficientes de contração no sistema cartesiano para o átomo de Hidrogênio (unidades atômicas) 


\section{APÊNDICE B - Os orbitais do espaço ativo nos cálculos multiconfiguracionais}

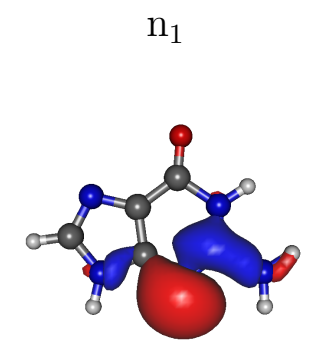

$\mathrm{n}_{2}$

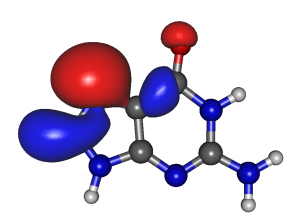

$\pi_{7}$

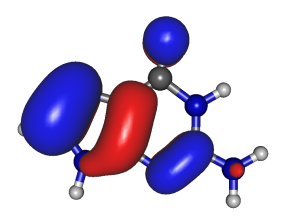

$\pi_{1}$

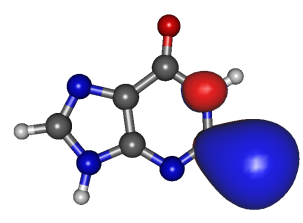

$\pi_{4}$

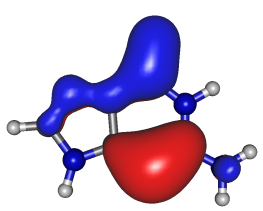

$\pi_{1}^{*}$

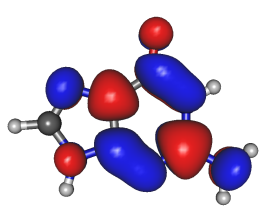

$\pi_{2}$

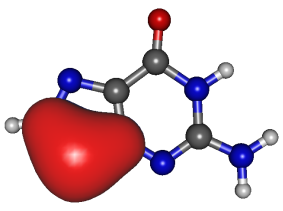

$\pi_{5}$

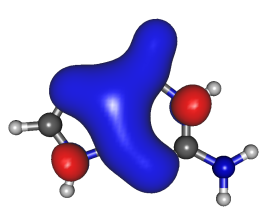

$\pi_{2}^{*}$

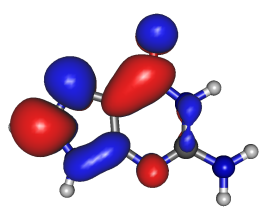

$\pi_{4}^{*}$

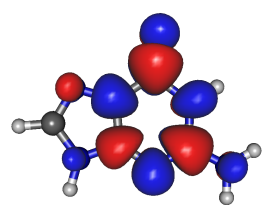

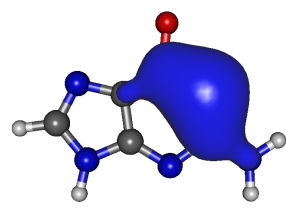

$\pi_{6}$

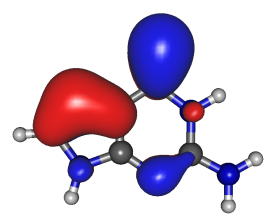

$\pi_{3}^{*}$

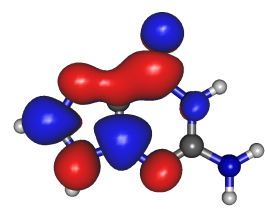

Figura B1 - Espaço ativo utilizado nos cálculos de energia mínima de excitação da Guanina. 


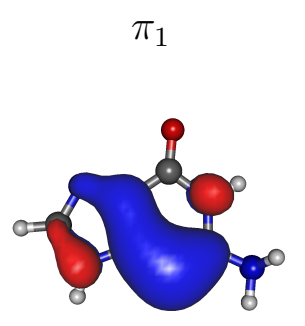

$\pi_{1}^{*}$

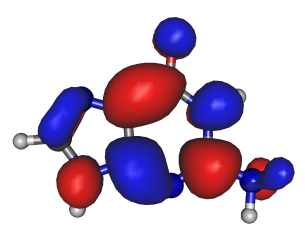

$\sigma_{C-N H_{2}}$

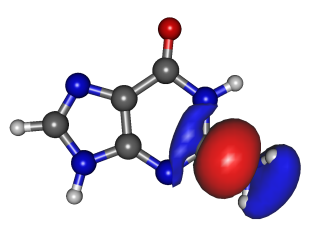

$\pi_{2}$

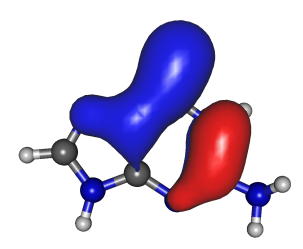

$\pi_{2}^{*}$

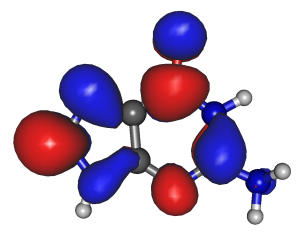

$\sigma_{\mathrm{C}-\mathrm{NH}}^{*}$

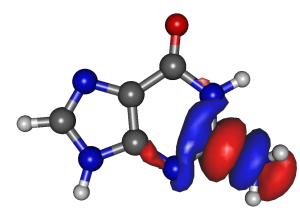

$$
\sigma_{N_{1}-H}
$$

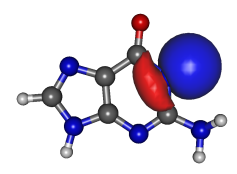

$\pi_{3}$

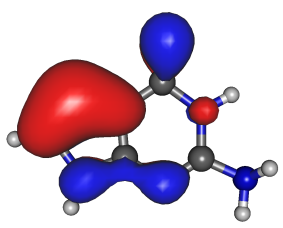

$\pi_{3}^{*}$

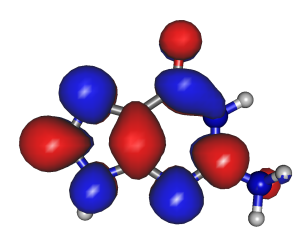

$\sigma_{N_{9}-H}$

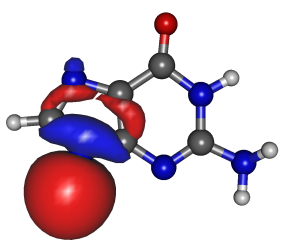

$\sigma_{N_{1}-H}^{*}$

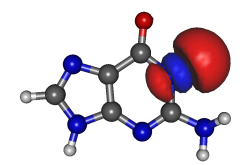

$\pi_{4}$

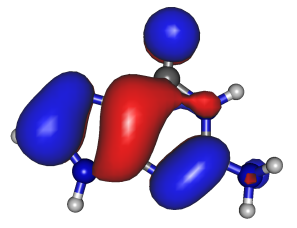

$\pi_{4}^{*}$

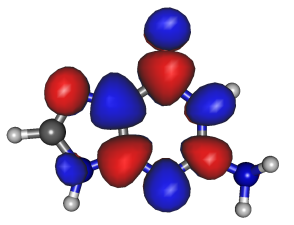

$\sigma_{N_{9}-H}^{*}$

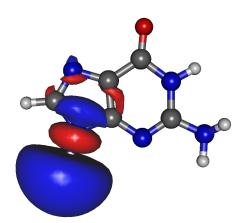

Figura B2 - Orbitais utilizados no espaço ativo dos cálculos de estimativa das ressonâncias e de acoplamentos não adiabáticos para o ânion de G. Os orbitais $\pi$ e $\pi^{*}$ estão presente em todos os cálculos enquanto apenas os orbitais $\sigma$ e $\sigma^{*}$ na coordenada estudada estão presentes nos cálculos, formando um espaço ativo com 10 orbitais para os cálculos de acoplamentos $\pi^{*} / \sigma^{*}$. 
$\pi_{1}$

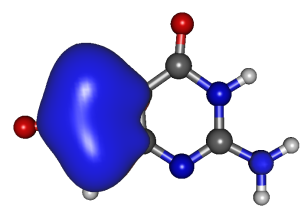

$\mathrm{n}_{1}$

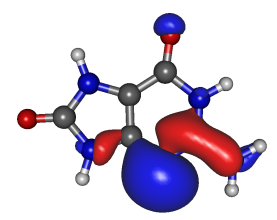

$\pi_{8}$

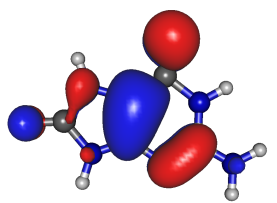

$\pi_{2}$

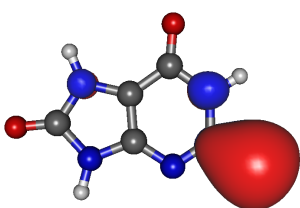

$\pi_{5}$

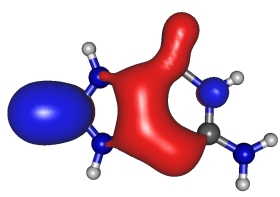

$\pi_{1}^{*}$

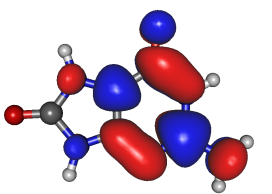

$\pi_{3}$

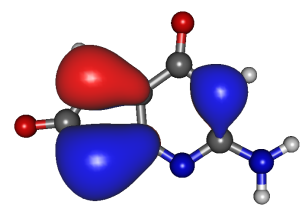

$\pi_{6}$

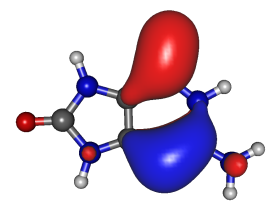

$\pi_{2}^{*}$
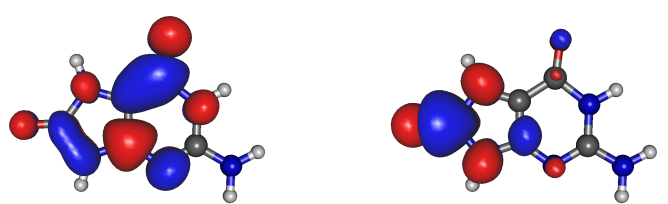

$\pi_{4}^{*}$

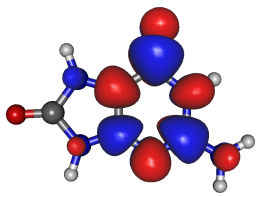

Figura B3 - Espaço ativo utilizado nos cálculos de energia mínima de excitação da 8-oxoG 
$\pi_{1}$

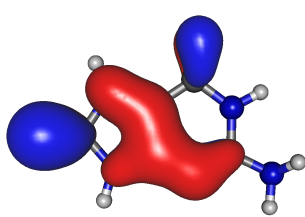

$\pi_{1}^{*}$

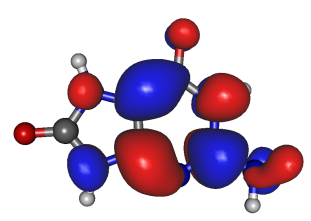

$\sigma_{N_{1}-H}$

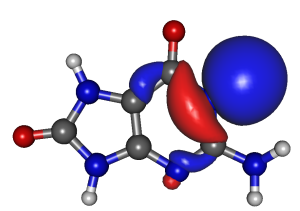

$\pi_{2}$

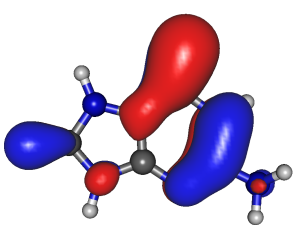

$\pi_{2}^{*}$

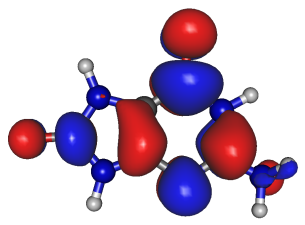

$\sigma_{N_{1}-H}^{*}$

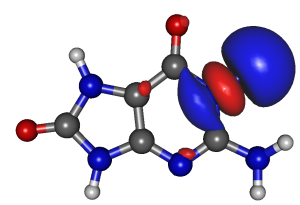

$\pi_{3}$

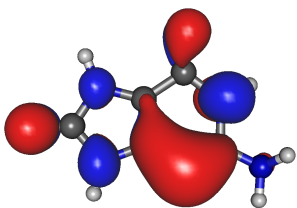

$\pi_{3}^{*}$

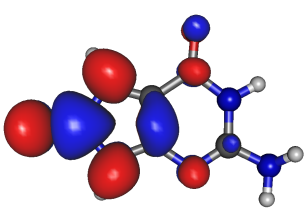

$\sigma_{\mathrm{C}-\mathrm{NH}} \mathrm{H}_{2}$

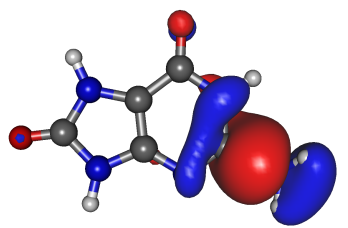

$\pi_{4}$

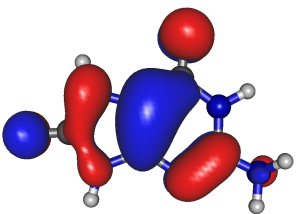

$\pi_{4}^{*}$

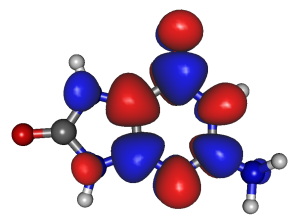

$$
\sigma_{C-N H_{2}}^{*}
$$

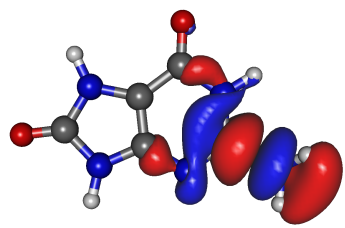

Figura B4 - Orbitais utilizados no espaço ativo dos cálculos de estimativa das ressonâncias e de acoplamentos não adiabáticos para o ânion de 8-oxoG. Os orbitais $\pi$ e $\pi^{*}$ estão presente em todos os cálculos enquanto apenas os orbitais $\sigma$ e $\sigma^{*}$ na coordenada estudada estão presentes nos cálculos, formando um espaço ativo com 10 orbitais para os cálculos de acoplamentos $\pi^{*} / \sigma^{*}$. 